\title{
Measurements near the Atmospheric Surface Flux Group tower at SHEBA: Near-surface conditions and surface energy budget
}

\author{
P. Ola G. Persson, ${ }^{1}$ Christopher W. Fairall, ${ }^{2}$ Edgar L. Andreas, ${ }^{3}$ Peter S. Guest, ${ }^{4}$ \\ and Donald K. Perovich ${ }^{3}$ \\ Received 2 November 2000; revised 24 October 2001; accepted 14 November 2001; published 12 October 2002.
}

[1] Measurements at the Surface Heat Budget of the Arctic Ocean Experiment (SHEBA) Atmospheric Surface Flux Group (ASFG) tower site from October 1997 to October 1998 are used to describe the annual cycle of the near-surface environment and the surface energy budget (SEB). Comparisons with historical data and climatological estimates suggest that the SHEBA site was $3-8^{\circ} \mathrm{C}$ warmer in March and April. The unique SHEBA profile measurements showed that the mean near-surface environment is strongly stable during 6 winter months, and near neutral or weakly stable during the other months.

However, one-hour data show that neutral stratification does occur $25 \%$ of the time during the winter. The monthly mean flux profiles suggest that turbulent processes cool the nearsurface atmosphere during the winter and warm it during the summer, though the sign of the sensible heat flux is negative during both the winter and July. The SHEBA SEB calculation is unique in its nearly exclusive use of observed rather than derived values. The magnitude of the best estimate of the annual net observed surface energy surplus at SHEBA $\left(8.2 \mathrm{~W} \mathrm{~m}^{-2}\right)$ was consistent with the observed surface ice and snowmelt and was in reasonable agreement with most previous estimates of the net annual SEB over the Arctic pack ice. However, the partitioning of the various components of the SEB differed in the SHEBA data. The SHEBA site had unusually large incoming longwave radiation in the fall and spring, giving an annual mean that was larger by $10.4-19.3 \mathrm{~W} \mathrm{~m}^{-2}$. The site also had substantially less incoming solar radiation during most months than in previous estimates, producing a difference in the annual mean of 5.0-9.5 $\mathrm{W} \mathrm{m}^{-2}$ when compared to these estimates. The observed magnitudes of the sensible $\left(-2.2 \mathrm{~W} \mathrm{~m}^{-2}\right)$ and latent $\left(1.1 \mathrm{~W} \mathrm{~m}^{-2}\right)$ heat fluxes at SHEBA were smaller than previous climatological estimates, as were the conductive flux estimates $\left(2.4-5.0 \mathrm{~W} \mathrm{~m}^{-2}\right)$ at this site. Estimates of the measurement errors suggest that they are not likely to alter the conclusions concerning the SEB terms presented here but will prevent us from conclusively determining the reasons for the net thinning of the ice observed during SHEBA. INDEXTERMS: 3349 Meteorology and Atmospheric Dynamics: Polar meteorology; 3394 Meteorology and Atmospheric Dynamics: Instruments and techniques; 3359 Meteorology and Atmospheric Dynamics: Radiative processes; 3339 Meteorology and Atmospheric Dynamics: Ocean/atmospheric interactions (0312, 4504); 3309 Meteorology and Atmospheric Dynamics: Climatology (1620); KEYWORDS: surface energy budget, arctic pack ice meteorology, Arctic annual cycle

Citation: Persson, P. O. G., C. W. Fairall, E. L. Andreas, P. S. Guest, and D. K. Perovich, Measurements near the Atmospheric Surface Flux Group tower at SHEBA: Near-surface conditions and surface energy budget, J. Geophys. Res., 107(C10), 8045, doi:10.1029/2000JC000705, 2002.

\section{Introduction}

[2] In recent years, understanding the climate of the Arctic has become increasingly important for understand-

\footnotetext{
${ }^{1}$ Cooperative Institute for Research in Environmental Sciences/NOAA/ ETL, Boulder, Colorado, USA.

${ }^{2}$ NOAA/Environmental Technology Laboratory (ETL), Boulder, Colorado, USA.

${ }^{3}$ Army Cold Regions Research and Engineering Laboratory (CRREL), Hanover, New Hampshire, USA.

${ }^{4}$ Naval Postgraduate School (NPS), Monterey, California, USA.

Copyright 2002 by the American Geophysical Union. 0148-0227/02/2000JC000705\$09.00
}

ing and modeling climate change processes. Studies have shown that the greatest sensitivity to climate change is in the Arctic [e.g., Manabe and Stouffer, 1980; Houghton et al., 1990], and that the Arctic atmospheric, cryospheric, and oceanographic processes have a large influence on the global climate. Unfortunately, the climatic processes in the Arctic region are poorly understood, principally because of a dearth of observations for diagnosing the processes and validating numerical models. Invaluable climatological data are available over the pack ice from measurement efforts beginning with Fridtjof Nansen's expedition in 1893-1896 [Mohn, 1905; Sverdrup, 1933], and including the 31 drifting ice stations deployed by the former Soviet Union in 1937-1991 [Marshunova, 1961; Maykut, 1982; 
Colony et al., 1992, available at the Applied Physics Laboratory, University of Washington, Seattle, WA 98195; Marshunova and Mishin, 1994; National Snow and Ice Data Center (NSIDC), 1996, available at nside@kryos.Colorado.edu; Lindsay, 1998], but the spatial and temporal coverage is poor. Recent efforts include synthesizing the surface-based data with satellite observations and numerical models to provide an analysis of the Arctic near-surface temperature [Martin and Munoz, 1997; Rigor et al., 2000]. To understand and model the physical processes, however, standard climate observations are inadequate. Specialized measurements addressing specific processes important for the energy budget in the Arctic are needed. These include radiative fluxes, cloudiness and cloud properties, turbulent heat fluxes, and snow and ice characteristics. Such measurements have occasionally been available from previous measurement campaigns, and been analyzed for the purpose of understanding the climate processes [e.g., Sverdrup, 1933; Untersteiner, 1961; Maykut and Untersteiner, 1971; Pritchard, 1980; Maykut, 1982; Ebert and Curry, 1993; Lindsay, 1998; Jordan et al., 1999], but at no time have there been adequate direct observations of all components of the surface energy budget at one location in the pack ice throughout an entire annual cycle. Typically, some or all of the important fluxes are computed using parameterizations with uncertain accuracies.

[3] Observations of the near-surface atmospheric environment and all components of the surface energy budget were collected during the Surface Heat Budget of the Arctic Ocean Experiment (SHEBA) [Moritz et al., 1993; Perovich et al., 1999; Uttal et al., 2002]. A primary objective of SHEBA was to collect the data necessary for understanding the atmospheric, cryospheric and oceanic processes determining the surface heat budget of the Arctic Ocean during an entire annual cycle. The measurements focused on the ice-albedo and cloud-radiation feedback mechanisms [e.g., Curry et al., 1996], and are intended to eventually improve air-sea-ice interaction parameterizations in climate models. The objective of the Atmospheric Surface Flux Group (ASFG) was to obtain measurements of the surface energy budget, focusing on the turbulent heat fluxes and the nearsurface boundary layer structure during the entire annual cycle [Andreas et al., 1999].

[4] Section 2 describes the data collected on or near the 20-m-tall ASFG tower at the main SHEBA ice station, the techniques used in processing these data, and the data accuracy. This is followed in sections 3 and 4 by discussions of the near-surface atmospheric environment and the surface energy budget terms at SHEBA as represented by this data set. The data are unique because they include 1) near-surface profiles of temperature, humidity, wind, and turbulent fluxes; and 2) direct measurements of all components of the surface energy budget, except conduction, with hourly resolution. Discussions of the annual and diurnal cycles will be included. We will emphasize the unique aspects of the data set and will include comparisons to historical and climatological data. The observations to be presented will serve to illustrate the accuracy of the data set. Though uncertainties in the data exist, our error estimates give us confidence in our conclusions of the relative importance of the various surface energy budget terms. Nevertheless, as will be demonstrated, other climatologically important conclusions require accuracy beyond that possible from this data set. Section 5 presents a summary and a discussion of the effects of uncertainties in the data on the conclusions.

[5] Readers are referred to Persson et al. [2002] (available at the National Technical Information Service, 5285 Port Royal Road, Springfield, VA 22061) and the ASFG SHEBA website (http://www.weather.nps.navy.mil/ psguest/sheba/) for more detailed descriptions of the site, data calibrations, editing and processing, and comparisons to other data sources at SHEBA. The data set can be obtained at http:// www.joss.ucar.edu/cgi-bin/codiac/projs?SHEBA.

\section{Site and Measurement Description}

\subsection{Site Description}

[6] From October 1997 to October 1998, the SHEBA ice floe drifted more than $1400 \mathrm{~km}$ in the Beaufort and Chukchi Seas, with the latitude varying from $74^{\circ} \mathrm{N}$ to $81^{\circ} \mathrm{N}$. The ASFG site was located $280-350 \mathrm{~m}$ from the icebreaker Des Groseilliers at the edge of the main ice station, and consisted of a 20-m tower, two short masts, several other instruments placed on the surface, and a wooden data acquisition hut ("Met hut") (Figures 1 and 2). The direction and distance of the ASFG site from the ship and other obstacles varied during the year because the ice floe rotated and sheared apart (Figure 3). A steady rotation occurred during the first 4 months, with episodic rotation thereafter, especially in late August. Leads also formed episodically at various distances from the tower, with the closest being about 100 meters in February and March at the location of the "Camp Ridge" shown in Figure 1. During the summer, more than $25 \%$ of the floe was covered by meltponds (Figure 2d) [Perovich et al., 2002] (M. A. Tschudi et al., Airborne observations of summertime surface features and their effect on surface albedo during SHEBA, submitted to Journal of Geophysical Research, 2001, hereinafter referred to as Tschudi et al., submitted manuscript, 2001). The ASFG site can be characterized as multiyear pack ice with summertime meltponds and occasional nearby leads.

[7] Each level of the ASFG tower had a temperature/ relative humidity $(\mathrm{T} / \mathrm{RH})$ probe and a sonic anemometer (Table 1; Figure 2b). The heights of the tower-mounted instruments above the snow/ice surface varied during the year because of snow accumulation and surface melt; the mean heights and the range of heights for each of the five sensor levels are given in Table 1. These heights were obtained using the snow depth measurements and occasional manual height measurements. The top level of the tower was lower during the winter than the summer, so two mean heights are given. An Ophir fast hygrometer was mounted on a $3-\mathrm{m}$ boom at an intermediate level $0.8 \mathrm{~m}$ below level 4 (Figure 2c). During seven periods of $1-10$ days each, the lower and upper levels, mounted on carriages, were moved to perform intercomparisons between the tower levels. Adjustments to the data were based on these intercomparison results.

[8] Other instruments not on the tower but at the ASFG site include the Eppley pyrgeometers and pyranometers on a shorter mast ("A" in Figures 1 and 2d) measuring the four 

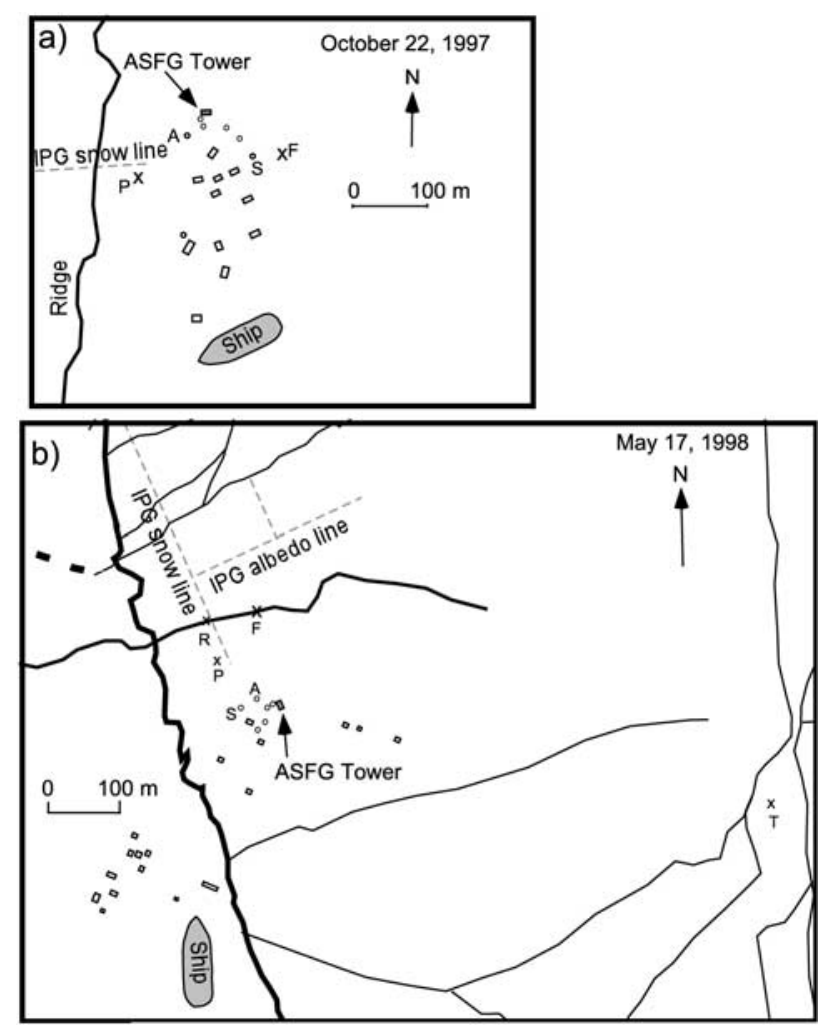

Figure 1. Map of the ASFG site in (a) October 1997, and (b) May 1998. The ASFG tower is shown as a shaded rectangle. The small circles near the ASFG tower show other instrument sites, such as the radiometer mast (A) and the sodar (S). Huts or other obstacles are shown as open rectangles. The Florida PAM station (F) and IPG thermistor string sites at Pittsburgh (P), Ridge (R), and Tuk (T) are shown by x's. The location of the IPG snow depth and albedo measurement lines are also shown. Ice ridges are shown as solid, long lines, with the line thickness indicating the relative height of the ridge (thin-lower; thick-higher). The "Camp Ridge" is shown by the heaviest solid line in (b). The heavy dashed line is an open-water lead.

broadband radiative components; a Barnes PRT-5 radiometer, a General Eastern (GE) thermometer/hygrometer, and a surface thermistor measuring the surface temperature; a thermistor measuring the snow/ice interface temperature; STI optical and ETI weighing bucket precipitation gauges; and a stake to provide snow depth measurements. The snowstake and the thermistors were near the base of the tower, while the other sensors were slightly farther away (Figures 1 and 2b). Two remote sensors were also located at the ASFG site. The transmitter of a scintillometer using a 300-m baseline was located at the site to obtain a spatially averaged friction velocity and sensible heat flux (E. L. Andreas et al., Probability distributions for the inner scale and the refractive index structure parameter and their implications for flux averaging, submitted to Journal of Applied Meteorology, 2002). This instrument was only operational sporadically, principally during the winter. A sodar was also operated at the site (Figure 1), giving wind profiles and turbulent backscatter measurements up to about $200 \mathrm{~m}$. This instrument operated throughout the year, but analysis of these data has only just begun. Data from the remote sensors will not be discussed in this paper.

\subsection{Measurements}

[9] The data stream is divided into "slow" and "fast" data, and the processing was initially done separately, with the parameters combined and edited at a later stage. The slow data include data from the T/RH sensors, the Eppley pyrgeometers and pyranometers, the GE thermometer and hygrometer, the Barnes radiometer, the precipitation gauges, and the two thermistors located at the snow surface and the snow/ice interface. Instantaneous slow data were collected by Campbell data loggers at 5 -second intervals, producing 1 - and 10-minute means and 10-minute statistics in realtime. In postprocessing, the 10-minute means were used to compute hourly averages, with the 10-minute statistics used for quality-control editing. Hourly averages of atmospheric pressure, calculated from 5-minute means, were obtained directly from the Portable Automated Mesonet (PAM) station named "Florida" [Horst, 2000, available at http:// www.atd.ucar.edu/sssf/projects/sheba]. The fast data from the sonic anemometers and the Ophir fast hygrometer were saved directly on a computer hard drive at $10 \mathrm{~Hz}$ and $20 \mathrm{~Hz}$, respectively.

\subsubsection{Temperature and Relative Humidity}

[10] The temperature and humidity data recovery was high, generally above 90\% (Figure 4a). The intercalibrations of the main tower temperature and relative humidity (RH) probes provide corrections for temperature and relative humidity that are a function of time, since the biases were found to change slowly during the year. After these corrections, we estimate that the tower temperatures were accurate (within one standard deviation) relative to each other to within $0.05^{\circ} \mathrm{C}$, except during high frost periods. Their absolute accuracy may be slightly worse; but based on the variations between sensors we estimate that an accuracy of $0.07^{\circ} \mathrm{C}$ is reasonable for most periods. The manufacturer guarantees an accuracy of $\pm 0.2^{\circ} \mathrm{C}$ for temperatures between $-70^{\circ} \mathrm{C}$ and $+50^{\circ} \mathrm{C}$.

[11] All of the RH biases were quite small. We estimate that the corrected relative accuracy of our tower RH values is less than $1 \%$ at the $95 \%$ confidence level. However, the absolute accuracy of the RHs is a subject of concern. The instrument specifications indicate an accuracy of $\pm 1 \%$ for $\mathrm{RH}$ from $0-90 \%$ between $-70^{\circ}$ and $+50^{\circ} \mathrm{C}$. However, the environment at SHEBA was always close to ice saturation [Andreas et al., 2002], leaving uncertainty in the applicability of the specifications. On the other hand, these humidity sensors show responses that are physically believable during large wintertime thermal transitions, with changes from slight supersaturation with respect to ice during clear, cold periods (with frequent indications of suspended ice crystals from lidar measurements) to slight subsaturated conditions during relatively warmer, cloudy periods with enhanced turbulent, near-surface mixing [Persson et al., 1999b]. At this point, there is no evidence that the $\mathrm{RH}$ values obtained on the ASFG tower are significantly in error, while there is indirect physical evidence that they are reasonable and behave in a physically consistent manner. There is also direct evidence from postexperiment coldchamber tests that these sensors performed better in wintertime SHEBA-like conditions than did other RH sensors 

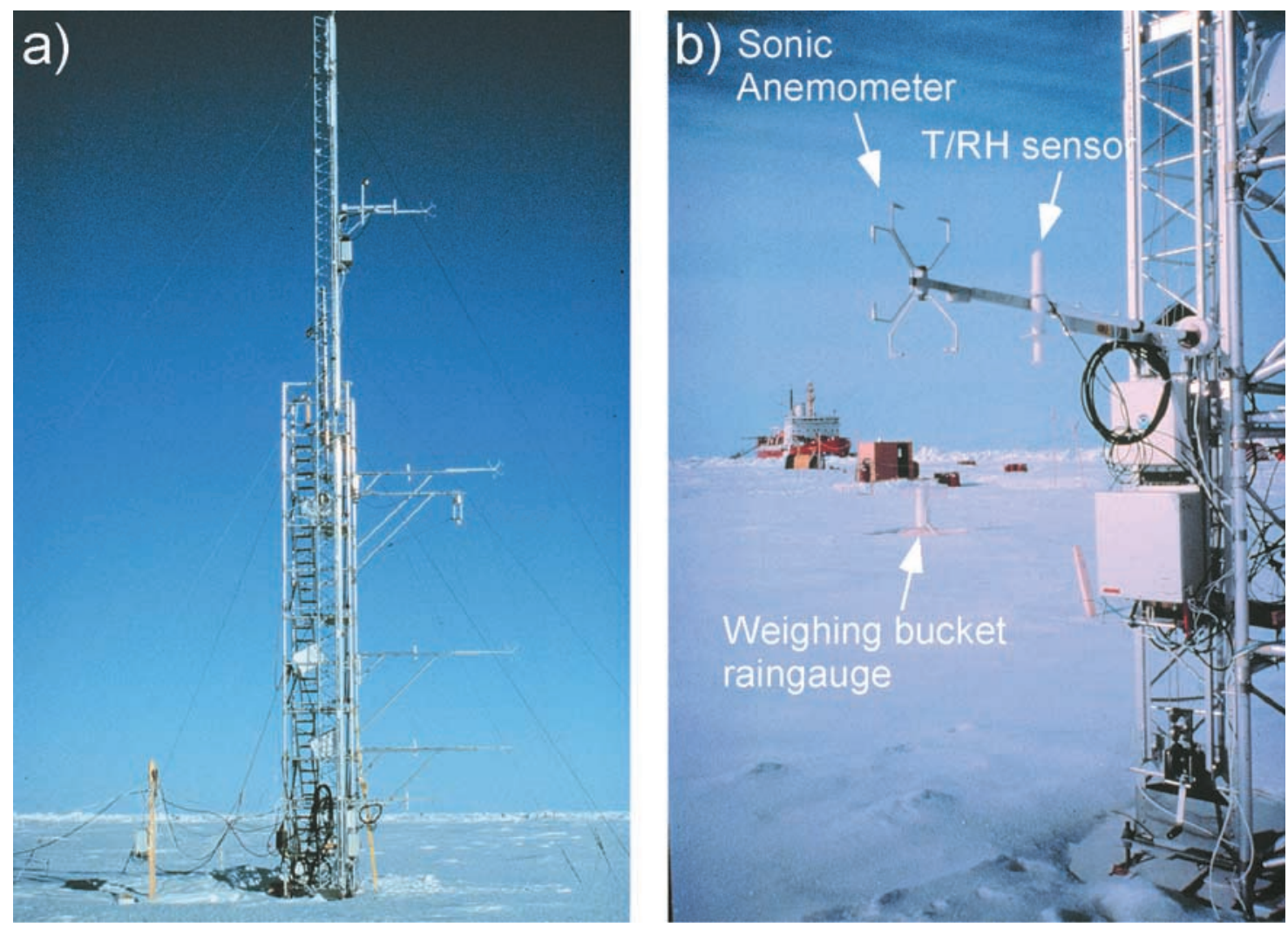

Figure 2. Photographs of (a) the ASFG tower looking towards the NNW on 11 April 1998, (b) the ATI sonic anemometer and shielded T/RH probe at the lowest level on the tower in early June, (c) the Ophir fast hygrometer and the level-4 sonic anemometer looking northeast on 11 April, and (d) the Eppley radiometer stand on 3 August, taken from the 10-m level on the tower. The winter surface conditions in the predominant northeast wind direction are seen in (c), and the large melt pond to the right in (d) affects the summer outgoing pyranometer and pyrgeometer measurements. The ETI rain gauge is seen in the background in (b).

deployed (Horst, private communication), though quantifying their accuracy has been hampered by concerns over the accuracy of the chamber reference. Further cold-chamber studies will be done to establish the absolute accuracy of RH measurements in ice-saturated conditions at low temperatures from instruments deployed at SHEBA.

\subsubsection{Shortwave and Longwave Radiation and Albedo}

[12] One of the main SHEBA project goals was to obtain multiple, varied, and redundant measurements of all the components of the surface energy budget. As a result, seven research groups provided radiometer measurements, though only the ASFG and the Atmospheric Radiation Measurement (ARM) group provided measurements of all four broadband components during the entire year. At the ASFG tower site, Eppley Precision Infrared Radiometer (PIR) hemispheric flux pyrgeometers were used to measure the broadband longwave (LW) fluxes, and Eppley Precision Solar pyranometers (PSP) were used to obtain the broadband shortwave (SW) radiative fluxes (Table 1). Two sets of each radiometer were mounted to look both upward and downward, thus corresponding to the four components. The ASFG radiometer domes were maintained relatively ice-free due to frequent cleaning, proximity to the ship, and the installation of fans at the initial deployment. Comparisons to other radiometers during the winter show the relative ice- free nature of the ASFG LW measurements [Russell et al., 1999]. This subsection will briefly describe the processing and accuracy of the radiative fluxes. Persson et al. [2002] present more details and further comparisons.

[13] The ASFG radiometers were located approximately $1.5-2 \mathrm{~m}$ above the snow surface on a small mast about $25 \mathrm{~m}$ from the base of the 20-m meteorological tower ("A" in Figure 1). The radiometer site was at the downwind edge of a snowdrift in the lee of the tower. Thus, the snow remained at this site a few days longer in the early summer than at most sites on the SHEBA Ice Physics Group (IPG) snow line [Perovich et al., 1999, 2002], but not as long as at the ASFG snow stake closer to the tower. In early July, a melt pond appeared in the field of view of the downward facing radiometers (Figure 2d), affecting the outgoing $\mathrm{SW}\left(\mathrm{Q}_{\mathrm{so}}\right)$ and $\mathrm{LW}\left(\mathrm{Q}_{\mathrm{lo}}\right)$ radiation until late August. A shadow from the 20-m tower fell on the radiometer stand during parts of the year when solar radiation was present. This shadow occurred near 1800-1900 UT (locally midmorning) during the spring and summer.

[14] The radiometer thermopile voltage outputs and the PIR dome and case temperatures were sampled at a rate of 5 seconds. Means and standard deviations were stored at 1- and 10-minute intervals as described above. Each of these parameters was averaged to one-hour intervals, from 

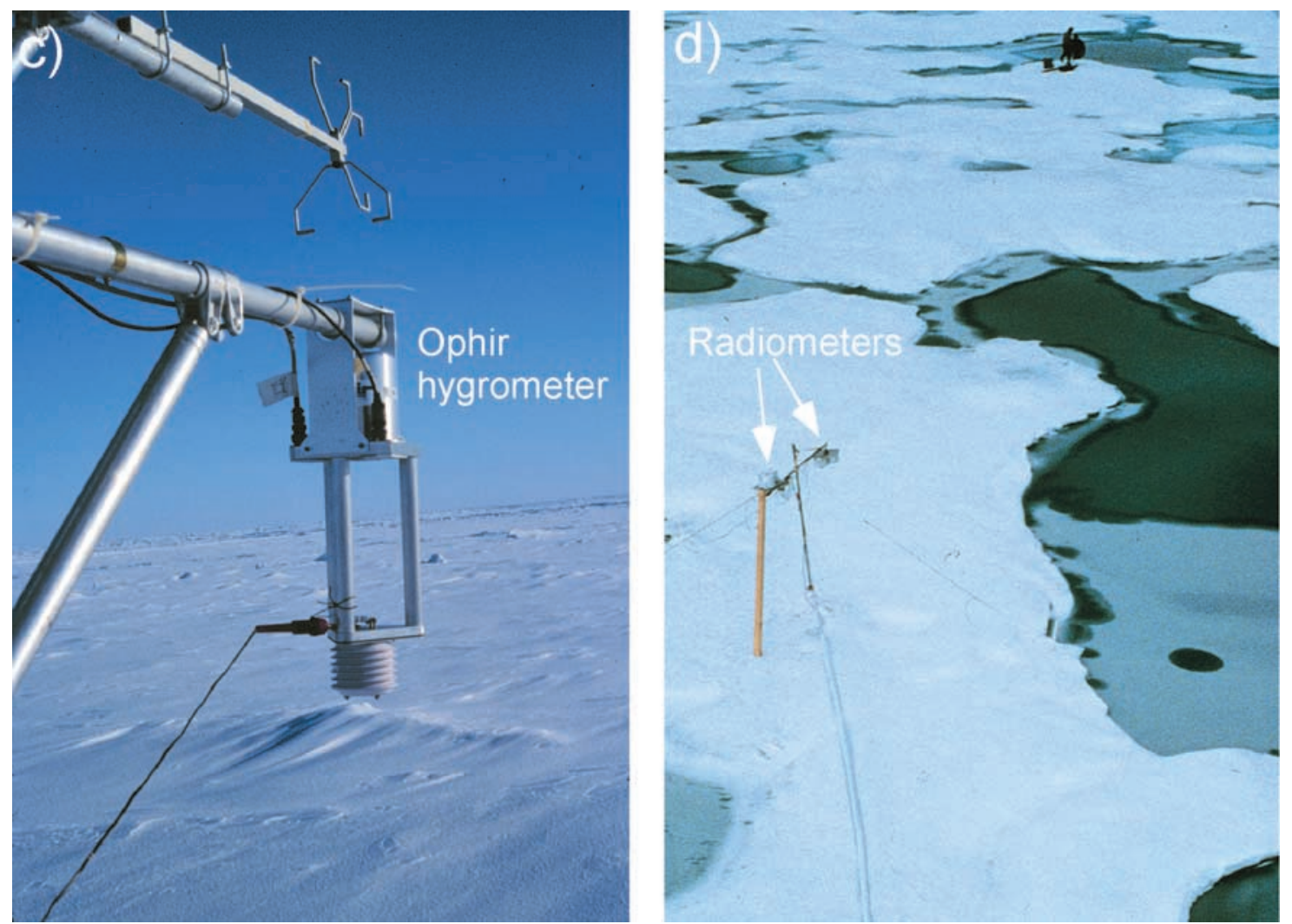

Figure 2. (continued)

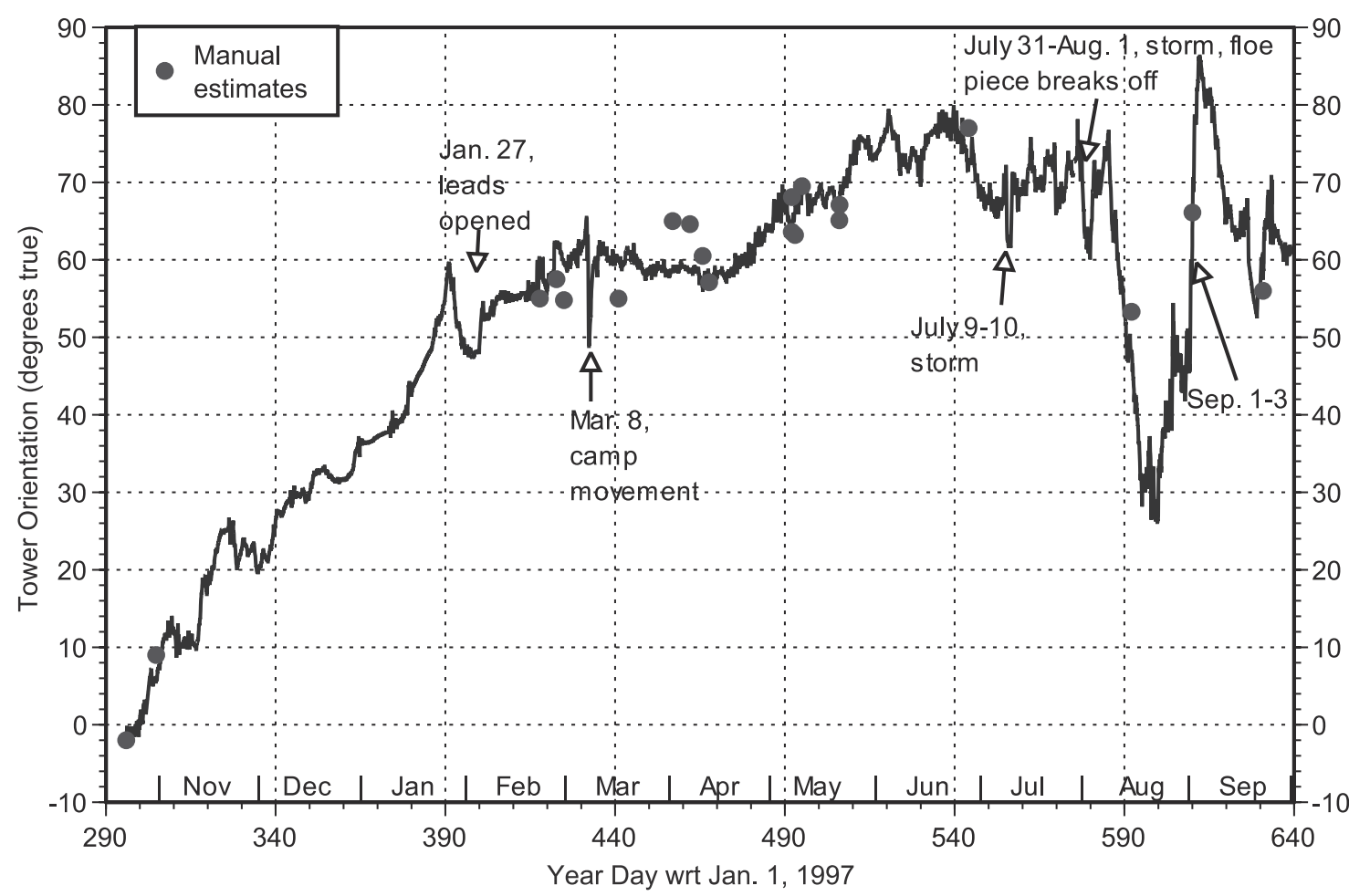

Figure 3. Daily means of the orientation of the SHEBA ASFG tower with respect to true north during the year. Handheld compass measurements are shown as dots. 
Table 1. List of Instruments at the ASFG Site ${ }^{a}$

\begin{tabular}{|c|c|c|c|c|}
\hline Instrument & Parameters Measured & Height, $\mathrm{m}$ & Sampling Rate & Time Period \\
\hline $\begin{array}{l}\text { Väisälä HMP } 235 \text { T/RH probe, } \\
\text { R.M. Young aspirated shields }\end{array}$ & $\mathrm{T}, \mathrm{RH}$ & $\begin{aligned} & \text { 1) } 2.2(1.9-3) \\
& \text { 2) } 3.2(2.8-3.9) \\
& \text { 3) } 5.1(4.7-5.8) \\
& \text { 4) } 8.9(8.5-9.6) \\
& \text { 5a) } 13.8(13.6-15.0) \\
& \text { 5b) } 18.2(17.6-18.8)\end{aligned}$ & $\begin{array}{c}5 \mathrm{~s} \\
(1 \mathrm{~min})\end{array}$ & $10 / 31 / 97-9 / 28 / 98$ \\
\hline $\begin{array}{l}\text { Applied Technologies Inc. (ATI) } \\
\text { sonic anemometers }\end{array}$ & $\begin{array}{l}\mathrm{u}, \mathrm{v}, \mathrm{w}, \mathrm{WS} \\
\mathrm{WD}, u_{*}, H_{\mathrm{s}}, \mathrm{H}_{1}, \\
\text { turb. spectra }\end{array}$ & $\begin{array}{l}\text { Levels 1), 2), 3), 4), } \\
\text { 5a), 5b) as above }\end{array}$ & $10 \mathrm{~Hz}$ & $10 / 31 / 97-9 / 28 / 98$ \\
\hline Ophir fast hygrometer & $\mathrm{q}^{\prime}, \mathrm{H}_{1}$ & $8.1(7.7-8.8)$ & $20 \mathrm{~Hz}$ & $10 / 31 / 97-8 / 16 / 98$ \\
\hline $\begin{array}{l}\text { Eppley pyrgeometers (PIR) } \\
\quad(4.0-50.0 \mu \mathrm{m} \text { wavelength) }\end{array}$ & $\mathrm{Q}_{\mathrm{li}}, \mathrm{Q}_{\mathrm{lo}}$ & $1.5-2.0$ & $5 \mathrm{~s}(1 \mathrm{~min})$ & $10 / 31 / 97-9 / 28 / 98$ \\
\hline $\begin{array}{l}\text { Eppley pyranometers (PSP) } \\
\quad(0.29-2.80 \mu \mathrm{m} \text { wavelength) }\end{array}$ & $\mathrm{Q}_{\mathrm{si}}, Q_{\mathrm{so}}$ & $1.5-2.0$ & $5 \mathrm{~s}(1 \mathrm{~min})$ & $10 / 31 / 97-9 / 28 / 98$ \\
\hline General Eastern thermometer, hygrometer & $T_{\mathrm{ge}}, T_{\mathrm{dge}}, \mathrm{T}_{\mathrm{sge}}$ & 0.1 & $5 \mathrm{~s}(1 \mathrm{~min})$ & $10 / 31 / 97-9 / 28 / 98$ \\
\hline $\begin{array}{l}\text { Barnes PRT }-5 \\
\quad(9.5-11.5 \mu \mathrm{m} \text { wavelength })\end{array}$ & $\mathrm{T}_{\text {srb }}$ & 1.0 & $5 \mathrm{~s}(1 \mathrm{~min})$ & $10 / 31 / 97-8 / 20 / 98$ \\
\hline Thermistors & $\mathrm{T}_{\text {ice }}, \mathrm{T}_{\text {sth }}$ & $-1.0-0,0$ & $5 \mathrm{~s}(1 \mathrm{~min})$ & $10 / 31 / 97-9 / 28 / 98$ \\
\hline Scientific Tech. Inc model 815 optical raingauge & precip rate & 1.0 & $5 \mathrm{~s}(1 \mathrm{~min})$ & $10 / 31 / 97-9 / 28 / 98$ \\
\hline $\begin{array}{l}\text { ETI NOAH-II weighing } \\
\text { raingauge }(0.254 \mathrm{~mm} \text { water resolution) }\end{array}$ & precip rate & 0.5 & $5 \mathrm{~s}(1 \mathrm{~min})$ & $10 / 31 / 97-9 / 28 / 98$ \\
\hline Vaisala PTB 220B digital barometer & air pressure & 0.5 & $1 \mathrm{~s}(5 \mathrm{~min})$ & $10 / 22 / 97-9 / 30 / 98$ \\
\hline Snow stake & snow depth & N/A & $1 /$ day or less & $10 / 31 / 97-7 / 10 / 98$ \\
\hline Lowrance Global Positioning System & lat, lon & N/A & $2 \mathrm{~Hz}$ & $10 / 31 / 97-9 / 28 / 98$ \\
\hline Scintec scintillometer & $H_{\mathrm{s}}, u *$ & $2.60-2.88$ & $1 \mathrm{~min}$ & $\begin{array}{c}10 / 20-12 / 2 / 97 \\
5 / 20-8 / 2 / 98\end{array}$ \\
\hline AeroVironment Sodar, Model 4000 & $\begin{array}{l}\mathrm{u}, \mathrm{v}, \mathrm{w} \text {, acoustic } \\
\text { backscatter }\end{array}$ & $8-200$ & $5 \mathrm{~s}(15 \mathrm{~min})$ & $10 / 31 / 97-10 / 2 / 98$ \\
\hline
\end{tabular}

${ }^{\mathrm{a}}$ The first three instrument types were mounted on the $20-\mathrm{m}$ tower, with the first two mounted at the five main levels. The second column shows the directly measured and derived parameters from each instrument. The average heights are in column three, with the range due to changes in the surface level given in parentheses. The sampling rate is given in the fourth column, with the minimum stored resolution of the averaged data given in parentheses if different than the sampling rate. The time period when each instrument was operational is given in the last column. The pressure sensor was actually located at the nearby Florida PAM station. $T_{\mathrm{ge}}$ and $T_{\mathrm{dge}}$ are the temperature and dew point at the General Eastern thermometer/hygrometer, respectively. The other parameters are defined in the text.

which time series of hourly upward and downward radiances were produced. The LW flux was computed from the PIR using the methods of Fairall et al. [1998, equation (22)]. The SW flux was calculated directly from the PSP thermopile voltages. The NOAA Climate Monitoring and Diagnostics Laboratory (CMDL) calibrated all radiometers prior to (August 1997) and after (February 1999) the SHEBA field deployment using standard methods [e.g., Philipona et al., 1995, 1998; Michalsky et al., 1999]. The calibration coefficients were linearly interpolated in time over the experiment. The data recovery from both the PIRs and the PSPs was excellent, averaging above $90 \%$ for most months (Figure 4b).

[15] Several inconsistencies in direct spot-check measurements and in parameters derived from the PIR-derived surface temperatures suggest that a temporally varying error of a few tenths of a degree in the radiometer case and dome temperatures occurred. Applying temporally dependent corrections for these temperature errors produced flux corrections ranging from $-1.0 \mathrm{~W} \mathrm{~m}^{-2}$ in November 1997 to +0.8 $\mathrm{W} \mathrm{m}{ }^{-2}$ in late June in each of the LW components, but very little change in the net LW flux.

[16] The PSP data were corrected using the CMDLdetermined zenith angle and temperature response functions, combined with the ratios of the direct to diffuse SW radiation made at the nearby ARM site. No correction was made for the LW radiation effect on the PSP measurements [Bush et al., 2000], which can cause deficits as large as -6 to $-17 \mathrm{~W} \mathrm{~m}^{-2}$ for unventilated upward facing PSPs on sunny days in California. Such corrections are only possible if separate diffuse and direct measurements are made [Dutton et al., 2001]. In addition, the CMDL calibrations (which included conditions of clear skies), the use of a radiation shield, and the strong ventilation of the domes should all have contributed to reducing the LW effects. Because the downward facing unit does not see the cold sky, it is expected to have smaller bias under strong solar flux. Finally, the nighttime offset under conditions of nearzero net LW flux is subtracted from the data and is assumed to be produced by an unknown error source. These offset values were $-2.6 \mathrm{~W} \mathrm{~m}^{-2}$ and $-2.2 \mathrm{~W} \mathrm{~m}^{-2}$ for the $\mathrm{SW}$ incoming and outgoing fluxes, respectively.

[17] Continuous measurements of incoming $\mathrm{LW}\left(\mathrm{Q}_{\mathrm{li}}\right)$ and $\mathrm{SW}\left(\mathrm{Q}_{\mathrm{si}}\right)$ fluxes at the main SHEBA ice station were also made at the ARM site, the two SHEBA Project Office (SPO) sites, and at the Portable Automated Mesonet (PAM) station named "Florida" (FLA). Upwelling broadband radiation was also measured at the ARM and FLA sites; separate diffuse and direct downwelling SW fluxes were only measured at the ARM site. All sites were located within $400 \mathrm{~m}$ of each other. Objective and subjective editing for outliers was done on all data sets before comparisons were made. The downward-facing radiometers were not compared because they viewed different surfaces. Comparisons of the LW fluxes reveal a mean difference of 1.5-1.6 $\mathrm{W} \mathrm{m}^{-2}$ between the ASFG, ARM, and FLA instruments (Table 2), with RMS differences of less than $3 \mathrm{~W} \mathrm{~m}^{-2}$. For the $\mathrm{SW}$ radiative fluxes (Table 3), the mean 

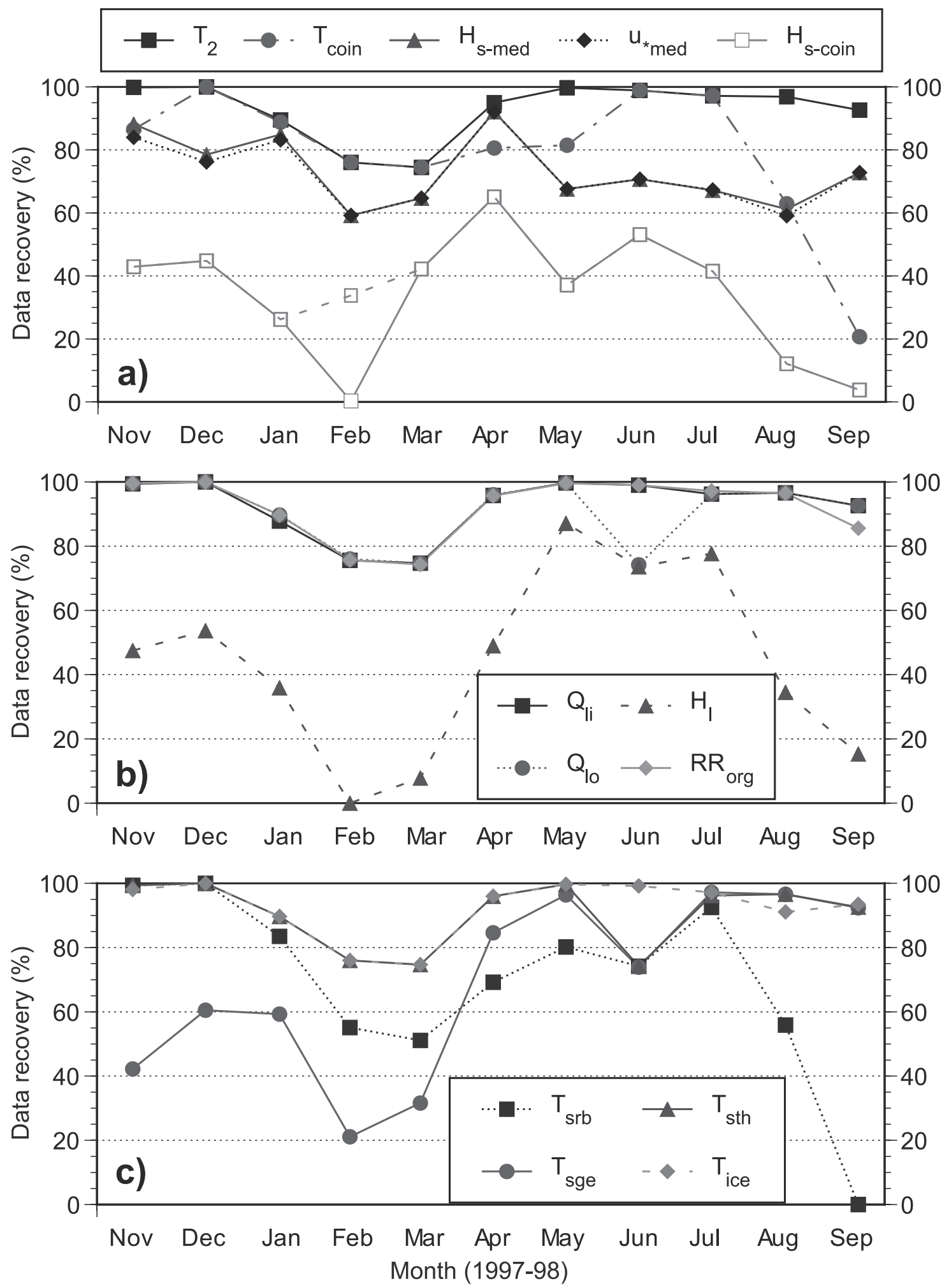

Figure 4. Monthly data recovery for (a) the level-2 temperature sensor $\left(\mathrm{T}_{2}\right)$, coincident temperature data at all five levels $\left(\mathrm{T}_{\mathrm{coin}}\right)$, sensible heat flux $\left(H_{\mathrm{s}-\mathrm{med}}\right)$ and friction velocity $\left(u_{*_{\mathrm{med}}}\right)$ at at least one level, coincident sensible heat flux at all five levels (except four levels in February) $\left(H_{\mathrm{s} \text {-coin }}\right)$, (b) incoming $\left(\mathrm{Q}_{\mathrm{li}}\right)$ and outgoing $\left(\mathrm{Q}_{10}\right)$ longwave radiation (shortwave fluxes are similar for February-September), covariance latent heat flux $\left(\mathrm{H}_{1}\right)$, optical precipitation gauge $\left(\mathrm{RR}_{\text {org }}\right)$, and (c) the snow/ice interface temperature $\left(T_{\text {ice }}\right)$ and the surface temperature from the Barnes radiometer $\left(T_{\text {srb }}\right)$, GE hygrometer $\left(T_{\text {sge }}\right)$, and in-situ thermistor $\left(\mathrm{T}_{\text {sth }}\right)$. In (a), $\mathrm{T}_{\text {coin }}$ and $\mathrm{T}_{2}$ are identical for December-March and June-July. In (b) $\mathrm{Q}_{\mathrm{li}}, \mathrm{Q}_{\mathrm{lo}}$, and $\mathrm{RR}_{\text {org }}$ are identical for all months, except June when $\mathrm{Q}_{1 \mathrm{o}}$ is less and September when $\mathrm{RR}_{\text {org }}$ is less. 
Table 2. Comparison Statistics ${ }^{\mathrm{a}}$ Between Hourly Measurements of Incoming LW Radiation at the ASFG Site and That at Other Sites at SHEBA for the Time Period 1 December to 30 September $1998^{\mathrm{b}}$

\begin{tabular}{lccccr}
\hline & $\begin{array}{c}\text { Mean, } \\
\mathrm{W} \mathrm{m}^{-2}\end{array}$ & $\begin{array}{c}\mathrm{RMS}, \\
\mathrm{W} \mathrm{m} \mathrm{m}^{-2}\end{array}$ & $\begin{array}{c}\mathrm{STD}, \\
\mathrm{W} \mathrm{m}^{-2}\end{array}$ & $\begin{array}{c}\text { Correlation } \\
\text { Coefficient }\end{array}$ & $\begin{array}{c}\text { Distance to } \\
\text { ASFG Site, m }\end{array}$ \\
\hline ASFG-ARM (Epp) & +1.6 & $2.5(1.1 \%)$ & 1.95 & 0.9996 & 400 \\
ASFG-FLA (Epp) & +1.5 & $2.9(1.2 \%)$ & 2.45 & 0.9991 & 200 \\
ASFG-SPO (Epp) & +3.0 & $4.6(2.0 \%)$ & 3.50 & 0.9985 & $150-300$ \\
\hline
\end{tabular}

${ }^{a}$ Comparison statistics include the mean difference, root-mean-square difference, standard deviation of the differences, and correlation coefficient of the measurements.

${ }^{\mathrm{b}}$ All instruments were Eppley PIR pyrgeometers. The mean incoming LW at the ASFG site for the data used in these statistics was $235 \mathrm{~W} \mathrm{~m}^{-2}$. Objective and subjective editing of all data sets were done to eliminate "outliers."

differences between the ASFG, ARM, and FLA data are also excellent, being less than $1.1 \mathrm{~W} \mathrm{~m}^{-2}$, though RMS SW differences are larger than for the LW (7.2-9.2 $\mathrm{W} \mathrm{m}^{-2}$ ). These small biases support the accuracy estimates below. The RMS differences may be due to differences in instrument response, data editing, as well as real spatial differences in cloud cover optical depth. The differences with the SPO site are larger.

[18] Fairall et al. [1998] characterize the PIR accuracy as follows: when using laboratory calibrations, a typical unit will have a mean bias of about $5 \mathrm{~W} \mathrm{~m}^{-2}$ with an additional random scatter of $5 \mathrm{~W} \mathrm{~m}^{-2}$ for 1 -h average values. The mean bias can be reduced by comparing against an absolute standard in the field or an ensemble of PIRs (the ensemble approach assumes that the basic PIR calibration method is unbiased). The comparisons with the ARM and FLA data suggest that these estimates of both the mean bias and the random error may be high, at least for the ASFG $Q_{1 i}$ data. In addition, the $\pm 0.5^{\circ} \mathrm{C}$ accuracy estimate for the surface temperature (see section 2.2.3) [Persson et al., 2002] suggests that the error in $\mathrm{Q}_{\mathrm{lo}}$ is only about $\pm 1.7 \mathrm{~W} \mathrm{~m}^{-2}$. Hence, we estimate absolute bias accuracies of the PIRs of $\pm 2.5 \mathrm{~W} \mathrm{~m}^{-2}$ for each LW component $\left(\mathrm{Q}_{\mathrm{li}}\right.$ and $\left.\mathrm{Q}_{\mathrm{lo}}\right)$, and \pm 4 $\mathrm{W} \mathrm{m}^{-2}$ for the net $\mathrm{LW}$ radiation $\left(\mathrm{Q}_{1}=\mathrm{Q}_{\mathrm{li}}-\mathrm{Q}_{\mathrm{lo}}\right)$. We estimate random scatter of $\pm 4 \mathrm{~W} \mathrm{~m}^{-2}$ for 1 -h averages of each component.

[19] Ruffieux et al. [1995] compared an ensemble of eight side-by-side PSPs at an Arctic ice camp in the spring and found an RMS disagreement of $2 \%$. Our RMS differences in Table 3 are larger than this, but the instruments were separated by a few hundred meters. Based on this information and the discussion above, we estimate our uncertainty in the downward SW to be $\pm 3 \%$ with a bias from -5 to $+1 \mathrm{~W} \mathrm{~m}^{-2}$ and in mean upward $\mathrm{SW}$ to be $\pm 3 \%$ with a bias of -3 to $0 \mathrm{~W} \mathrm{~m}^{-2}$; mean net solar radiation $\left(\mathrm{Q}_{\mathrm{s}}=\mathrm{Q}_{\mathrm{si}}-\right.$ $\left.\mathrm{Q}_{\mathrm{so}}\right)$ is uncertain by $\pm 4.5 \%$ with a bias of 0 to $-6 \mathrm{~W} \mathrm{~m}^{-2}$.
[20] Because determining the albedo $(\alpha)$ accurately is primary for the SHEBA objectives, several different groups measured $\alpha$ with different methods. Two of those measurements are used in this study. At the ASFG site, $\alpha$ was calculated using $\mathrm{Q}_{\mathrm{si}}$ and $\mathrm{Q}_{\mathrm{so}}$ from the Eppley pyranometers. Hourly albedos were calculated only for those hours for which the downward solar radiation was greater than $25 \mathrm{~W} \mathrm{~m}^{-2}$, thereby avoiding large zenith angles. Daily averages were only calculated if there were at least four such hours during the day. This fixed-site method has the advantage of yielding measurements with high temporal resolution throughout the annual cycle but the disadvantage of not integrating over all surface types (i.e., meltponds, leads, bare ice, snow covered ice, etc.) in the proportion they occurred in areal averages. However, some variability of surface type is represented when a meltpond developed within view of the radiometers in late June (Figure $2 \mathrm{~d}$ ). The IPG measured $\alpha$ at least weekly every $2.5 \mathrm{~m}$ along a 200-m survey line a few hundred meters away from the ASFG tower from April through October (see Figure 1 for location) [Perovich et al., 2002]. From June through August, albedo measurements were made every other day. Albedos integrated over the spectral wavelength range of 0.3 to $3.0 \mu \mathrm{m}$ were measured using a Kipp \& Zonen albedometer, which was positioned about a meter or less above the local surface at the end of a long rod supported by a tripod. This method had the advantage of sampling most, if not all, surface types, though perhaps not in the proportion they occurred in a larger areal average. These measurements had poorer temporal resolution than the fixed sites.

[21] Though the albedo measurements will be discussed further in section 3, an estimate of the uncertainties in the ASFG albedo will be presented here. An accuracy estimate of the hourly albedos before the onset of spring melt, when the surface was more uniform, can be obtained by

Table 3. Comparison Statistics ${ }^{\mathrm{a}}$ Between Hourly Measurements of Incoming SW Radiation at the ASFG Site and That at Other Sites at SHEBA for the Time Period 1 March to 30 September $301998^{\mathrm{b}}$

\begin{tabular}{lccccr}
\hline & $\begin{array}{c}\text { Mean, } \\
\mathrm{W} \mathrm{m}^{-2}\end{array}$ & $\begin{array}{c}\mathrm{RMS}, \\
\mathrm{W} \mathrm{m}^{-2}\end{array}$ & $\begin{array}{c}\mathrm{STD}, \\
\mathrm{W} \mathrm{m}^{-2}\end{array}$ & $\begin{array}{r}\text { Correlation } \\
\text { Coefficient }\end{array}$ & $\begin{array}{r}\text { Distance to } \\
\text { ASFG, m }\end{array}$ \\
\hline ASFG-ARM (dir + dif) & +0.2 & $9.2(5.7 \%)$ & 9.2 & 0.9983 & 400 \\
ASFG-ARM (Epp) & -1.1 & $7.2(4.4 \%)$ & 7.1 & 0.9990 & 400 \\
ASFG-FLA (K\&Z) & +0.8 & $9.1(5.6 \%)$ & 9.1 & 0.9986 & 200 \\
ASFG-SPO (Epp) & +7.7 & $11.1(6.9 \%)$ & 7.9 & 0.9991 & $150-300$ \\
\hline
\end{tabular}

${ }^{a}$ Comparison statistics include the mean difference, root-mean-square difference, standard deviation of the differences, and correlation coefficient of the measurements.

b "dir + dif" indicates the sum of the direct and diffuse ARM radiation measurements, "Epp" indicates an unshaded Eppley pyranometer, and "K\&Z" indicates an unshaded Kipp and Zonen pyranometer. The mean incoming SW at the ASFG site for the data used in these statistics was $162 \mathrm{~W} \mathrm{~m}^{-2}$. 


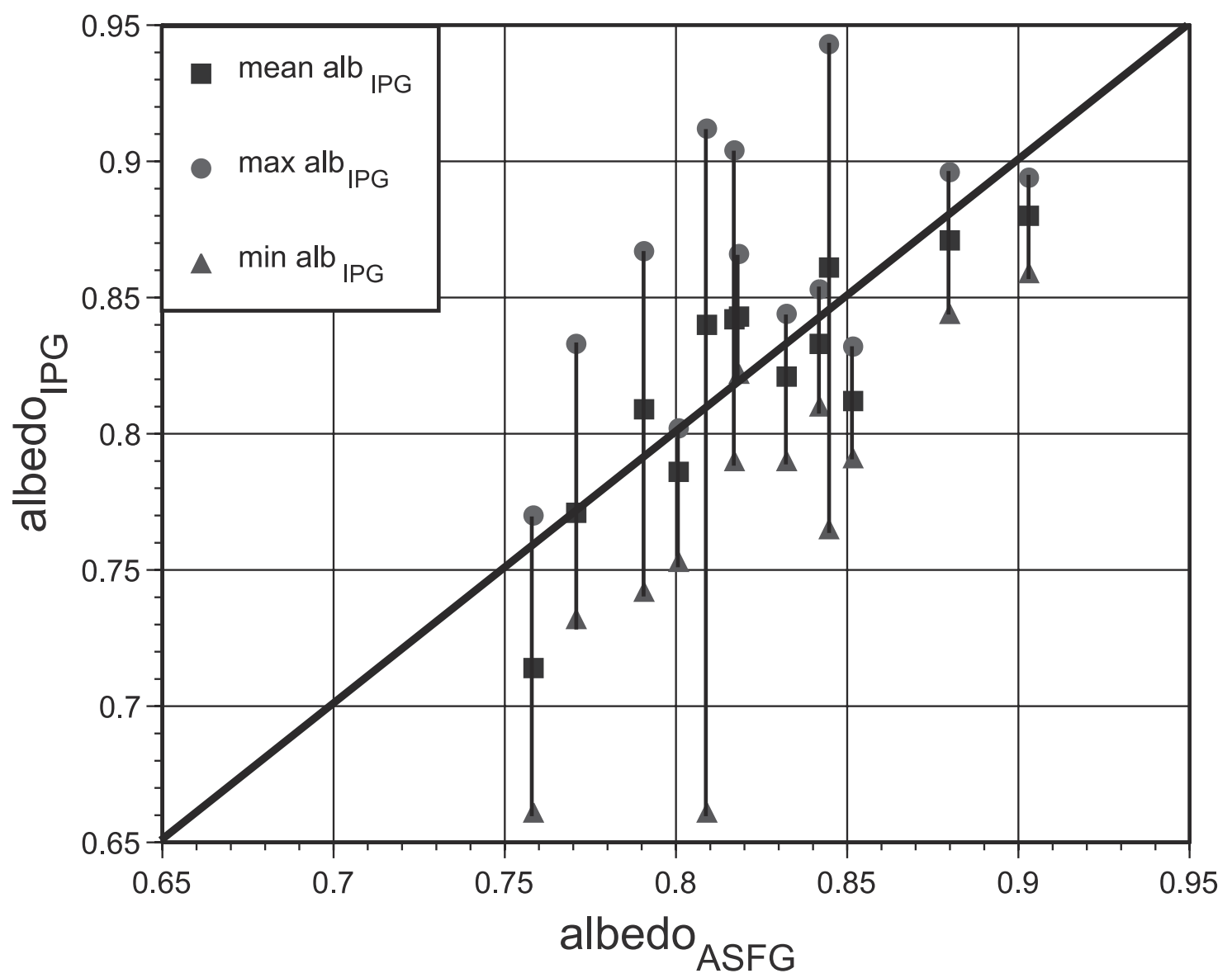

Figure 5. The IPG mean, maximum, and minimum albedos as a function of the albedo values at the ASFG mast from the hour closest to the time of the IPG measurements. Only springtime data from before the appearance of meltponds on 6 June are used. The mean and root-mean-square differences $\left(\alpha_{\mathrm{ASFG}}-\alpha_{\mathrm{IPG}}\right)$ are +0.003 and 0.024 , respectively.

comparing the ASFG hourly albedos near the time of the IPG measurements (typically midday). This eliminates diurnal and cloudiness effects [e.g., Grenfell and Perovich, 1984]. The absolute bias of these 13 pairs is less than 0.01 (Figure 5), with a root-mean-square difference of 0.024 and a maximum absolute difference of 0.05 . This comparison is likely more representative of the true albedo uncertainties in the ASFG data than any comparisons made at other times of the year.

\subsubsection{Surface and Snow-Ice Interface Temperatures}

[22] The surface temperature $\left(\mathrm{T}_{\mathrm{s}}\right)$ is an important parameter for obtaining flux parameterizations and for understanding the surface energy budget. However, it is a difficult parameter to measure accurately, so the values available in the SHEBA ASFG data set have a sizable accuracy limitation.

[23] Four different methods were used to measure surface temperature at the ASFG site [Claffey et al., 1999]. One method used the LW radiative flux measurements from the Eppley radiometers to estimate the radiative surface temperature $\left(\mathrm{T}_{\text {sre }}\right)$ from the relation

$$
\mathrm{T}_{\text {sre }}=\left\{\left[\mathrm{Q}_{\mathrm{lo}}-\left(1-\varepsilon_{\mathrm{s}}\right) \mathrm{Q}_{\mathrm{li}}\right] /\left[\varepsilon_{\mathrm{s}} \sigma\right]\right\}^{0.25},
$$

where $\mathrm{Q}_{\mathrm{lo}}$ is outgoing $\mathrm{LW}$ radiation, $\mathrm{Q}_{\mathrm{li}}$ is incoming $\mathrm{LW}$ radiation, and $\varepsilon_{\mathrm{s}}$ is surface emissivity. The accuracy of this method is limited by the uncertainties in $\varepsilon_{\mathrm{s}}$ and the errors in radiative fluxes. For the SHEBA data, $\varepsilon_{\mathrm{s}}=0.99$ throughout the year regardless of whether the surface is snow or ice. This is justified by a recent study [Grenfell et al., 1998] that gives a range for $\varepsilon_{\mathrm{s}}$ of $0.98-0.995$. The errors in $\mathrm{Q}_{\text {lo }}$ have a much larger effect. An error of $\pm 5 \mathrm{~W} \mathrm{~m}^{-2}$ results in an error in $\mathrm{T}_{\text {sre }}$ of about $\pm 1.5^{\circ} \mathrm{C}$, with the largest occurring in winter. However, since the potential temperature difference using $\mathrm{T}_{\text {sre }}$ and level 2 of the tower $\left(\theta_{\text {sre }}-\theta_{2}\right)$ should be zero when the sensible heat flux at level $1\left(H_{\mathrm{s} 1}\right)$ is zero, the monthly distributions of this difference around zero were used to determine that the accuracy of hourly values of $\mathrm{T}_{\text {sre }}$ is actually about $\pm 0.5^{\circ} \mathrm{C}$ for most of the year. These distributions also showed that sporadic low $\mathrm{T}_{\text {sre }}$ values occurred in March-June, principally during May-June. Large sporadic negative spikes in June were corrected when a loose wire was found on 28 June, and it appears likely that this problem produced sporadic low $\mathrm{T}_{\text {sre }}$ (and $\mathrm{Q}_{\mathrm{lo}}$ ) measurements as early as March, but with a smaller but still measurable effect than the obvious spikes. Hence, these low values remain in the data set. Because $T_{\text {sre }}$ appears to be accurate to within $\pm 0.5^{\circ} \mathrm{C}$ (except in May and June), had few data gaps (data recovery $>90 \%$ see Figure $4 \mathrm{~b}$ ), had comparatively little drift, and represents a true surface measurement, $\mathrm{T}_{\text {sre }}$ is used as the estimate of $\mathrm{T}_{\mathrm{s}}$ through most of the year, except as described below. 
[24] Measurements of a second surface temperature $\left(\mathrm{T}_{\mathrm{srb}}\right)$ were made with a downward pointing Barnes radiometer mounted on a post about $1 \mathrm{~m}$ above the surface. Though using a narrower spectral window than the Eppley radiometer (9.5-11.5 $\mu \mathrm{m}$ wavelength range), the Barnes radiometer also provides a true surface radiative measurement. $\mathrm{T}_{\text {srb }}$ were calculated using the hourly averaged output voltages, with corrections for the reflected longwave radiation obtained from hourly averaged Eppley radiation values. Unfortunately, the Barnes radiometer used during SHEBA required frequent difficult and tedious recalibrations and often jumped to a warmer calibration level. Hence, the time-series of $T_{\text {srb }}$ is occasionally good but has many data gaps and is frequently of questionable accuracy. Fortunately, an extensive calibration of this radiometer was done in May, so the $\mathrm{T}_{\text {srb }}$ from 24 May to 28 June are used to replace the $T_{\text {sre. }}$ With this replacement, the distribution of the potential temperature gradient $\left(\theta_{\mathrm{srb}}-\theta_{2}\right)$ indicates that the June surface temperatures are accurate to within $\pm 0.6^{\circ} \mathrm{C}$. However, $\mathrm{T}_{\text {srb }}$ in April and most of May often has larger errors than $\mathrm{T}_{\text {sre }}$.

[25] Additional estimates of $T_{\mathrm{s}}$ are available from dewpoint measurements at about $12 \mathrm{~cm}$ above the surface using the GE hygrometer [Andreas, 1986], and from a thermistor that was kept near the snow or ice surface. The hygrometer measurements also had numerous gaps, with a data recovery of about $69 \%$, and had an apparent calibration shift at temperatures below about $-19^{\circ} \mathrm{C}$. Claffey et al. [1995] found roughly the same behavior for this hygrometer over Antarctic sea ice. These data could be useful for filling in data gaps at temperatures above $-19^{\circ} \mathrm{C}$ such as in April and May, but this has not been done. The surface thermistor had two serious error sources, both resulting in overestimates of $\mathrm{T}_{\mathrm{s}}$. First, it was very difficult to keep this instrument at the snow surface, as drifting snow tended to cover it quickly after repositioning. With even a small amount of snow cover during winter and spring, this sensor showed temperatures significantly above $\mathrm{T}_{\text {sre }}$. During the spring and summer, this thermistor was also affected by solar radiation, often warming by several degrees compared to $\mathrm{T}_{\text {sre }}$ and producing significant spurious diurnal variations in $\mathrm{T}_{\mathrm{s}}$. Wrapping the sensor in aluminum foil on 25 June (JD 541) helped somewhat but did not eliminate the problem. Though the data recovery for this instrument was about $93 \%$ (Figure $4 \mathrm{c}$ ), the recovery of useful data is significantly less.

\subsubsection{Turbulent Fluxes}

[26] Each of the sonic anemometers mounted at the five levels listed in Table 1 provided measurements of the three wind components and virtual temperature at a frequency of $10 \mathrm{~Hz}$. The data are rotated in three dimensions to streamwise flow ( $u_{s}$ is streamwise, $v_{s}$ is cross-stream) based on the mean wind direction during the longest period of continuous data during the hour. To obtain "hourly" values of momentum flux and heat flux, cospectra were normally computed from seven overlapping, Hamming-windowed, linearly detrended, 13.65-minute data blocks (corresponding to $2^{13}$ data points). If no more than two breaks in the continuous data occurred during the hour, the cospectra were computed from overlapping 13.65-minute data blocks for the longest period of consecutive data, as long as this period was at least $27.3 \mathrm{~min}$ long providing at least three overlapping blocks. Normally, it was $54.6 \mathrm{~min}$ long. Note that the mean wind direction was determined from the longest period of continuous data (usually $60 \mathrm{~min}$ ), which was generally longer than the period used for the spectral calculations $(54.6 \mathrm{~min})$. The frequency integration of the cospectra provided covariances $\left(\overline{u_{s}^{\prime} w^{\prime}}, \overline{v_{s}^{\prime} w^{\prime}}, \overline{T_{s n}^{\prime} w^{\prime}}\right)$ for perturbations with periods between $0.2 \mathrm{~s}$ and $13.65 \mathrm{~min}$. Here, $\mathrm{w}$ is the vertical velocity, $\mathrm{T}_{\mathrm{sn}}$ is the sonic virtual temperature, and the prime indicates a turbulent quantity.

[27] The $\overline{q^{\prime} w^{\prime}}$ covariance (where $\mathrm{q}$ is specific humidity) was computed similarly from a single fast hygrometer at 8.1 $\mathrm{m}$ (Table 1), which sampled humidity at a frequency of 20 $\mathrm{Hz}$. To match the sampling rate of the sonic anemometers, the data from the fast hygrometer were resampled at $10 \mathrm{~Hz}$ by using only every other data point, and the covariance spectra were computed using the vertical velocities from the level-4 sonic anemometer. Because this anemometer was located $0.8 \mathrm{~m}$ above the hygrometer and displaced about 1 $\mathrm{m}$ horizontally (Figure 2c), the magnitudes of the fluxes have been increased by $11 \%$ based on the study by Kristensen et al. [1997]. Though such adjustments should depend on the scale of the turbulent eddies, the wind speed, and the wind direction, such sophistication has not been employed.

[28] Once covariance values are computed, the friction velocity $(u *)$, sensible heat flux $\left(H_{\mathrm{s}}\right)$, and latent heat flux $\left(\mathrm{H}_{1}\right)$ were determined from

$$
\begin{gathered}
\mathrm{u} *=-\left(\overline{u_{s}^{\prime} w^{\prime}}\right)^{0.5} \\
\mathrm{H}_{\mathrm{s}}=\mathrm{C}_{\mathrm{p}} \rho \overline{T^{\prime} w^{\prime}}=\mathrm{C}_{\mathrm{p}} \rho\left[\overline{T_{s n}^{\prime} w^{\prime}}-0.51 \mathrm{~T} \overline{q^{\prime} w^{\prime}}\right] \\
\mathrm{H}_{\mathrm{l}}=\left(\mathrm{L}_{\mathrm{e}}+\mathrm{L}_{\mathrm{f}}\right) \rho \overline{q^{\prime} w^{\prime}},
\end{gathered}
$$

where $T$ is the mean air temperature, $\rho$ is the air density, $C_{p}$ is the heat capacity of air at constant pressure, $L_{e}$ is the latent heat of vaporization, and $\mathrm{L}_{\mathrm{f}}$ is the latent heat of fusion. However, because the data recovery of $\mathrm{H}_{1}$ was significantly less than that of the $H_{\mathrm{s}}$ (Figures $4 \mathrm{a}$ and $4 \mathrm{~b}$ ), the processed $H_{\mathrm{s}}$ in the data set are computed using the covariance $\frac{H^{\prime} w^{\prime}}{q^{\prime}}$ when available, and bulk estimates of $\mathrm{H}_{1}$ $\left(\mathrm{H}_{1 \mathrm{~b}}\right)$ when not. A very minor correction to $\mathrm{H}_{1}$ for the Webb effect [Webb et al., 1980] was applied.

[29] Each 1-h flux value was quality controlled based on objective and subjective methods, some of which used validity limits for the streamwise and vertical velocity variances. All flux data for wind directions for which the tower structure was upwind of the sonic anemometers have been removed, but wind speeds and directions for these times have not since these are still useful in describing the climatology of the site. Most of the station structures and the Des Groseilliers itself were located within these sectors. However, a line of huts was placed near the tower-relative wind directions of $30-35^{\circ}$ on 1 April (true direction of $100^{\circ}-105^{\circ}$ in Figure 1b). Because the influences appear to be minor, fluxes from these directions have been retained. The winds only blew from the affected wind sectors about $10 \%$ of the time during the year, with the highest frequency (27\% of the time) occurring during the summer. For the entire year, the most frequent tower-relative wind directions were from $15^{\circ}$ to 
Table 4. The Median Bias and Standard Deviations of $H_{\mathrm{s}}($ Level 1$)-H_{\mathrm{s}}($ Levels $2,3,4,5)\left(\mathrm{W} \mathrm{m}^{-2}\right)$ and $u_{*}$ Comparisons $\left(\mathrm{m} \mathrm{s}^{-1}\right)$ For All the Calibration Periods Combined ${ }^{\mathrm{a}}$

\begin{tabular}{|c|c|c|c|c|c|c|c|c|c|}
\hline \multirow[t]{2}{*}{$\Delta H_{\mathrm{s}}$ Levels } & \multirow[t]{2}{*}{ Bias } & \multirow{2}{*}{$\begin{array}{l}\text { Standard } \\
\text { Deviation }\end{array}$} & \multicolumn{2}{|c|}{$99 \%$ Interval, $\mathrm{W} \mathrm{m}{ }^{-2}$} & \multirow[t]{2}{*}{$\Delta u *$ Levels } & \multirow[t]{2}{*}{ Bias } & \multirow{2}{*}{$\begin{array}{l}\text { Standard } \\
\text { Deviation }\end{array}$} & \multicolumn{2}{|c|}{$99 \%$ Interval, $\mathrm{m} \mathrm{s}^{-1}$} \\
\hline & & & Day & Month & & & & Day & Month \\
\hline$H_{\mathrm{s}} 1-H_{\mathrm{s}} 2$ & 0.2 & 1.42 & \pm 0.81 & \pm 0.14 & $u * 1-u * 2$ & 0.00 & .0158 & \pm 0.009 & \pm 0.002 \\
\hline$H_{\mathrm{s}} 1-H_{\mathrm{s}} 3$ & 0.1 & 3.07 & \pm 1.76 & \pm 0.30 & $u * 1-u * 3$ & -0.01 & .0282 & \pm 0.016 & \pm 0.003 \\
\hline$H_{\mathrm{s}} 1-H_{\mathrm{s}} 4$ & 0.5 & 2.18 & \pm 1.25 & \pm 0.21 & $u_{*} 1-u_{*} 4$ & 0.00 & .0332 & \pm 0.019 & \pm 0.003 \\
\hline$H_{\mathrm{s}} 1-H_{\mathrm{s}} 5$ & 0.8 & 1.50 & \pm 0.86 & \pm 0.14 & $u_{*} 1-u_{*} 5$ & -0.01 & .0276 & \pm 0.016 & \pm 0.003 \\
\hline
\end{tabular}

${ }^{\mathrm{a}}$ The table includes only data when the level 1 tower-relative wind direction was $>300^{\circ}$ or $<100^{\circ}$. Also shown are the $99 \%$ confidence intervals for differences of daily and monthly mean values using the two-tailed $t$ test and assuming that the differences have the standard deviation given during the calibration periods.

$75^{\circ}$, and this was also the direction of the strongest winds. However, during the summer, some strong winds occurred in the affected wind sectors. Fluxes from at least one level were available at least $60 \%$ of the time throughout the year (Figure 4a). Concurrent data from all 5 levels were available $20-60 \%$ of the time in most months.

[30] The turbulent fluxes were compared during the calibration periods, but no corrections to these parameters have been made. The comparisons of the turbulent fluxes from two instruments at the same level during the calibration period are summarized in Table 4, providing an estimate of the accuracy of the flux measurements. Bias errors in sensible heat flux are very low, less than $1 \mathrm{~W}$ $\mathrm{m}^{-2}$, and random errors (standard deviations) are generally less than $3 \mathrm{~W} \mathrm{~m} \mathrm{~m}^{-2}$. These latter values imply that comparing individual hourly values from different levels requires large differences before there is any confidence that the difference is significant $\left(3-6 \mathrm{~W} \mathrm{~m}^{-2}\right.$ at $70 \%$ confidence, $18-39 \mathrm{~W} \mathrm{~m}^{-2}$ at $95 \%$ confidence). However, differences of only $1.8 \mathrm{~W} \mathrm{~m}^{-2}$ and $0.3 \mathrm{~W} \mathrm{~m}^{-2}$ are significant at the $99 \%$ confidence level for daily and monthly mean values, respectively. Biases in $u_{*}$ are small $(0.01 \mathrm{~m} / \mathrm{s})$. Hence, hourly comparisons require differences of $0.031-.065 \mathrm{~ms}^{-1}$ (at $70 \%$ confidence) or $17-36 \%$ of the annual mean $u_{*}$ of $0.18 \mathrm{~m} / \mathrm{s}$. As Table 4 shows, differences of daily and monthly means are significant at much smaller values. Results in section 3 show systematic vertical and temporal differences of a few $\mathrm{W} \mathrm{m}^{-2}$ in the mean sensible heat fluxes, suggesting that physical signals are present.

[31] Bulk fluxes were computed from specifications of 1-hr mean surface temperature, and air temperature, humidity, and wind speed interpolated to 10 meters. The surface specific humidity is obtained from the surface temperature, assuming ice-saturated conditions. A modified form of the Coupled Ocean Atmosphere Response Experiment (COARE) sea-air flux algorithm [Fairall et al., 1996] was used. A velocity roughness length $\left(\mathrm{z}_{0}\right)$ of $4.5 \times 10^{-4} \mathrm{~m}$ was specified; this gave a good fit to the monthly mean covariance stress measurements over the annual cycle (see section 3.2). Temperature and moisture roughnesses were taken from the snow-ice parameterization of Andreas [1987]. Monthly mean bulk and covariance values agree well, especially for stress (Figure 6). The underestimation of the sensible heat flux by the bulk method for April and May by $3-4 \mathrm{~W} \mathrm{~m}^{-2}$ is likely due to the intermittent underestimation of the surface temperature, as discussed previously. Underestimation by the bulk method by $2-3 \mathrm{~W} \mathrm{~m}^{-2}$ in November and December may be due to inaccurate treatment of the very stable conditions in the bulk parameterization. Studies already begun will examine the applicability of various parameterizations for the very stable conditions occurring at SHEBA [e.g., Grachev et al., 2002]. In contrast to the sensible heat flux, the latent heat flux is overestimated by the bulk method in May and June by $2-4 \mathrm{~W} \mathrm{~m}^{-2}$ and underestimated in August and September by similar amounts. The reasons for these discrepancies are unclear. Until further diagnosis of this problem is made and because the data recovery for the covariance latent heat flux is frequently low (Figure 4b), we will use the bulk values of the latent heat flux $\left(\mathrm{H}_{\mathrm{lb}}\right)$ for calculations of the surface energy budget later in this study.

\subsubsection{Wind Speed and Direction}

[32] The archived SHEBA ASFG data contain the wind directions corresponding to the longest consecutive data period used for the flux calculations (typically $60 \mathrm{~min}$, but possibly as short as $27 \mathrm{~min}$ ). The wind speeds, including the vertical wind component, correspond to the flux calculation periods (typically $54.6 \mathrm{~min}$, but possibly as short as 27 min). The calculation of the true wind direction from the tower-relative wind direction used hourly information on the orientation of the instrument booms on the ASFG tower derived from the electronic compass at the nearby Florida PAM station.

[33] Because of possible errors that depend on wind direction, such as wake effects from the meteorological tower, the calibration of the wind measurements was more complicated than for the temperature and relative humidity. However, the approach was similar. The sonic wind calibration uncertainties were sometimes large, and unexplainable. Hence, the corrected wind speeds have standard deviation calibration errors of approximately $3 \%$ and twice that for the $95 \%$ confidence interval. Airflow effects add more error, especially for relative wind directions in the $110^{\circ}-260^{\circ}$ range. Because of these uncertainties, care must be exercised when evaluating parameters such as the von Kármán's constant and stability functions. No attempt was made to calibrate the hourly mean vertical component $(\mathrm{w})$. This has no impact on the turbulent flux calculations, as the standard three-dimensional rotation implies an assumption of a zero hourly mean w (see section 2.2.4).

\subsubsection{Ancillary Measurements}

[34] To obtain estimates of conductive flux at the ASFG site, a thermistor was placed at the ice/snow interface about $4 \mathrm{~m}$ from the southwest corner of the 20-m tower during initial deployment in October 1997 and allowed to be 

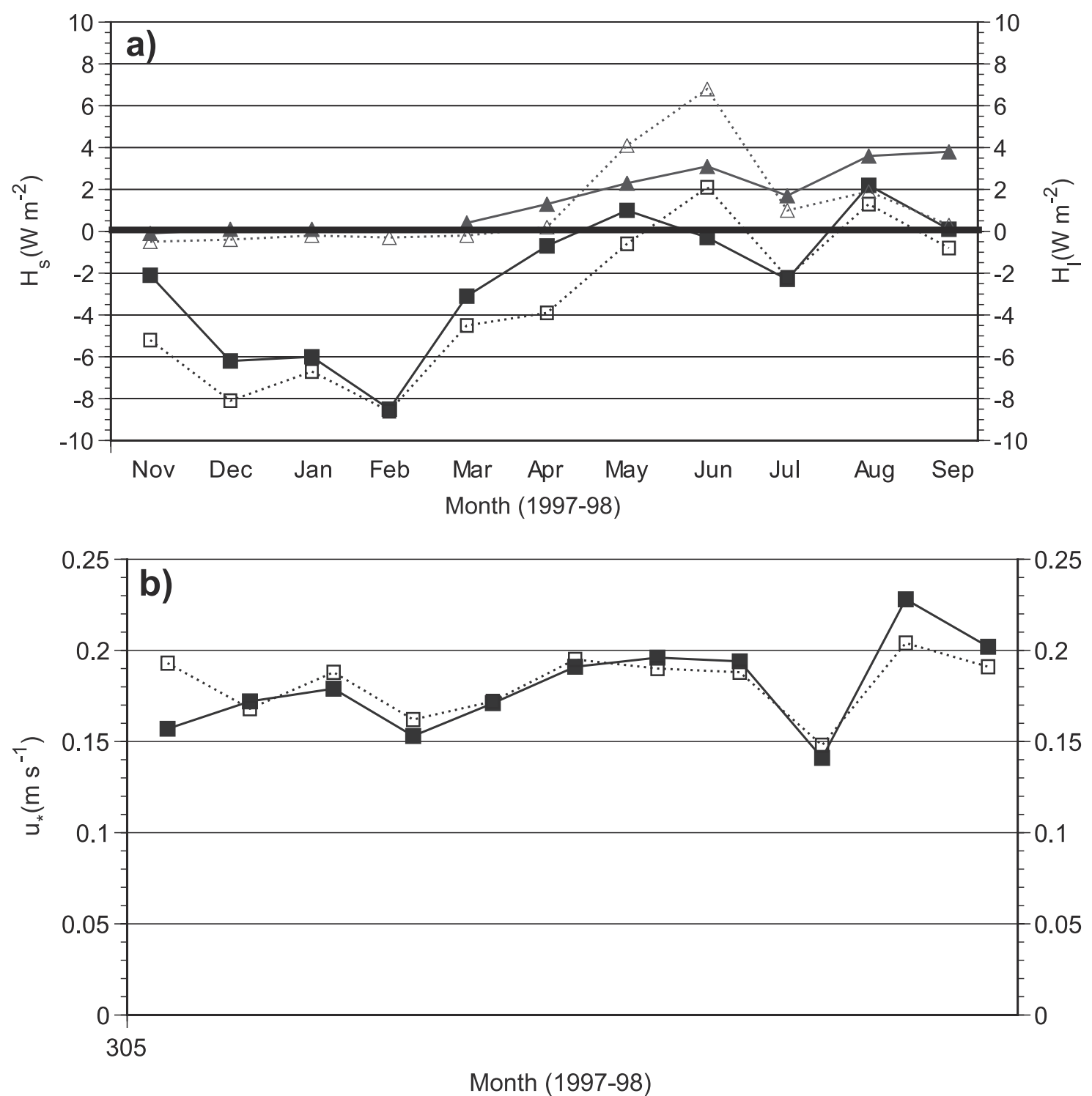

Figure 6. Monthly means of the covariance (solid) and bulk (open) fluxes. Shown are (a) sensible (squares) and latent (triangles) heat flux, and (b) friction velocity.

covered by snow during the ensuing winter. This thermistor was then reexposed the following summer when the snow melted. This snow/ice interface temperature, $\mathrm{T}_{\text {ice, }}$, can be combined with manual snow depth measurements at the same location $\left(\mathrm{d}_{\mathrm{s}}\right)$ and with $\mathrm{T}_{\mathrm{s}}$ to estimate the conductive heat flux. Because of the rotation of the floe, the site for the $T_{\text {ice }}$ and $d_{s}$ measurements was in the lee of the $20-\mathrm{m}$ tower, and the snow depth was unrepresentatively deep by a factor 2-3 (Figure 7) compared to other sites. In addition, $\mathrm{T}_{\mathrm{s}}$ was measured at the radiometer stand (or the Barnes radiometer stand) where the snow was significantly shallower, so the $T_{S}$ values used may be slightly different than the actual surface temperature above the $\mathrm{T}_{\text {ice }}$ and $\mathrm{d}_{\mathrm{s}}$ measurements. These factors must be considered when making conductive flux estimates from these measurements. Values for sites with more representative snow depths or values with a shorter time scale variability are obtainable using the IPG thermistor-string sites.
[35] Precipitation measurements were also made at the ASFG site using both an optical precipitation gauge and a weighing bucket (Table 1). The optical precipitation gauge was greatly affected by drifting snow during the winter; it appeared to detect extended periods of "diamond dust" when temperatures were between $-30^{\circ} \mathrm{C}$ and $-38^{\circ} \mathrm{C}$, and it wasn't calibrated for the very small densities of the snow and the diamond dust. Hence, it registered too much "precipitation" during the winter. During weak winds at relatively high wintertime temperatures and during the summer when the dominant phase was rain, it gives a measurement of the occurrence of precipitation at high temporal resolution. The daily precipitation amounts from this gauge for the summer $\left(\mathrm{T}_{10 \mathrm{~m}}>-2^{\circ} \mathrm{C}\right)$ are shown in Figure 7 .

[36] The weighing bucket underestimated the precipitation amounts, and appears to have occasionally given spurious precipitation readings. C. S. Bretherton et al. (A comparison of the ECMWF forecast model with obser- 


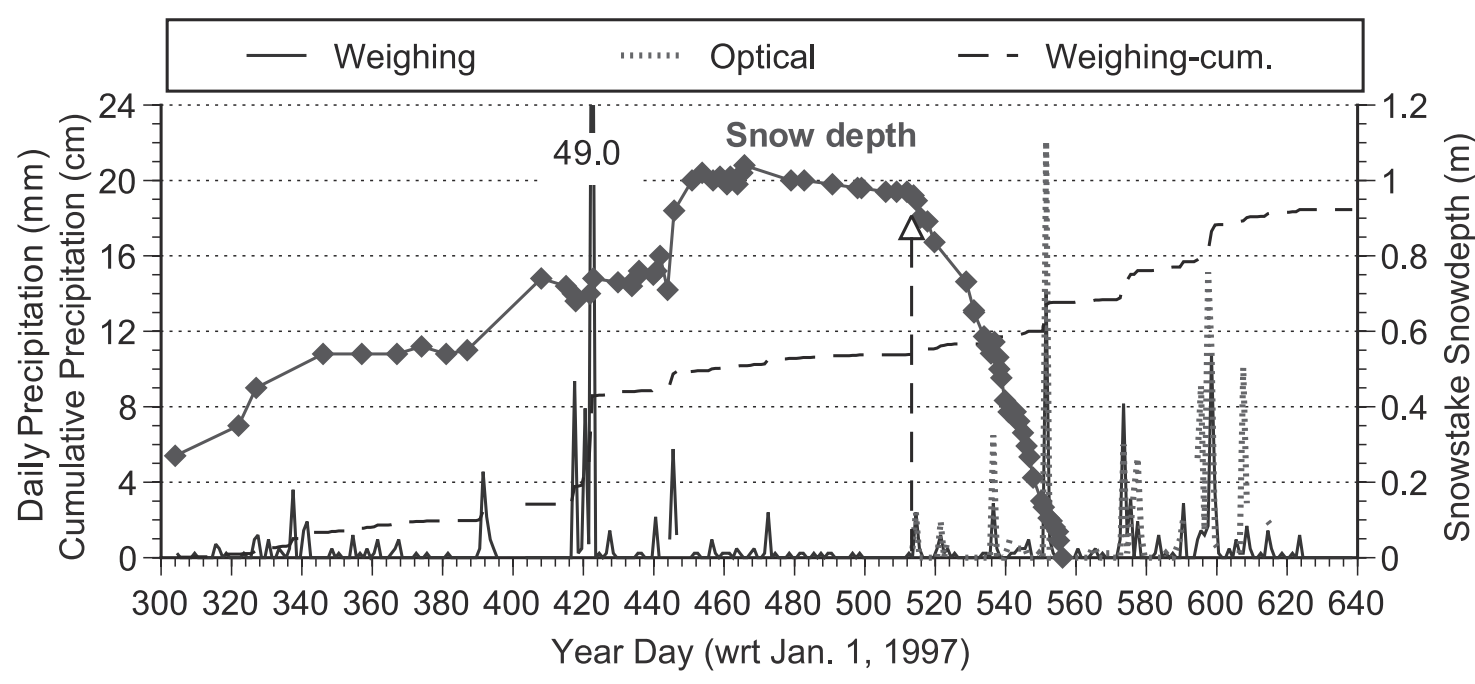

Figure 7. Daily precipitation ( $\mathrm{mm}$ ) from the weighing bucket (solid line) and the optical (dotted line) rain gauges, and snow depth from the ASFG snow stake (triangles). Also shown is the cumulative precipitation from the weighing bucket (dashed line). During JD 514-556, the snow depth has been linearly adjusted for a settling of the stake of $21 \mathrm{~cm}$. The dashed arrow shows the onset of melt on 29 May (YD 514).

vations over the annual cycle at SHEBA, submitted to Journal of Geophysical Research, 2000, hereinafter referred to as C. S. Betherton et al., submitted manuscript, 2000) show that the daily weighing bucket estimates from the tower site are very similar to the uncorrected daily precipitation values collected by the SPO Nipher shielded gauge system. They suggest that the long-term average weighing bucket values underestimate the precipitation by about $40 \%$ (see their Figure 7). The uncorrected weighing bucket values are given in Figure 7. Of the 30 significant daily accumulations (those greater than $1 \mathrm{~mm}$ ), the 22 shown have been verified with the occurrence of at least one hour of radar reflectivities $>5 \mathrm{dBZ}$; the others have been assumed to be spurious and removed. The $49 \mathrm{~mm}$ of water equivalent precipitation recorded by the gauge on 26 February (JD 422) is most likely much too large, though significant precipitation did fall on that day. Note that the occurrence of summertime precipitation is in good agreement between the weighing bucket and the optical rain gauge. C. S. Bretherton et al. (submitted manuscript, 2000) use the various precipitation sources at SHEBA to assess the precipitation amounts more accurately.

\subsubsection{Measurement Uncertainties}

[37] The uncertainties of the various measurements made in this study and discussed above are summarized in Table 5 .

\section{Near-Surface Meteorological Variables}

[38] The near-surface meteorological variables at the ASFG site, located on multiyear ice near the SHEBA ice station, are discussed in this section.

\subsection{Annual Cycle}

[39] Figure 8 shows daily average values of ice/snow interface temperatures, surface temperature, air temperature, and relative humidity with respect to ice. The last two are interpolated to the 10-meter level. Daily average wintertime (December-February) air temperatures ranged between $-40^{\circ}$ and $-19^{\circ} \mathrm{C}$, with frequent rapid transitions. Such transitions are related to the occurrence of low clouds [Sverdrup, 1933; Persson et al., 1999b], and have been observed for winter pack ice conditions elsewhere in the Arctic Basin, even near the North Pole [e.g., Mohn, 1905; Lindsay, 1998; Jordan et al., 1999]. During the cold episodes, the daily surface temperatures at SHEBA could be as much as $5^{\circ} \mathrm{C}$ lower than at the $10-\mathrm{m}$ level. The minimum hourly averaged surface temperature was $-44.1^{\circ} \mathrm{C}$, in good agreement with estimates of absolute minimum temperatures of -44 to $-49^{\circ} \mathrm{C}$ based on a balance between outgoing longwave radiation and minimum incoming longwave radiation and conductive flux through the ice [Sverdrup, 1933].

Table 5. Summary of Estimated Random Errors and Biases For Selected Parameters and Fluxes at the ASFG Site ${ }^{a}$

\begin{tabular}{lcc}
\hline Parameter & $\begin{array}{c}\text { Random Errors } \\
\text { (Hourly) }\end{array}$ & Bias \\
\hline $\mathrm{T}$ & $\pm 0.05^{\circ} \mathrm{C}$ & $\pm 0.07^{\circ} \mathrm{C}$ \\
$\mathrm{T}_{\mathrm{s}}$ & $\pm 0.6^{\circ} \mathrm{C}$ & $\pm 0.5^{\circ} \mathrm{C}$ \\
$\mathrm{RH}$ & $\pm 1 \%$ & $\pm 1 \%(?)$ \\
$\mathrm{Q}_{\mathrm{si}}$ & $\pm 3 \%$ & $-5-+1 \mathrm{~W} \mathrm{~m}^{-2}$ \\
$Q_{\mathrm{so}}$ & $\pm 3 \%$ & $-3-0 \mathrm{~W} \mathrm{~m}^{-2}$ \\
$\mathrm{Q}_{\mathrm{s}}$ & $\pm 4.5 \%$ & $-6-0 \mathrm{~W} \mathrm{~m}^{-2}$ \\
$\mathrm{Q}_{\mathrm{li}}$ & $\pm 4 \mathrm{~W} \mathrm{~m}^{-2}$ & $\pm 2.5 \mathrm{~W} \mathrm{~m}^{-2}$ \\
$\mathrm{Q}_{\text {lo }}$ & $\pm 4 \mathrm{~W} \mathrm{~m}^{-2}$ & $\pm 2.5 \mathrm{~W} \mathrm{~m}^{-2}$ \\
$\mathrm{Q}_{1}$ & $\pm 4 \mathrm{~W} \mathrm{~m}^{-2}$ & $\pm 4 \mathrm{~W} \mathrm{~m}^{-2}$ \\
$\alpha$ & \pm 0.03 & \pm 0.01 \\
$H_{\mathrm{s}}$ & $\pm 4.1 \mathrm{~W} \mathrm{~m}^{-2}$ & $\pm 0.8 \mathrm{~W} \mathrm{~m}^{-2}$ \\
$\mathrm{H}_{1}$ & $\pm 50 \%$ & $\sim-30 \%$ \\
$u_{*}$ & $\pm 0.05 \mathrm{~m} \mathrm{~s}^{-1}$ & $\pm 0.015 \mathrm{~m} \mathrm{~s}^{-1}$ \\
$C$ & $> \pm 100 \%$ & $\pm 2.5 \mathrm{~W} \mathrm{~m}^{-2}$ \\
Precipitation & $>80 \%$ & $\sim-40 \%$ \\
\hline
\end{tabular}

${ }^{\mathrm{a}}$ The various symbols are defined in the text. The random errors are estimates of errors in the hourly values. The biases represent estimates of errors in long-term means. 

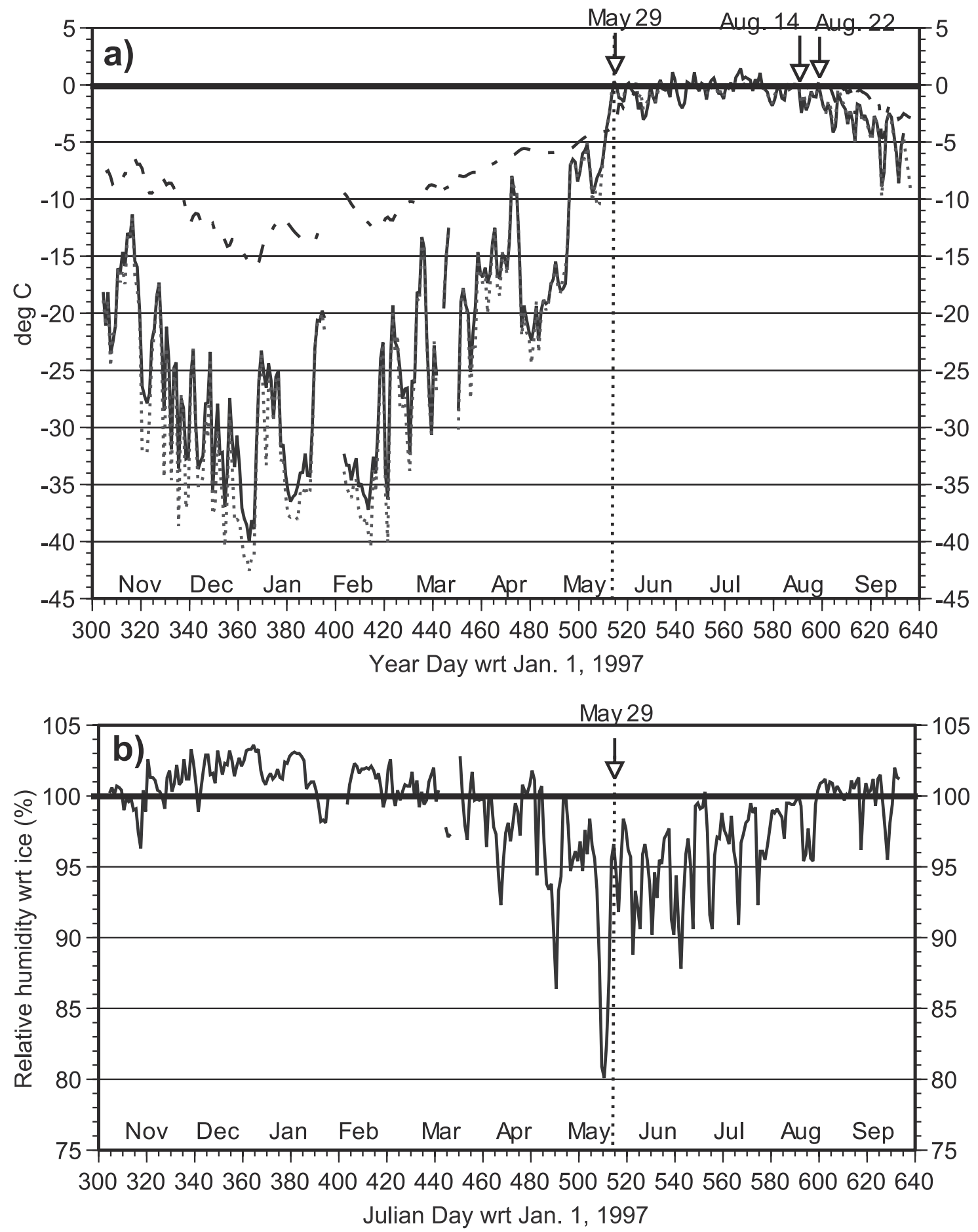

Figure 8. Near-surface conditions at the SHEBA site. Shown are daily mean values of (a) 10-m air temperature (solid), surface temperature (dotted), ice/snow interface temperature (dot-dashed), and (b) $10-\mathrm{m}$ relative humidity with respect to ice.

The spring warm-up occurred in spurts, again with large, rapid transitions in near-surface temperature. Compared to previous in-situ measurements and various climatologies, the temperatures at SHEBA were close to normal throughout most of the year (Figure 9a). However, during the spring (March-April), temperatures were $3^{\circ}-8^{\circ} \mathrm{C}$ above normal. Compared to the last 21 years at the SHEBA site represented by the POLES data, the SHEBA winter was $3^{\circ}-6^{\circ} \mathrm{C}$ below normal. However, it is unknown whether the differences between the POLES data and the other data sources are due to spatial or temporal variations, as the other sources represent other sites in the Arctic Basin and the POLES data include the effects of recent Arctic warming trends.

[40] The summer melt season, indicated by the nearly constant $0^{\circ} \mathrm{C}$ temperature, clearly started on 29 May (JD 

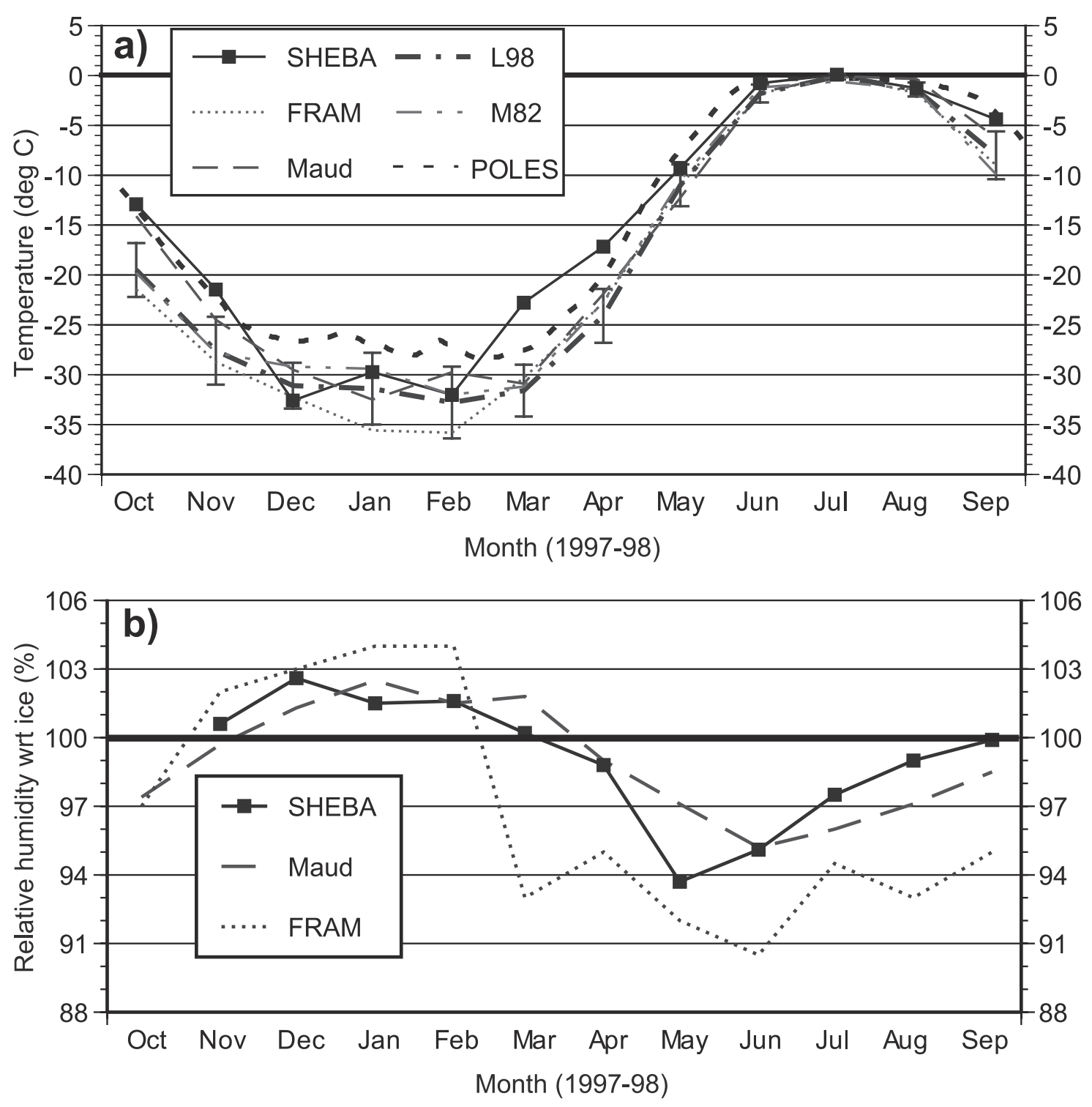

Figure 9. Monthly means of (a) 2.5-m air temperature and (b) 2.5-m relative humidity with respect to ice at the SHEBA ASFG tower (solid squares). Panel (a) also shows the monthly means of near-surface temperatures from the "Fram" (1893-1896 [Mohn, 1905]; dotted) and "Maud" (1923-1925 [Sverdrup, 1933]; dashed) expeditions, Maykut [1982] (M82; dash-double dot) and Lindsay [1998] (L98; dash-dot). The POLES (Polar Exchange at the Sea Surface) climatological 2-m temperature [Rigor et al., 2000] for the SHEBA locations is shown as a bold dashed line. The error bars show \pm one standard deviation of the monthly means from L98. The dotted and dashed lines in (b) show the relative humidity with respect to ice from the "Fram" and "Maud" expeditions [Malmgren, 1927], respectively.

514 ) with a day of drizzle (Figure 8a, see also Figure 7) and ended between 14 August (JD 591) and 22 August (JD 599). Hence, the melt season was 77-85 days long. Using the criteria of Rigor et al. [2000] (i.e., a 14-day running mean of the level $1(2-3 \mathrm{~m})$ temperature and $\mathrm{a}-1.0^{\circ} \mathrm{C}$ threshold for the melt season) gives 1 June as the onset of melt, 17 August as the onset of freezing, and a melt season of 77 days, in good agreement with the above subjective assessment using daily surface temperatures and snow conditions. The onset of melt on 1 June occurred 10 days earlier than that in the 1979-1997 climatology presented by Rigor et al. [2000]. Hence, the SHEBA melt season was significantly longer than the 54-68 days observed at the Soviet drifting ice stations during 1950-1990 [Colony et al., 1992] and the 71 days analyzed for 1979-1997 [Rigor et al., 2000] principally because of an early onset.

[41] Figure $8 \mathrm{~b}$ also shows that the relative humidity with respect to ice was generally slightly supersaturated during the winter, slightly subsaturated during the summer, but almost always very close to saturation. Only a few dry periods occurred, such as near JD 508-512 (23-27 May). The nearsaturation of the near-surface environment over the Arctic pack ice and its annual variation (Figure 9b) were noted by early scientific measurements from both the "Fram" (1893- 


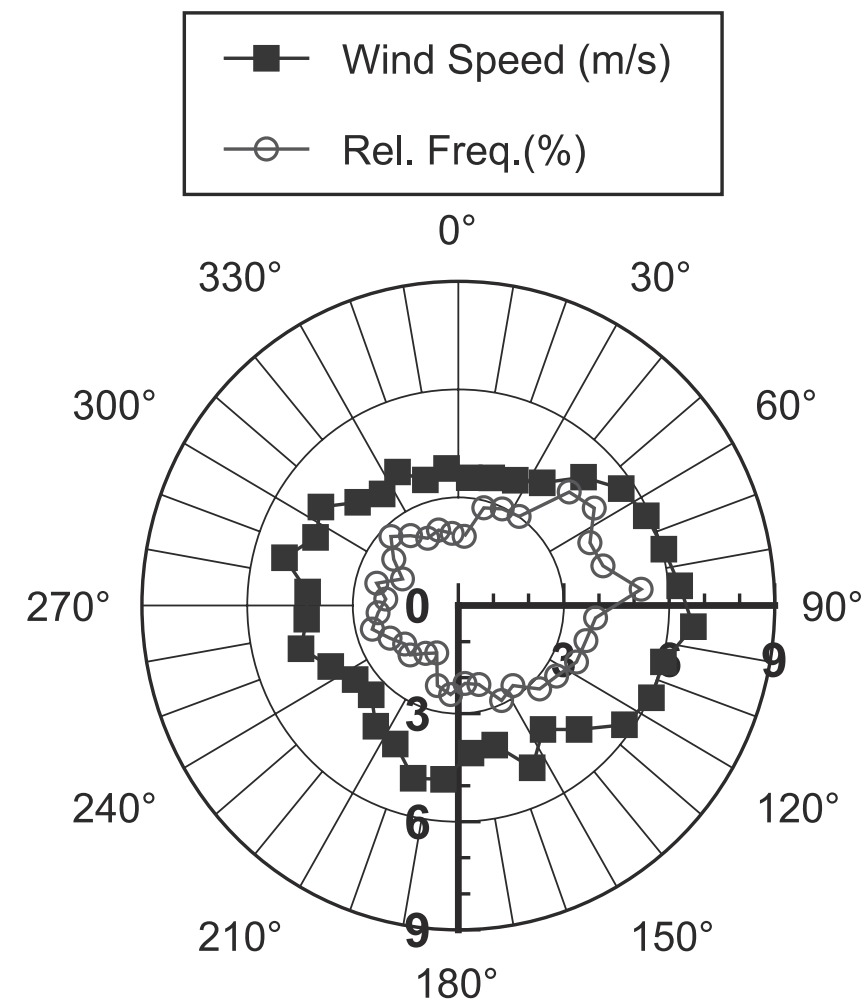

Figure 10. Annual wind rose using true wind directions. The radius shows mean wind speeds (squares; $\mathrm{m} / \mathrm{s}$ ) and relative frequency of occurrence (circles; \%) for $10^{\circ}$ wind sectors.

1896) and the "Maud" (1923-1925) expeditions [Malmgren, 1927; Sverdrup, 1933]. They may result from a flux of warm, moist near-surface air from open leads that is subsequently cooled by radiative and turbulent processes over the multiyear pack ice [Andreas et al., 2002].

[42] The most frequent true wind directions during the entire year were from $40^{\circ}$ to $120^{\circ}$, with the strongest winds, averaging 6-7 $\mathrm{m} \mathrm{s}^{-1}$, coming from due east (Figure 10). The winds tended to be easterly in the spring and fall, to have a northerly component in the winter, and to have a southerly component in the summer. The winds were strongest in the winter and weakest in the summer. These seasonal changes in the wind statistics at the SHEBA site are probably due to a combination of true seasonal wind variations and the significant change in geographic location of the site.

\subsection{Surface-Layer Profiles}

[43] One of the unique aspects of the ASFG data set was the collection of continuous profiles of temperature, wind, and turbulent quantities in the lowest 20 meters over the pack ice throughout the year. The "Maud" expedition [Sverdrup, 1933] attempted to measure surface-layer temperature profiles over the pack ice, but the profiles were collected only during the dark months, were of questionable accuracy, and were from only two levels $(4.5 \mathrm{~m}$ onboard the ship and at $30 \mathrm{~m}$ on top of the mast). The ASFG data set includes profiles with five levels of data obtained with good data recovery and accuracy throughout the year.
[44] The monthly mean temperature profiles show the progression of stability throughout the year (Figure 11). In the mean during November through April, an inversion is present in the lowest 15 meters of the atmosphere over the pack ice. The inversion strength is a maximum in December, with the lowest level (about $2 \mathrm{~m}$ ) averaging $1.1^{\circ} \mathrm{C}$ less than the top level $(14 \mathrm{~m})$, and the surface temperature $\left(\mathrm{T}_{\mathrm{s}}\right)$ averaging $1.8^{\circ} \mathrm{C}$ less than the lowest tower level. The greatest stratification may occur in December rather than later because of a) an early winter abundance of warm air from leads and thin ice that is then cooled at the surface and b) the total lack of solar heating of the surface. The vertical gradient decreases after the sun rises in early February, and in May the vertical thermal gradient shown by the tower sensors reverses. From May to August, the top level (now at $18 \mathrm{~m}$ ) averages $0.12^{\circ}-0.21^{\circ} \mathrm{C}$ less than the lowest level, implying a well-mixed lower boundary layer since a dry adiabatic lapse rate corresponds to a $0.15^{\circ} \mathrm{C}$ difference. However, note that the top four levels have nearly identical mean temperatures for July, implying stable conditions above about $2.5 \mathrm{~m}$.

[45] The systematic increase of temperature with height during the winter and the systematic decrease of temperature with height during the summer support our claim in section 2.2.1 of a relative temperature error of less than $0.05^{\circ} \mathrm{C}$ between the sensors. Only levels 3 and 4 are reversed during three summer months, with level 4 being $0.01^{\circ}-0.02^{\circ} \mathrm{C}$ warmer than level 3 rather than $0.04^{\circ} \mathrm{C}$ cooler as expected from a dry adiabatic lapse rate. However, this is within our measurement errors. In section 2.2.3, we estimated that the surface temperature measurements were accurate to $\pm 0.5^{\circ} \mathrm{C}$. Comparisons with the tower profiles in Figure 11 suggest that $\mathrm{T}_{\mathrm{s}}$ is too low by $0.2-$ $0.4^{\circ} \mathrm{C}$ in May (as discussed in section 2.2.3) and possibly also in July.

[46] Although Figure 11 suggests stable conditions during the winter and well-mixed conditions during the summer, an examination of the hourly profiles shows a large number of occurrences of well-mixed conditions during the winter as well (Figure 12). These wintertime well-mixed conditions occur with clouds and higher wind speeds [Sverdrup, 1933; Persson et al., 1999b]. The summer conditions are always close to being well mixed, though occurrences of weak stability are fairly common, as also suggested by the July profile in Figure 11.

[47] The vertical structure of the water vapor mixing ratio (q) also shows an annual cycle (Figure 13a). From November to April, the lowest level is drier than the upper level. The maximum difference is greatest $(0.03 \mathrm{~g} / \mathrm{kg})$ in November and smallest in March. The magnitude of the difference is probably related to the temperature difference between the levels, the mean temperature, and the moisture availability. The greater cooling of the air nearest the surface removes water vapor through sublimation, producing the basic wintertime moisture inversion (and supersaturation). The early winter decrease in temperature reduces the absolute humidity and hence the vertical gradient, while decreasing amounts of open leads in late winter likely reduces the moisture supply and the relative humidity (Figure 9b), thereby continuing the decrease in the moisture inversion gradient through March. The mean relative humidity with respect to ice at each level averages greater 


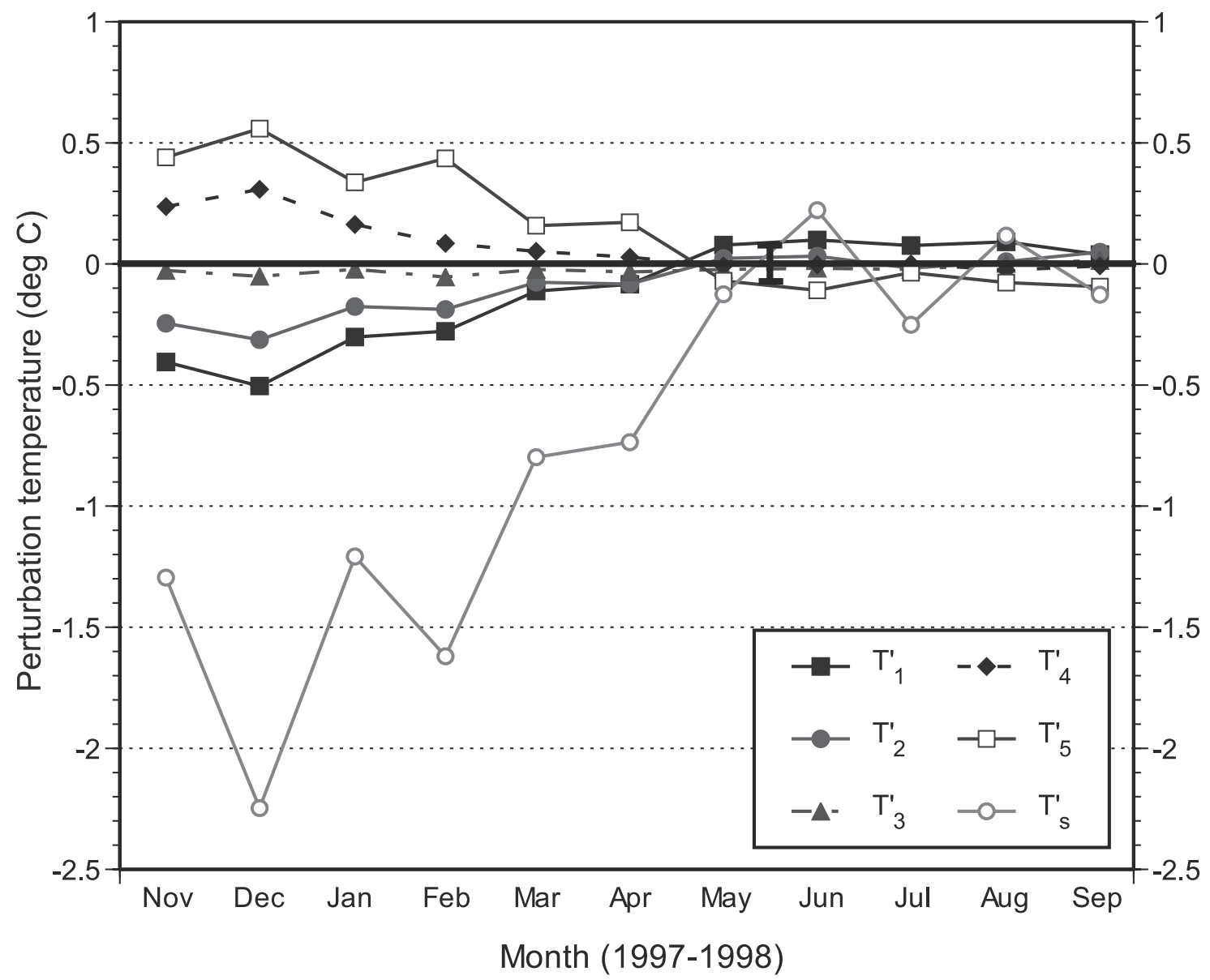

Figure 11. Perturbation monthly mean temperatures for each of the five levels on the ASFG tower and the radiative surface temperature $\left(T_{s}\right)$. The perturbations were calculated by using only concurrent data and subtracting the mean of the six levels for each month. The vertical bar between May and June shows the temperature difference between the top and bottom levels corresponding to a dry adiabatic lapse rate.

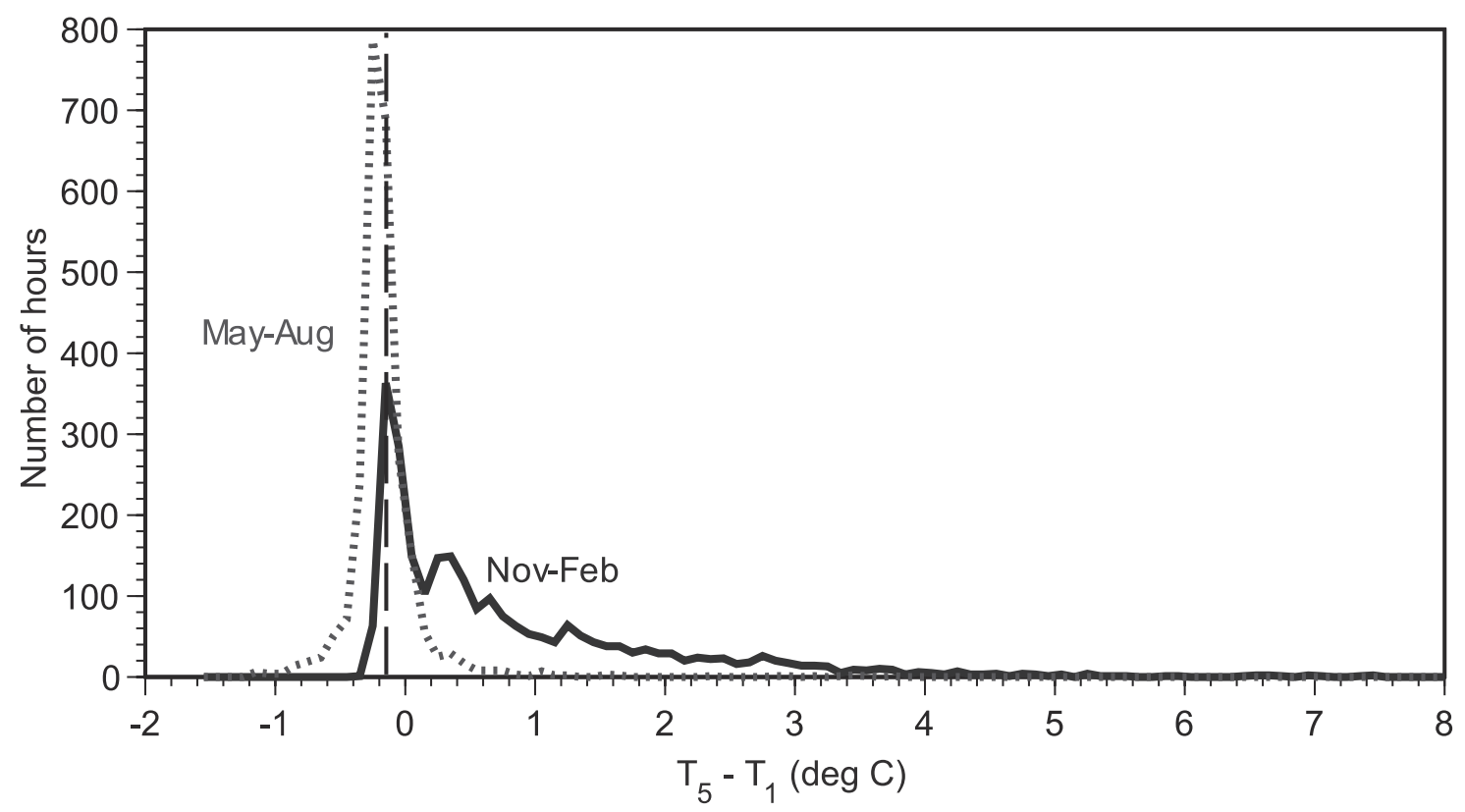

Figure 12. Frequency distribution of the temperature difference between levels 5 and 1 using $0.1^{\circ}$ bins for November-February (solid) and May-August (dotted). The vertical dashed line is the temperature difference corresponding to a dry adiabatic lapse rate. 

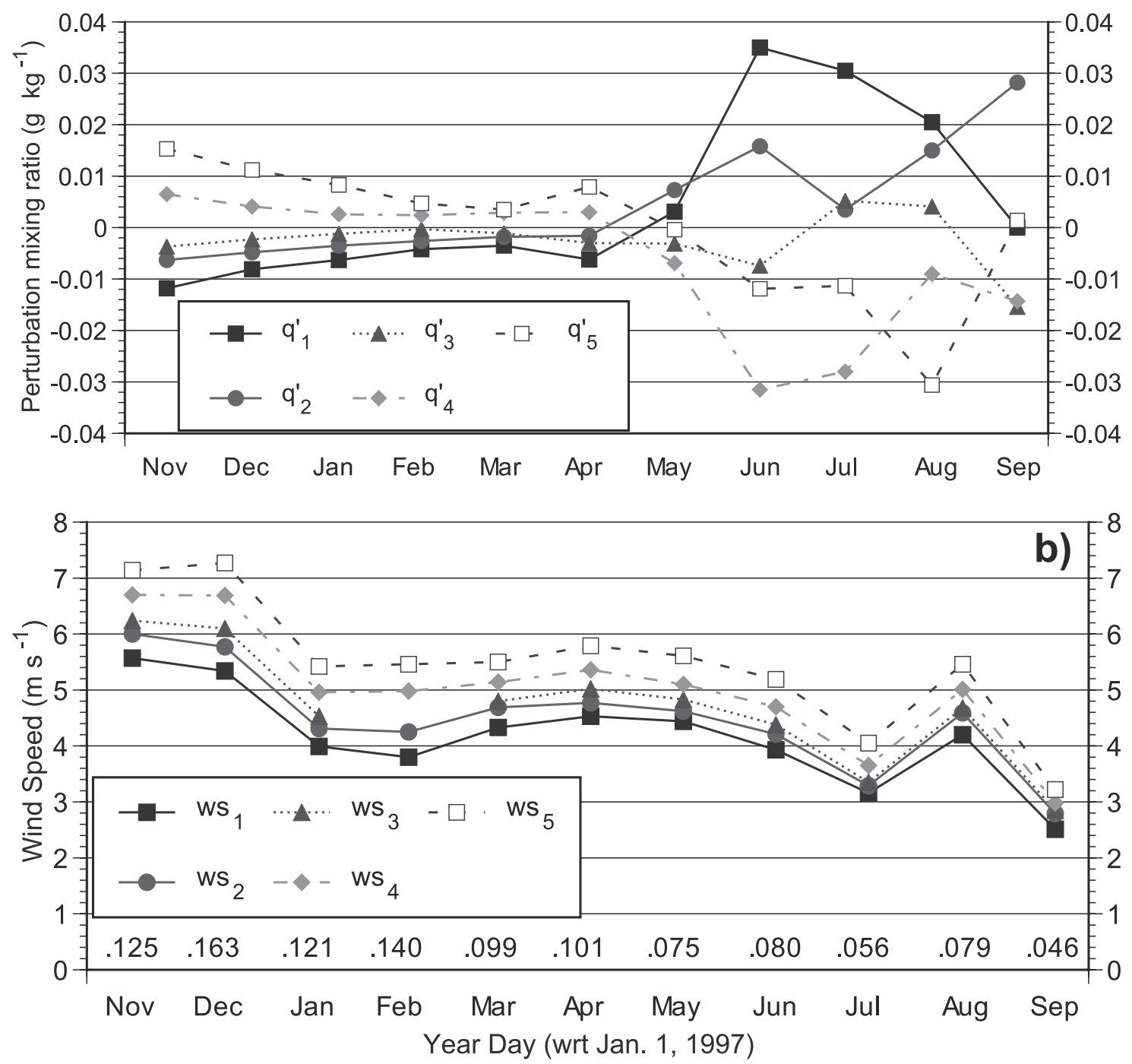

Figure 13. As for Figure 11 except (a) perturbation monthly mean mixing ratios and (b) monthly-mean wind speeds. The numbers below each point in (b) show the mean vertical wind speed shear in $\mathrm{s}^{-1}$.

than $100 \%$ for November-March (not shown); however, it has no obvious systematic vertical variation. With the springtime onset of surface-based mixing, the near-surface temperature inversion is removed, destroying the moisture inversion as well. During June-August, the vertical structure of $\mathrm{q}$ is reversed and the air is moistest near the surface and driest aloft, though this tendency is not as systematic as during the winter. The vertical gradient is also larger during the summer because of the much larger absolute humidities. Again, the relative humidity in the summer (not shown) shows no systematic vertical structure, though it averages slightly lower than during winter at 94\%-98\%.

[48] The sonic anemometers on the tower provide the vertical structure of the wind and turbulent quantities. The wind speed increases with height in every month (Figure $13 \mathrm{~b})$. However, the magnitude of the wind speed shear is about twice as strong in winter as in summer. One might expect this seasonal variation in the shear to be due to the seasonal change in stability. One might also expect a substantial variation in the shear during winter because of the large variation in the stratification during this season (see Figure 12).

[49] The vertical gradient in the sensible heat flux has several implications (Figure 14a). First, because the flux isn't constant with height, one would either expect MoninObukhov Similarity Theory (MOST) not to apply or that the top of the surface layer (defined as the layer with constant flux) is below the top of the tower. The latter undoubtedly occurred at times, while the former may also be occasionally true [Guest et al., 1999; Grachev et al., 2002]. Second, the vertical heat flux gradient implies vertical flux divergence and, hence, a change in air temperature due to turbulent mixing. The winter flux divergence between levels 2 and 3 implies a turbulent cooling a few meters above the surface. The summer vertical flux convergence implies a turbulent warming, particularly between levels 1 and $4(2.5 \mathrm{~m}$ and $9 \mathrm{~m}$ ). Note that there is a negative heat flux during both the winter and the month of July but that the thermal effect of the turbulent heat flux on the lower atmosphere is opposite in the two seasons. Table 4 in section 2.2.4 indicates that the 

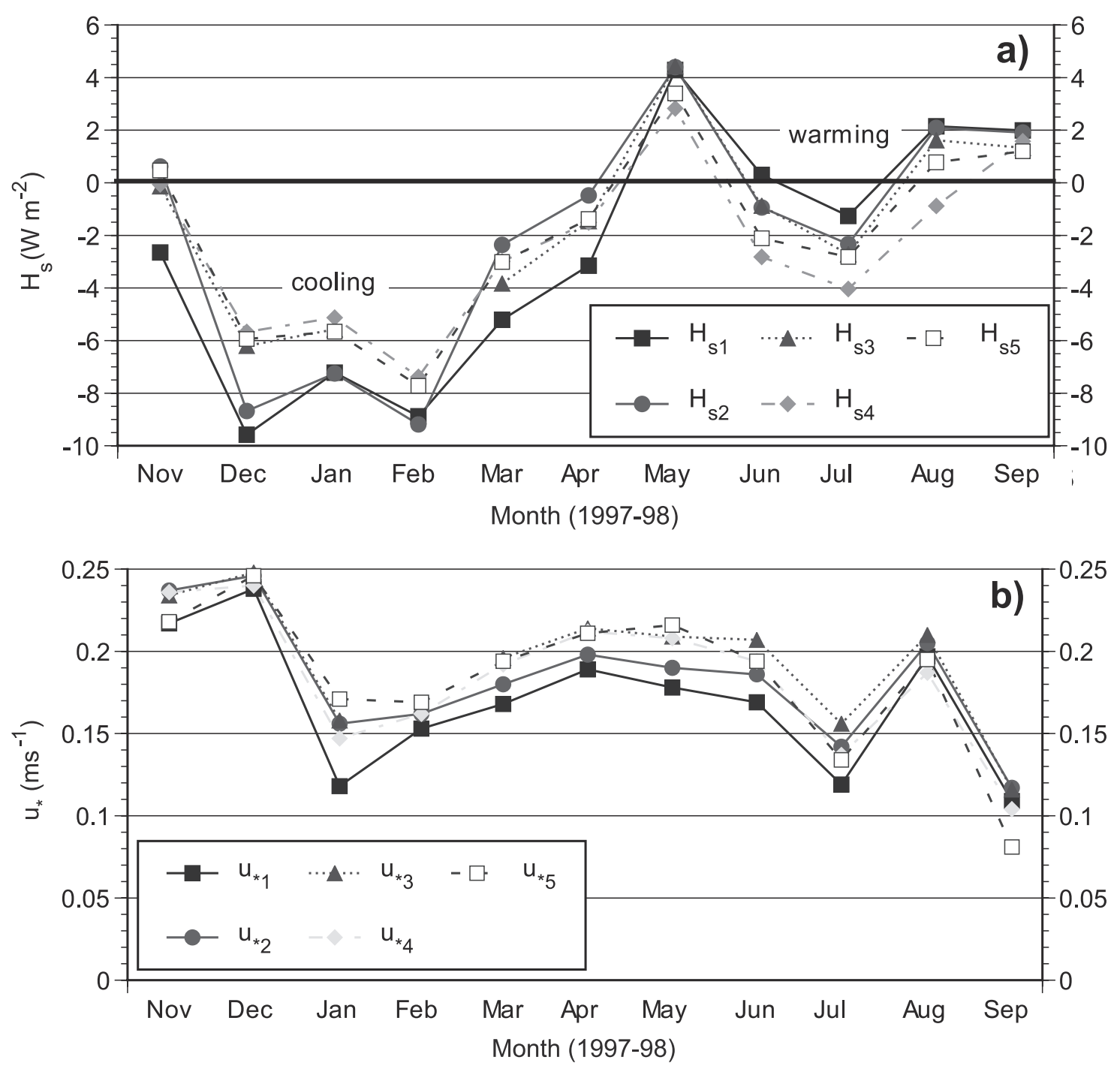

Figure 14. Monthly-mean values of (a) sensible heat flux $\left(H_{\mathrm{s}}\right)$ and (b) $u_{*}$ for concurrent data at the five tower levels. Note that the warming/cooling refers to the air, not the surface.

vertical differences of $2-4 \mathrm{~W} \mathrm{~m}^{-2}$ for the monthly means of $H_{\mathrm{s}}$ are significant.

[50] The friction velocities $\left(u_{*}\right)$ also varied with height throughout the year, with those at levels 1 and 2 generally lower than at the top three levels (Figure 14b). If the vertical profile of the wind is described by MOST, the increase with height of $u_{*}$ implies that the ice nearest the ASFG tower is smoother than that further away, especially from January to July. Surface roughness lengths $\left(\mathrm{z}_{0}\right)$, were estimated from the measured $u_{*}, H_{\mathrm{s}}$ and wind speed, the relationships of Andreas and Murphy [1986], and the stable-case stability correction terms of Holtslag and DeBruin [1988]. The $\mathrm{z}_{0}$ values also show this difference in roughness of the surfaces sampled by the different levels, since the annual means of the monthly medians of $\mathrm{z}_{0}$ are $3.1 \times 10^{-4} \mathrm{~m}$ from data at the lowest level and in the range $4.6-6.0 \times 10^{-4} \mathrm{~m}$ from the top three levels. The same vertical gradient exists if monthly means rather than the medians are used, though the values of $\mathrm{z}_{0}$ increase to $5.7-6.7 \times 10^{-4} \mathrm{~m}$ at the two lower levels to $10.8 \times 10^{-4} \mathrm{~m}$ at the top. These values are similar to those obtained during late winter and springtime measurement campaigns over smooth, multiyear ice with sonic anemometers [Banke et al., 1980; Leavitt, 1980; Ruffieux et al., 1995], but are about an order of magnitude lower than the values obtained from aircraft measurements [e.g., Overland, 1985]. This discrepancy may at least partially be explained by differences in the footprint of the respective measurements. Future work will continue to address this issue of the footprint of the data from different levels on the tower.

\subsection{Diurnal Cycles}

[51] Because the SHEBA site was substantially south of $90^{\circ} \mathrm{N}$ latitude, the diurnal amplitude of the incoming solar radiation $\left(\mathrm{Q}_{\mathrm{si}}\right)$ was largest in early May at $470 \mathrm{~W} \mathrm{~m}$ (Figure 15). However, the amplitude is asymmetric about the annual solar cycle, as the amplitudes after the summer solstice are smaller than for comparable times before the solstice, apparently because of greater cloudiness in late summer and fall. For example, the amplitude in early August is only about $200 \mathrm{~W} \mathrm{~m} \mathrm{~m}^{-2}$, while that for early May is $470 \mathrm{~W} \mathrm{~m} \mathrm{~m}^{-2}$. Even early July has an amplitude of only $310 \mathrm{~W} \mathrm{~m}^{-2}$. 


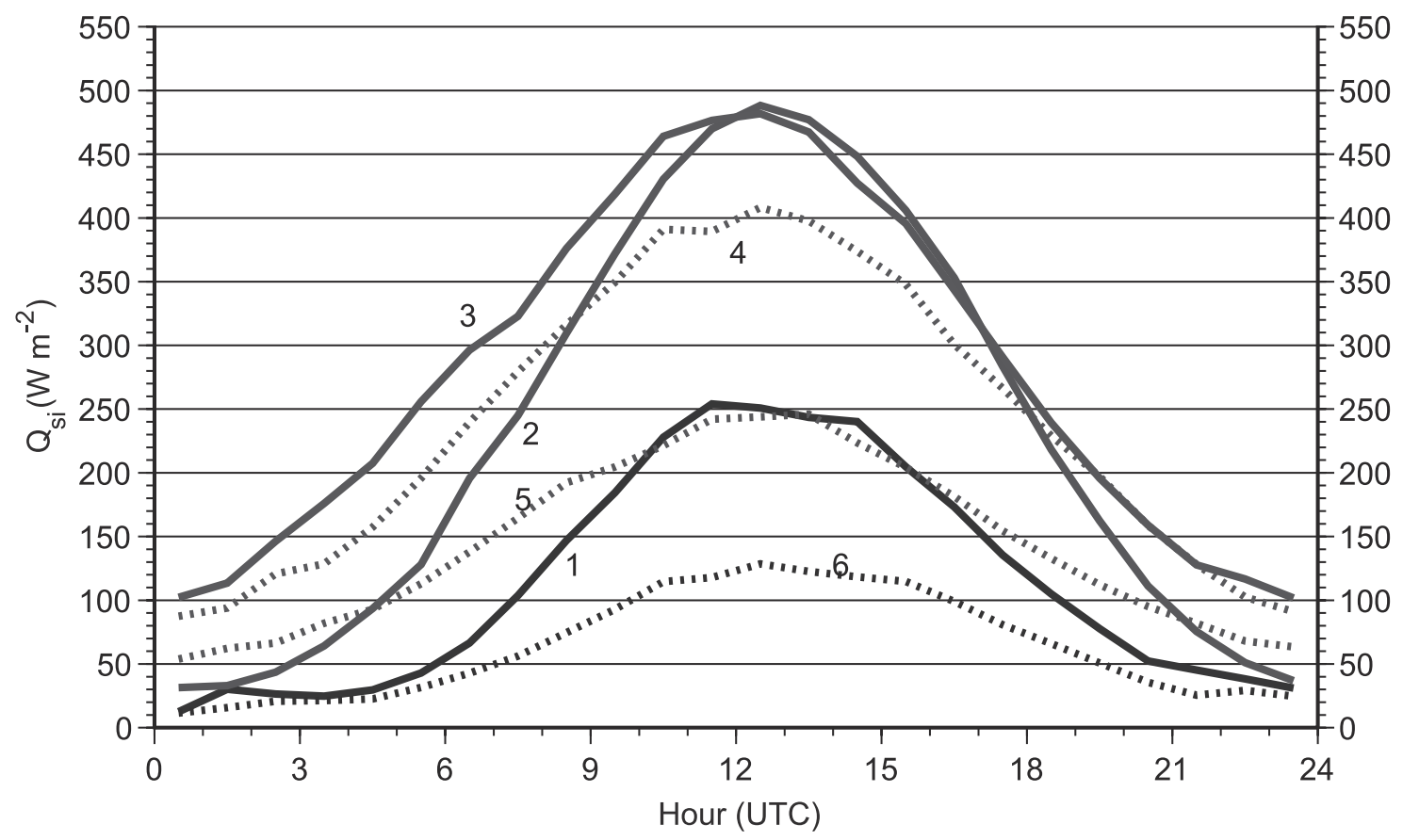

Figure 15. Means of incoming solar radiation $\left(\mathrm{Q}_{\mathrm{si}}\right)$ for each hour for three 30-day periods before (solid, curves 1,2,3) and after (dotted; curves 4,5,6) the summer solstice. The 30-day periods are numbered sequentially, with the summer solstice occurring between periods 3 and 4 .

[52] Although the diurnal cycle for $\mathrm{Q}_{\mathrm{si}}$ had the largest amplitudes in May and June, the largest amplitudes for the diurnal cycles of near-surface temperature $\left(3.3^{\circ} \mathrm{C}\right.$ at level 1$)$ and sensible heat flux $\left(21 \mathrm{~W} \mathrm{~m}^{-2}\right)$ occurred in April (Figures 16 and 17). The temperature cycle increased sharply from being small in March to largest in April. It then gradually decreased during May and June, being very small during July and the rest of the summer and fall.

[53] Sverdrup [1933] suggests that the phase difference between the annual solar amplitude and the near-surface temperature amplitude is due to two processes. First, when the surface temperature is free to vary, as it is before the onset of melt, a larger near-surface temperature cycle can be expected for conditions with greater stability since the daily solar cycle must only heat a shallower layer of the atmosphere. This would be true for the early part of the spring when the surface temperature is low. Figure 18a shows that the daytime atmosphere in April is, on average, unstable in the lowest few meters (up to level 2), well mixed to about $10 \mathrm{~m}$ (level 4), but stable above. In May (Figure 18b), the daytime atmosphere is, on average, unstable to at least $5 \mathrm{~m}$ (level 3) and weakly unstable or well mixed to the top of the tower $(18 \mathrm{~m})$ and probably beyond. This mechanism would also imply that the sensible heat flux would be greater later in the spring, when the stability was less and the solar amplitude greater. This is indeed the case, as $H_{\mathrm{s}}$ is substantially larger in May than in April (Figure 17a).

[54] The second process dominates once the surface temperature reaches $0^{\circ} \mathrm{C}$ on 29 May, preventing the first process from continuing into June. After this date, $\mathrm{T}_{\mathrm{s}}$ does not vary diurnally except on the few occasions when the net surface energy flux falls so low that melting stops and $\mathrm{T}_{\mathrm{s}}$ decreases. Since the atmosphere above the surface is free to warm through advection and subsidence, stable conditions develop, reducing $H_{\mathrm{s}}$ (Figure 17b) and forcing the near-surface atmospheric temperature to remain near the $0^{\circ} \mathrm{C}$ surface temperature. Figure $18 \mathrm{c}$ shows that the average daytime July atmosphere is unstable or neutral up to $5 \mathrm{~m}$ (level 3 ) but is stable above, similar to April. However, the July nighttime atmosphere is slightly unstable or near neutral to $5 \mathrm{~m}$ (level 3) rather than stable as in the previous months. Hence, even the nighttime near-surface atmospheric temperature doesn't differ substantially from the surface temperature. Our data clearly supports Sverdrup's [1933] hypothesis.

[55] The characterization of diurnal cycles during the SHEBA year is important for interpretation of the detailed observations of the Arctic boundary layer and clouds obtained by aircraft during May and July. The aircraft observations were generally obtained near local solar noon (2100-0100 UT) [Curry et al., 2000] (Tschudi et al., submitted manuscript, 2001). Hence, the aircraft-observed boundary layer structure in May will only be representative of conditions at local noon and will likely differ substantially from the nighttime structure. Though the reduced diurnal cycles in July imply smaller sampling biases, the seasonal variation in daytime stability indicates that a significantly different boundary layer structure was likely sampled in July compared to that obtained in May.

\subsection{Site Albedo}

[56] Daily average $\alpha$ at the ASFG site is shown in Figure 19. The minimum, average, and maximum $\alpha$ measured along the IPG albedo line are also shown. During the spring, the ASFG albedo was typically 0.85 , ranging from 0.77 to 0.94 and in good agreement with the IPG values. The day-to-day variation appears mostly to be due to effects of 

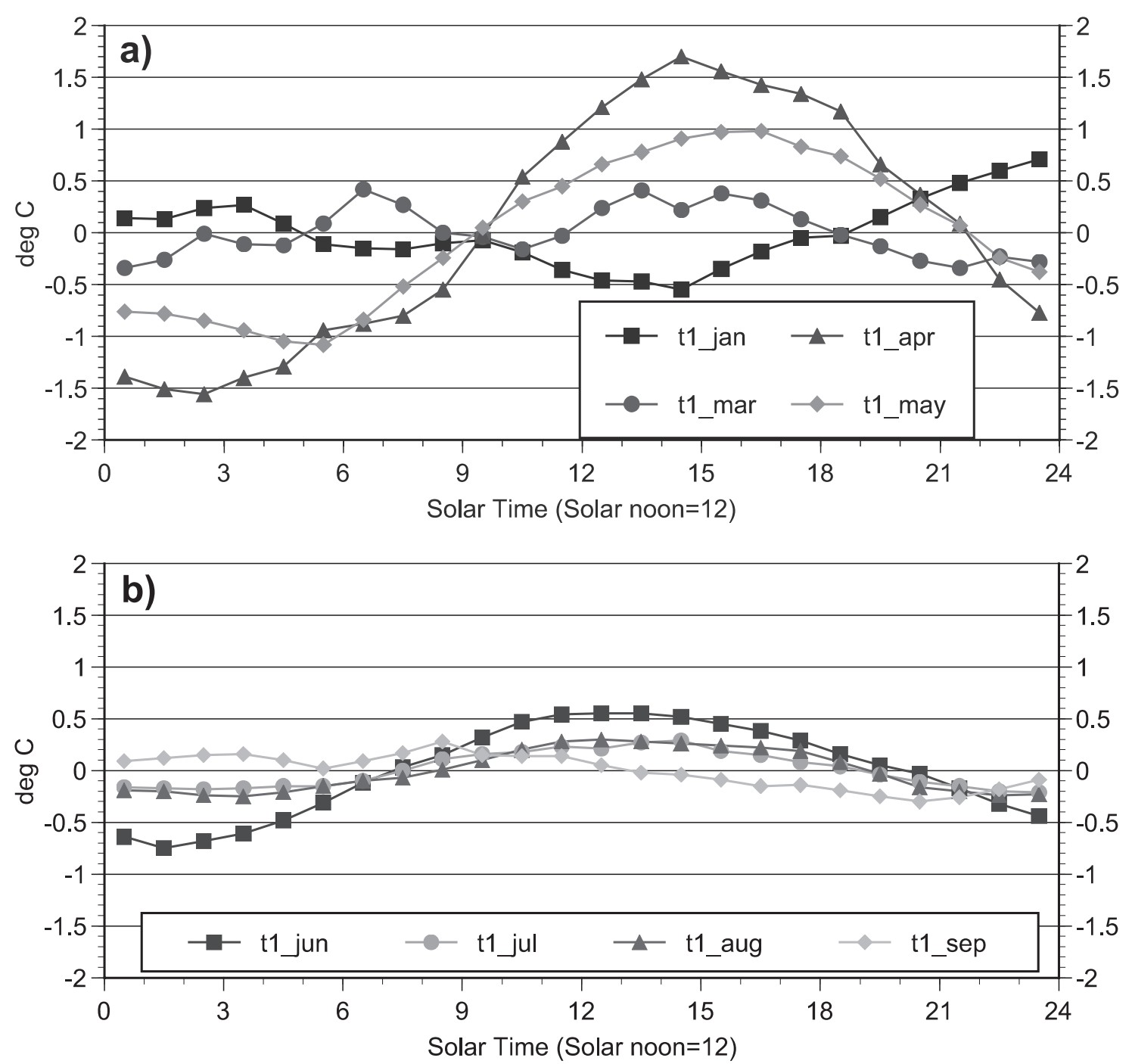

Figure 16. The diurnal amplitudes of temperature from level $1(1.9-3.0 \mathrm{~m})$ for (a) January, March, April and May, and (b) June, July, August, and September. Each hourly value is the monthly mean of the daily diurnal perturbation temperature for that hour (i.e., the daily mean was subtracted).

cloudiness, but this effect can occur on shorter time-scales as well and often accounts for the small differences with the IPG values. At onset of the melt season on 29 May, marked by a drizzle event [Persson et al., 1999a], an immediate lowering of $\alpha$ by about $0.04-0.05$ occurred in both the ASFG and IPG data sets because the snow became wet and the crystalline structure changed. The $\alpha$ gradually decreased during the next month with some mid-June fluctuations associated with light snowfall. During this time, the ASFG $\alpha$ were in good agreement with the IPG maxima. The lower IPG average $\alpha$ resulted from measurements over bare ice, melt ponds, and leads with lower values than those obtained over the deeper snow cover characteristic of the ASFG site. The fluctuations due to the snow events were seen in the IPG data as well.

[57] Near 1 July (JD 547), the snow cover within view of the radiometer disappeared, lowering $\alpha$ to $\sim 0.57$. Further lowering of $\alpha$ to $0.48-0.55$ occurred as a melt pond developed within view of the radiometer (Figure 2d). Hence, during the first 3 weeks of July, the ASFG $\alpha$ were close to the IPG average values and significantly lower than the IPG maximum values of 0.69 .

[58] At the end of July, a major synoptic event started to increase $\alpha$ over the bare ice and in a few melt ponds (including the ASFG melt pond; see Figure 2d), as seen by the ASFG and maximum IPG $\alpha$. However, the percentage of open water increased, thereby decreasing the IPG average $\alpha$. By the end of August (about JD 600), the effect of the melt pond near the ASFG site on $\alpha$ had become small, so the ASFG albedo was in good agreement with the IPG maxima thereafter. By JD 625 (17 September), the lead and melt pond surfaces had frozen and the ASFG values were in good agreement with the IPG average values. Because of the different amounts of snow covered ice, bare ice, meltponds, and leads represented in the two measurement methods, the IPG average $\alpha$ is significantly lower than the ASFG $\alpha$ during the month of snowmelt (JD 524-547; 8 June-1 July) and during the freeze-up (JD 575-625; 29 July-17 September). However, the differences are understandable in light of the different surface representations. 

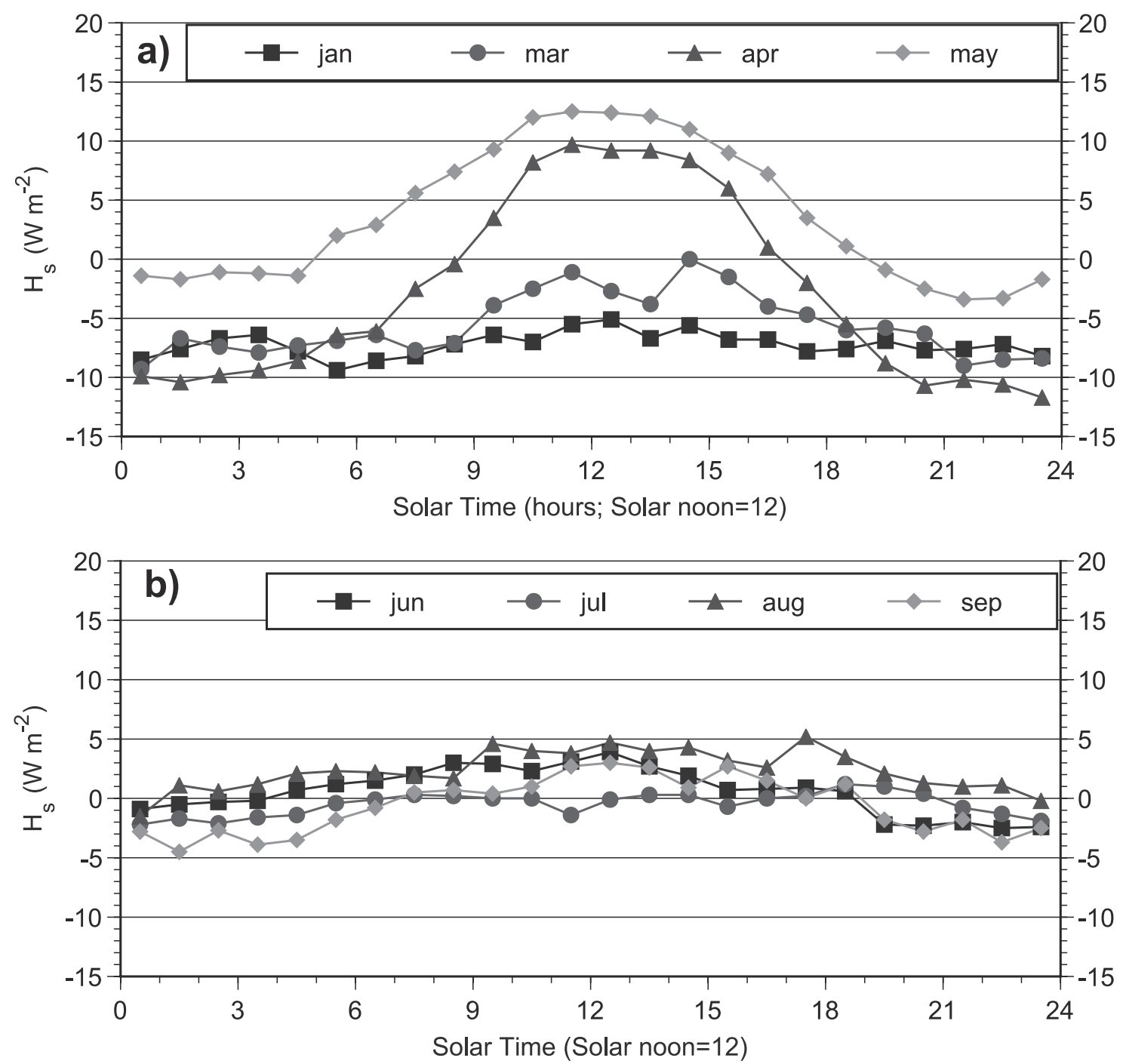

Figure 17. Monthly averages of sensible heat flux $\left(H_{\mathrm{s}}\right)$ at level $1(1.9-3.0 \mathrm{~m})$ for each hour. Shown are (a) January, March, April and May, and (b) June, July, August, and September.

[59] In-depth studies comparing all surface albedo measurements made at the SHEBA site or assessing the various factors producing variability in $\alpha$ are clearly important but beyond the scope of this study. It will suffice to say that the $\alpha$ measured at the ASFG site showed temporal variations only measurable with a continuous fixed site, with diurnal variations and variations with cloudiness. Additional analyses of the albedo at SHEBA are provided by Perovich et al. [2002] (see also Tschudi et al., submitted manuscript, 2001).

\section{Surface Energy Budget}

[60] We will now consider a surface slab of finite thickness consisting of snow during most of the year and ice with melt ponds during the summer, similar to that within view of the ASFG radiometer. The total energy flux, $F_{\text {tot }}$, into this surface slab is given by

$$
\mathrm{F}_{\mathrm{tot}}=\mathrm{Q}^{*}-\mathrm{H}_{\mathrm{s}}-\mathrm{H}_{\mathrm{l}}+\mathrm{C},
$$

where $\mathrm{Q}^{*}$ is the total net radiative flux given by

$$
\begin{aligned}
\mathrm{Q}^{*} & =\mathrm{Q}_{\mathrm{s}}+\mathrm{Q}_{\mathrm{l}} \\
& =\mathrm{Q}_{\mathrm{si}}-\mathrm{Q}_{\mathrm{so}}+\mathrm{Q}_{\mathrm{li}}-\mathrm{Q}_{\mathrm{lo}} \\
& =\mathrm{Q}_{\mathrm{si}}(1-\alpha)+\mathrm{Q}_{1} .
\end{aligned}
$$

Note that (4.2) assumes that all radiative flux is absorbed within this surface slab, implying a slab thickness of several centimeters for snow and 1-2 $\mathrm{m}$ for ice. Even with this ice thickness, a monthly average of $1-7 \mathrm{~W} \mathrm{~m}^{-2}$ of solar energy penetrates through the ice into the ocean during July and August (using an ice extinction coefficient of $1.5 \mathrm{~m}^{-1}$ [Maykut and Untersteiner, 1971]), so (4.2) slightly overestimates the energy input from above to this surface slab during these months.

[61] The conductive flux $(C)$ is estimated from the temperature gradient in the snowpack obtained from the ice/snow interface temperature $\left(\mathrm{T}_{\text {ice }}\right)$, the best radiative 

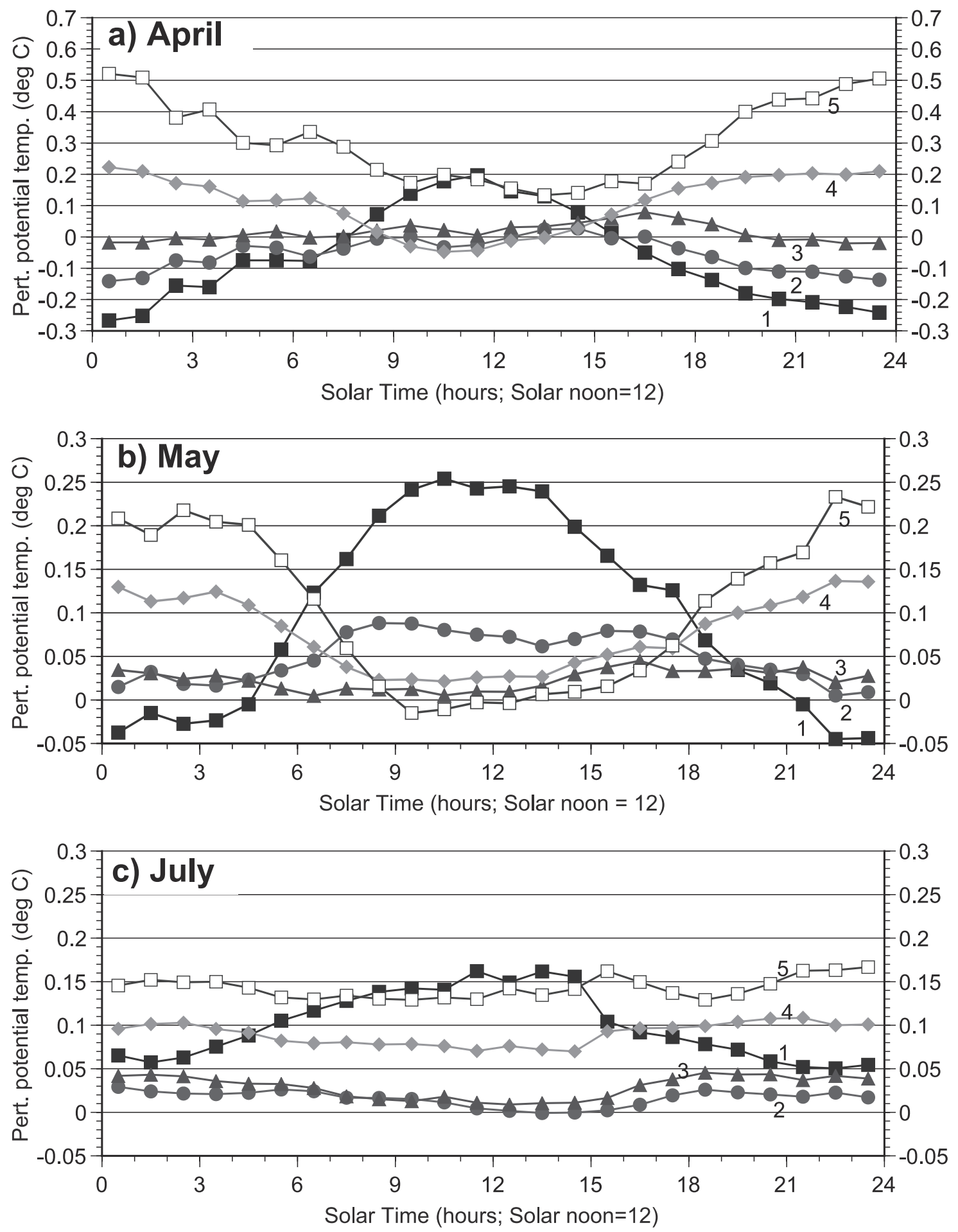

Figure 18. Monthly mean perturbation potential temperature $\left(\theta^{\prime}\right)$ for each hour and each level on the tower for (a) April, (b) May, and (c) July. The $\theta^{\prime}$ values are obtained by subtracting the mean of the five levels for each hour from the monthly mean potential temperature for each level and hour. Levels 1 (solid square), 2 (dot), 3 (triangle), 4 (diamond) and 5 (open square) are shown and labeled.

estimate of the surface temperature $\left(\mathrm{T}_{\mathrm{s}}\right)$, manual snow depth measurements $\left(\mathrm{d}_{\mathrm{s}}\right)$ at the ASFG site and the relation

$$
\mathrm{C}=-\mathrm{k}_{\mathrm{s}}\left[\left(\mathrm{T}_{\mathrm{s}}-\mathrm{T}_{\mathrm{ice}}\right) / \mathrm{d}_{\mathrm{s}}\right] .
$$

Two values for the thermal conductivity of the snow $\left(k_{\mathrm{s}}\right)$ are used. The first value $\left(0.14 \mathrm{~W} \mathrm{~m}^{-1} \mathrm{~K}^{-1}\right)$ was obtained with conductivity probe measurements by Sturm et al. [2002] in the vicinity of the SHEBA site in April. This value is a factor of $2-3$ lower than that often used for dry snow [e.g., 


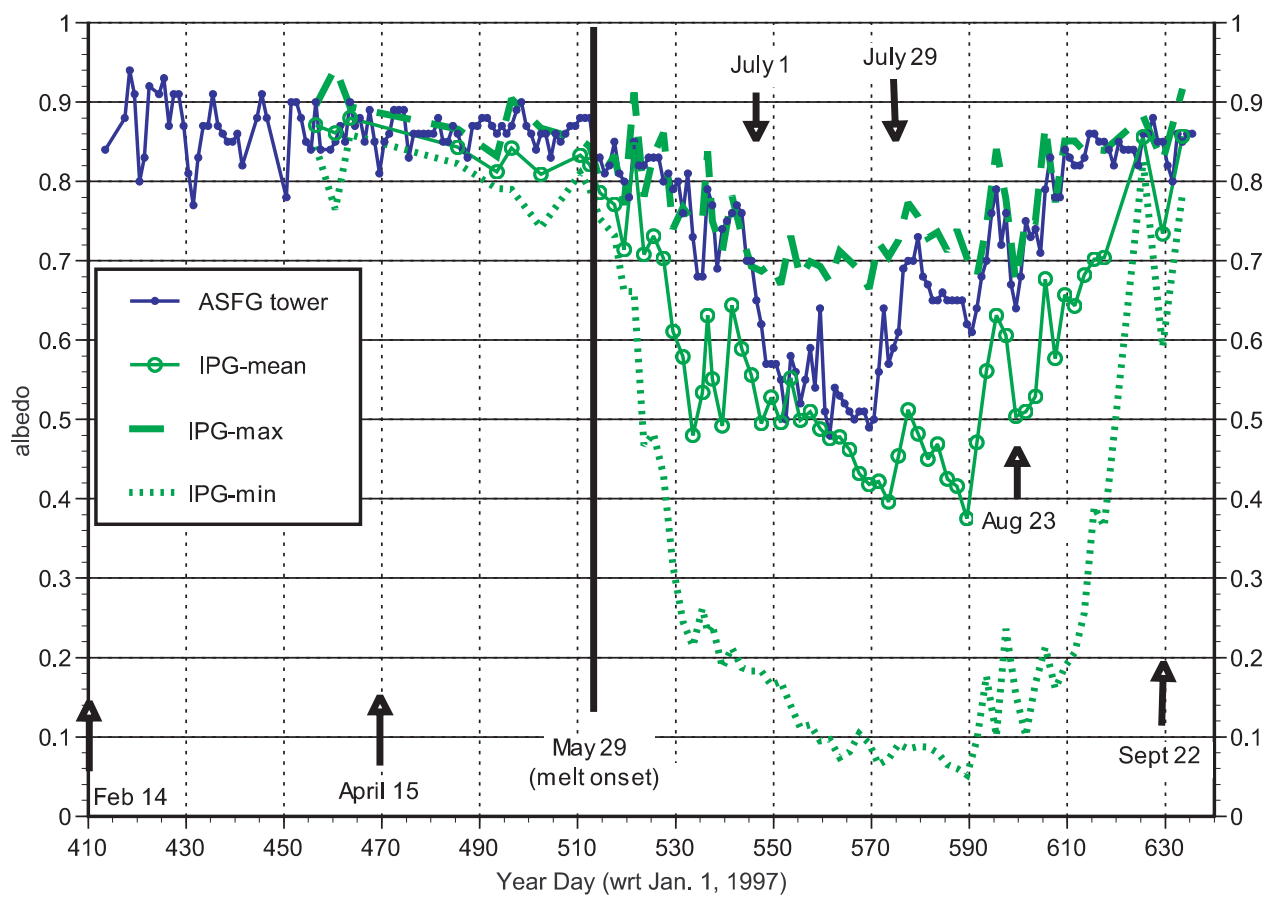

Figure 19. Daily mean albedos from the ASFG radiometer stand (dots). Also shown are the mean (open circles), maximum (dashed) and minimum (dotted) albedos from IPG albedo line. The heavy vertical black line marks the onset of surface melt.

Maykut, 1982], but results because of significant layers of depth hoar in the snowpack. However, Sturm et al. [2002] also show that this direct measurement of $k_{\mathrm{s}}$ is inconsistent with the observed wintertime bottom accretion of ice and evolution of the temperature profiles in the ice and snow. They conclude that an effective $k_{\mathrm{s}}$ for the SHEBA year would be more similar to previous conductivity studies [e.g., Sturm et al., 1997]. Hence, we also use a value of $k_{\mathrm{s}}=0.3 \mathrm{~W} \mathrm{~m}^{-1} \mathrm{~K}^{-1}$ in the surface energy budget calculations to give a range for $C$. During times with no snow cover, the conductive flux is calculated using the water temperature at the bottom of the ice $\left(\mathrm{T}_{\mathrm{w}}=-1.8^{\circ} \mathrm{C}\right)$, the approximate ice thickness $\left(\mathrm{d}_{\mathrm{i}}=2.0 \mathrm{~m}\right)$, the thermal conductivity of the ice $\left(\mathrm{k}_{\mathrm{i}}=2.0 \mathrm{~W} \mathrm{~m}^{-1} \mathrm{~K}^{-1}\right)$, and

$$
\mathrm{C}=-\mathrm{k}_{\mathrm{i}}\left[\left(\mathrm{T}_{\mathrm{s}}-\mathrm{T}_{\mathrm{w}}\right) / \mathrm{d}_{\mathrm{i}}\right] .
$$

[62] Because of the rotation of the floe, the site for the $T_{\text {ice }}$ and $d_{s}$ measurements ended up in the lee of the 20-m tower, resulting in a $1-\mathrm{m}$ maximum snow depth that was unrepresentatively large by a factor 2-3 (see Figure 7). A conductive flux estimated over such a large depth is not accurate on shorter (i.e., hourly) time scales, though it is more accurate over longer time scales. In addition, $\mathrm{T}_{\mathrm{s}}$ was measured at the radiometer stand where the snow was significantly shallower, so the $T_{s}$ values used may be slightly different than the actual surface temperature above the $T_{\text {ice }}$ and $d_{s}$ measurements. Because of these uncertainties, the conductive fluxes obtained from this site are considered coarse estimates. The thermistor-string sites [Perovich et al., 1999] maintained by the SHEBA Ice Physics Group (IPG) can provide estimates over more representative snow depths and with higher temporal resolution.
[63] Note that all terms on the right-hand side of (4.1) and (4.2) are directly measured at the ASFG site except $C$, which is calculated from (4.3a) and (4.3b). To increase the number of data points (see Figure 4), the median value of $H_{\mathrm{s}}$ from the five levels for each hour is used. Though $\mathrm{H}_{1}$ was directly measured through covariance techniques, its bulk estimate at $10 \mathrm{~m}, \mathrm{H}_{\mathrm{lb}}$, will be used in the calculations presented here, as discussed in section 2.2.4. Using $\mathrm{H}_{\mathrm{lb}}$ rather than $\mathrm{H}_{1}$ increases the latent heat flux during May and June by $2 \mathrm{~W} \mathrm{~m}^{-2}$ and $4 \mathrm{~W} \mathrm{~m}^{-2}$, respectively (Figure 6), but reduces it during April, August and September (and improves the data recovery). The energy budget was calculated at hourly intervals, and daily and monthly means of each term were then calculated from these hourly values.

[64] The total energy flux at a given time may be positive, negative, or zero. If $F_{\text {tot }}$ is positive, the snow or ice is gaining energy, which can be used to either increase the temperature of the snow or ice (energy storage) or, if the temperature is already at the melting point, to produce melting. If $F_{\text {tot }}$ is negative, energy is lost by the surface slab, and the slab temperature decreases. Note that we are including only the change of phase in this surface slab, not the change of phase at the bottom of the ice. As shown by Perovich et al. [1999], a spatial average of $0.34 \mathrm{~m}$ of snow and $0.70 \mathrm{~m}$ of ice melted from surface slab during the SHEBA year, while a net of $0.35 \mathrm{~m}$ of ice grew on the bottom of the ice. The first two values imply an expected net energy flux excess in the surface slab, and the latter a deficit at the bottom of the ice.

[65] The availability of 11 months of measurements of all terms in the SEB at the ASFG site at high temporal resolution offers a unique opportunity to study the SEB 

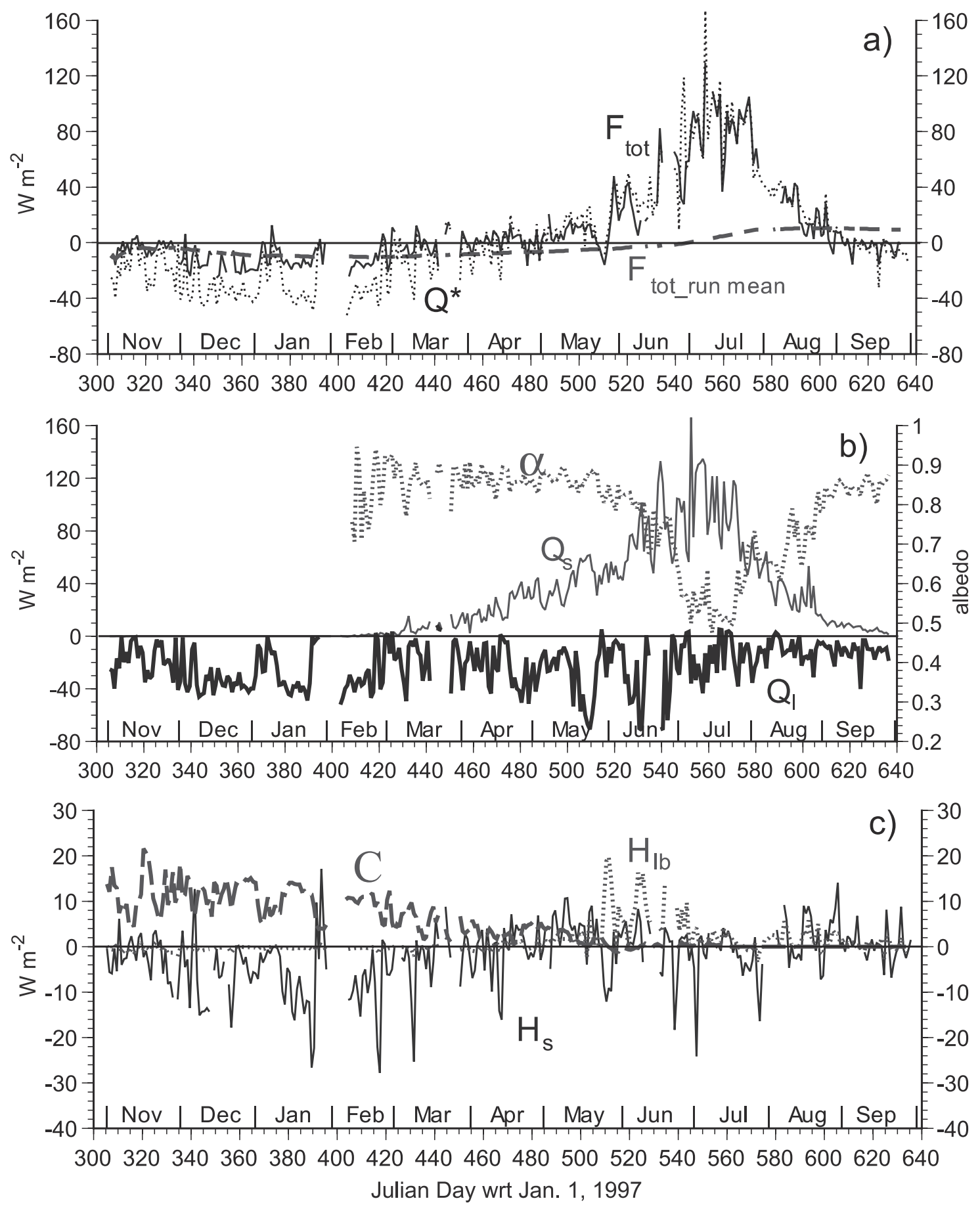

Figure 20. Surface energy budget using daily means. The terms are (a) $F_{\text {tot }}$ (solid), the cumulative mean of $F_{\text {tot }}$ beginning on November 1, 1997 (dashed), and Q* (dotted); (b) Q (light solid), Q (heavy solid), and $\alpha$ (dotted); and (c) $H_{\mathrm{s}}$ (solid), $\mathrm{H}_{\mathrm{lb}}$ (dotted), and $C$ (dashed) using $k_{\mathrm{s}}=0.3 \mathrm{~W} \mathrm{~m}^{-1} \mathrm{~K}^{-1}$.

over the Arctic pack ice with reliance on parameterizations limited to that described above. In this paper, our analysis will first briefly discuss the daily variability of the SEB. We will then focus on providing monthly means and annual averages of the various SEB components, relating these to observed mass changes in the surface ice and snow, and comparing these to previous studies which have incorporated models or parameterizations to a greater extent than done here. Detailed analyses utilizing the high-temporal characteristics of the data set will be reserved for future studies.

\subsection{Annual Cycle}

[66] Each surface energy budget term shows large day-today variability (Figure 20). During winter, $F_{\text {tot }}$ varies from $-25 \mathrm{~W} \mathrm{~m}^{-2}$ to $+12 \mathrm{~W} \mathrm{~m}^{-2}$, while in July it varies from +37 to $129 \mathrm{~W} \mathrm{~m}^{-2}$. This large day-to-day variability in $F_{\text {tot }}$ is due to a large variability in both shortwave and longwave 
radiative terms, as well as in the turbulent flux terms. The positive values of $F_{\text {tot }}$ in winter occur during cloudy periods, when $\mathrm{Q}_{1}$ is near zero [Persson et al., 1999b]. Throughout the year, $\mathrm{Q}_{1}$ tends to be either between -30 and $-50 \mathrm{~W} \mathrm{~m}^{-2}$ or near $0 \mathrm{~W} \mathrm{~m} \mathrm{~m}^{-2}$ (Figure 20b). The minima of -70 to $-75 \mathrm{~W} \mathrm{~m}^{-2}$ occurred in early summer under a clear sky when the surface temperature was high. The slightly positive $\mathrm{Q}_{1}$ values occurred during the summer under low-level clouds with above-freezing temperatures when the surface temperature was fixed at $0^{\circ} \mathrm{C}$.

[67] Variations in the net solar radiation occurred with variations in cloud cover and also with variations in albedo, when for instance, fresh snow had fallen (e.g., JD 535, JD 566) [see also Persson et al., 1999a]. The peak in net solar radiation occurred in early July, after the summer solstice, because rapidly decreasing surface albedo near 1 July reduced the outgoing solar radiation. At other sites with less snow cover, the net solar radiation would likely have peaked earlier.

[68] The turbulent heat flux has even greater day-to-day variability than do the radiative fluxes. Typically, each of the large peaks (in magnitude) of $H_{\mathrm{s}}$ and $\mathrm{H}_{1}$ corresponds to a synoptic event that has increased the wind speed. Most of the peaks are negative, showing downward heat transport and reflecting the stable stratification of the Arctic planetary boundary layer. Events with upward heat transport occur principally in May, June, and August, though some periods of upward heat transport occurred in conjunction with the wintertime near-neutral stratification events mentioned in section 3.2 and discussed by Persson et al. [1999b]. The large positive $H_{\mathrm{s}}$ on 27 January (JD 392) appears to be a plume from a lead that opened upwind of the ASFG tower in the vicinity of the SHEBA ice station.

[69] The variability of the conductive flux is less than for the other terms, reflecting the damping effect of the deep snow-layer for which $C$ was calculated. The large variability of the various energy budget terms shows that long-term sampling and high data recovery are needed to obtain reliable flux estimates.

[70] Most studies of the climate over Arctic pack ice use monthly mean values of the terms in the surface energy budget [e.g., Sverdrup, 1933; Maykut, 1982]. Hence, monthly mean values for the ASFG site are presented here and are compared to the earlier studies. The monthly means show a net flux energy deficit of $10-20 \mathrm{~W} \mathrm{~m}^{-2}$ from September through March and an energy surplus from April to August (Figure 21a), with a peak of about $85 \mathrm{~W} \mathrm{~m}^{-2}$ in July. (The October 1998 values are interpolated from September 1998 and November 1997 values.) Clearly, the radiative terms are dominant. The net shortwave has a positive impact from March to September, and the net longwave radiation is negative throughout the year (Figure $21 \mathrm{~b}$ ), resulting in a positive net radiation balance from May through August and a negative balance during September through March. Though a factor 5-10 smaller in magnitude, the average turbulent heat flux $\left(H_{\mathrm{s}}+\mathrm{H}_{\mathrm{lb}}\right)$ opposes the effect of the net radiation, except during July. That is, it warms the surface during the winter and July while cooling it slightly during May, June, and August. The July downward $H_{\mathrm{s}}$ results from warmer air aloft being present over a surface with a fixed temperature of $0^{\circ} \mathrm{C}$. Both of our estimates of the conductive flux have magnitudes compa- rable to the turbulent heat flux. It warms the surface during the winter and has a weak cooling effect during the summer as one would expect.

[71] Figure 21a shows the running mean of the net flux from November 1997 to October 1998. By October 1998, an annual average energy excess of $7.0-9.5 \mathrm{~W} \mathrm{~m}^{-2}$ exists, with the smaller and larger values corresponding to the use of the smaller and larger values of the thermal conductivity, respectively. This annual excess corresponds to a net melt of $0.84-1.14 \mathrm{~m}$ of ice. Interestingly, about $0.70 \mathrm{~m}$ of ice melted from the top of the undeformed multiyear ice pack during the year [Perovich et al., 1999] along with about 0.5 $\mathrm{m}$ of snow estimated for the radiometer site (equivalent to about $0.18 \mathrm{~m}$ of ice). Hence, the estimated excess energy in the surface slab and the observed surface melt of $0.88 \mathrm{~m}$ of ice agree well. Accretion and melting on the bottom of the ice also occurred, but these are irrelevant to the energy budget of the surface slab considered here.

\subsection{Comparisons to Previous Studies}

[72] Previous studies of the annual surface energy budget over the Arctic pack ice have relied on incoming radiative fluxes determined from sparse climatological estimates [Marshunova, 1961; Untersteiner, 1961; Doronin, 1963; Badgley, 1966; Maykut and Untersteiner, 1971; Maykut, 1982], derived from regressions using observed environmental conditions and estimates of cloud cover, albedo, and cloud optical depth [Sverdrup, 1933; Lindsay, 1998] or determined from models [Ebert and Curry, 1993]. Even the relatively rich data set from the North Pole drifting ice camps established by the former Soviet Union contain only limited downward longwave radiation measurements of questionable accuracy [Marushunova and Mishin, 1994; Lindsay, 1998; Jordan et al., 1999]. The other fluxes, such as $Q_{\mathrm{so}}, \mathrm{Q}_{\mathrm{lo}}, H_{\mathrm{s}}$, and $\mathrm{H}_{1}$, have been determined through parameterizations using state parameters and assumed parameters, such as albedo and turbulent transfer coefficients. The SHEBA field program is unique in that direct measurements of all of the fluxes but one (C) in (4.1) and (4.2) are available at 1-h resolution throughout the year. All state parameters are measured, and no assumption of albedo is needed. However, we are using specified values for the $\varepsilon_{\mathrm{s}}$ and $k_{\mathrm{s}}$, and we are also calculating a transfer coefficient for the latent heat flux to gain temporal coverage.

[73] Because the SHEBA estimate of the annual cycle of the surface energy budget is based entirely on flux measurements, comparisons with budgets from other studies using climatological data, models, and parameterizations could provide insights into the representativeness of the SHEBA year, reveal differences leading to new interpretations of the energy budget over the Arctic pack ice, and spark insights into possible model shortcomings. The studies of Badgley [1966] (B66), Maykut and Untersteiner [1971] (MU71), Maykut [1982] (M82), Ebert and Curry [1993] (EC93), and Lindsay [1998] (L98) are used here. Because Untersteiner [1961] (U61) did not provide monthly means, his SEB estimates will only be compared when examining the annual mean budget.

[74] Badgley [1966] used intermittent measurements made on drifting ice stations during and after the International Geophysical Year, supplemented by reports from Yakovlev [1954]. The solar fluxes were computed from the 

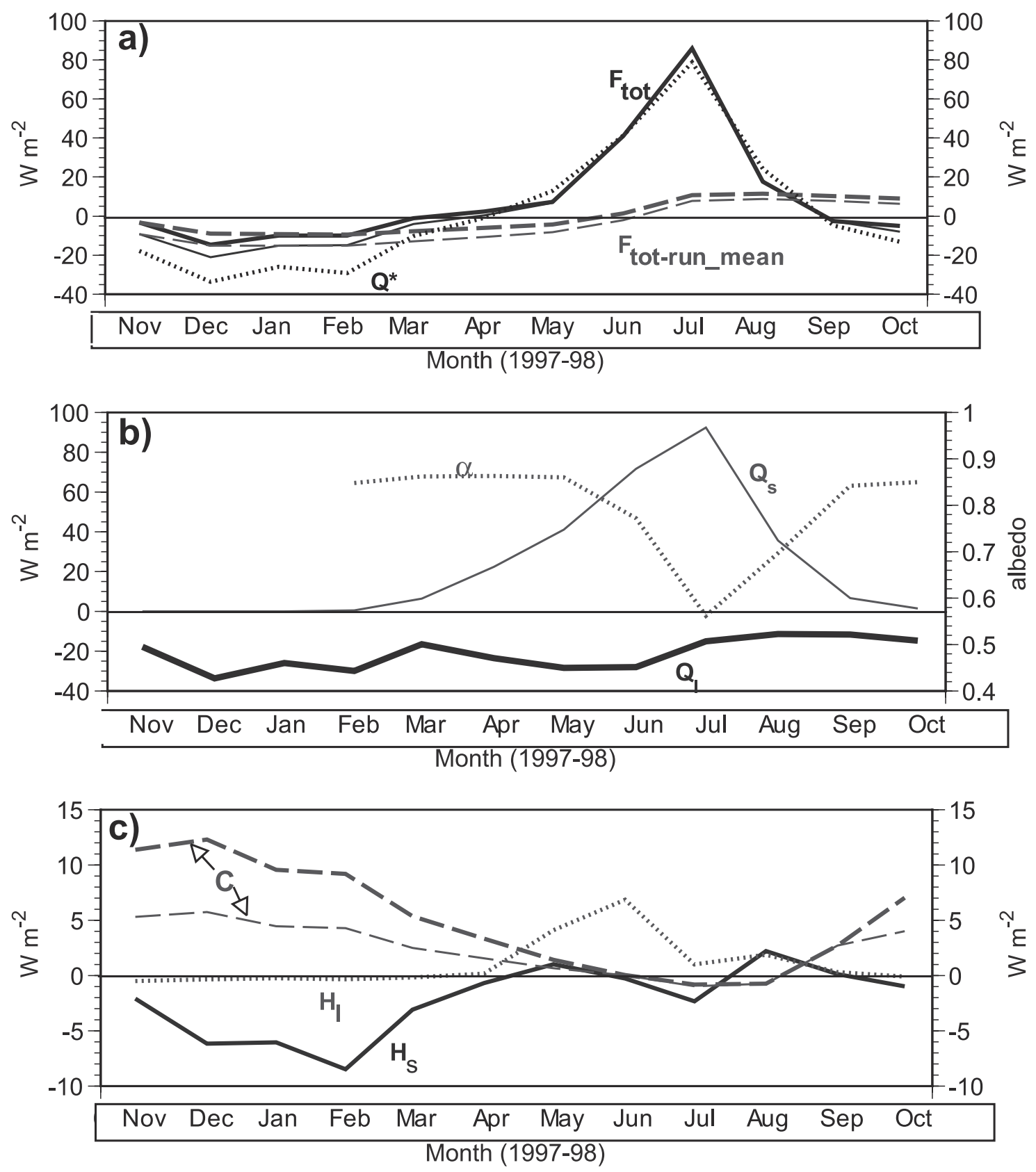

Figure 21. As for Figure 20, but using monthly means. In panels (a) and (c), values of $F_{\text {tot }}, F_{\text {tot-run_mean, }}$ and $C$ using the conductivity fluxes with $k_{\mathrm{s}}=0.14 \mathrm{~W} \mathrm{~m}^{-1} \mathrm{~K}^{-1}$ are also shown with a light line.

solar constant, the annual position of the sun, estimates of atmospheric transmissivity and surface albedo. Their results are valid between 70 and $90^{\circ} \mathrm{N}$. The turbulent fluxes are computed from bulk methods. The calculations by B66 combine the surface melt and the conductive flux, thereby eliminating the determination of $C$ and $F_{\text {tot }}$ as defined in our study. MU71 performed a 1-D modeling study over a uniform multiyear ice pack using climatological forcing parameters representative of the central Arctic. Atmospheric humidity, temperature, and $H_{\mathrm{s}}$ and $\mathrm{H}_{1}$ were derived from Doronin [1963] and climatological $\mathrm{Q}_{\mathrm{si}}$ and $\mathrm{Q}_{\mathrm{li}}$ and $\alpha$ were obtained from Marshunova [1961]. The monthly means were interpolated in time, and a constant oceanic heat flux was assumed. L98 used Soviet drifting ice station data from
1957 to 1990 in the Beaufort and Chukchi Seas from 73 to $90^{\circ} \mathrm{N}$ to derive estimates of forcing parameters, then used parameterizations to compute surface fluxes. The forcing parameters derived from the data include air temperature, mixing ratio, wind speed, air pressure, $\mathrm{Q}_{\mathrm{si}}$ and $\mathrm{Q}_{\mathrm{li}}$, snow depth and density, and $\alpha$. Because these stations were located on multiyear ice floes, this study probably did not include substantial effects of leads. In contrast, the modeling study by M82 partitioned the central Arctic pack ice into thickness categories, including leads, to obtain integrated surface fluxes. The model calculations for ice thickness categories greater than $0.8 \mathrm{~m}$ were similar to those by MU71, except that bulk estimates of $H_{\mathrm{s}}$ and $\mathrm{H}_{1}$ were computed in the model using a constant wind speed of 
Table 6. Comparison of Annual Energy Budget Components From the SHEBA Observations With Badgley [1966] (B66), Maykut and Untersteiner [1971] (MU71), Maykut [1982] (M82), Ebert and Curry [1993] (EC93), and Lindsay [1998] (L98) ${ }^{\mathrm{a}}$

\begin{tabular}{|c|c|c|c|c|c|c|c|c|}
\hline Parameter & SHEBA & $\begin{array}{c}\text { SHEBA } \\
\left(\alpha_{\text {July }}=0.64\right)\end{array}$ & B66 & MU71 & $\begin{array}{c}\text { M82 } \\
3 \mathrm{~m} \\
\end{array}$ & $\begin{array}{c}\mathrm{M} 82 \\
0.8-\infty \mathrm{m}\end{array}$ & EC93 & L98 \\
\hline $\mathrm{Q}_{\mathrm{si}}$ & 91.88 & 91.88 & 98.1 & 100.04 & 99.85 & 99.85 & 101.3 & 96.83 \\
\hline $\mathrm{Q}_{\mathrm{s}}$ & 23.36 & 21.77 & 23.5 & 24.16 & 23.74 & 23.74 & 29.49 & 23.23 \\
\hline $\mathrm{Q}_{\mathrm{li}}$ & 230.80 & 230.80 & 211.5 & 220.22 & 220.35 & 220.35 & 215.34 & 219.31 \\
\hline $\mathrm{Q}_{1}$ & -21.32 & -21.32 & -24.4 & -24.42 & -20.66 & -22.06 & -28.41 & -22.74 \\
\hline$H_{\mathrm{s}}$ & -2.20 & -2.20 & -1.3 & -3.58 & -3.59 & -3.59 & -1.84 & -3.01 \\
\hline $\mathrm{H}_{\mathrm{lb}}$ & 1.06 & 1.06 & 0.9 & 4.25 & 4.11 & 3.49 & 1.55 & 2.32 \\
\hline $\mathrm{Q}_{\mathrm{s}}+\mathrm{Q}_{1}-H_{\mathrm{s}}-\mathrm{H}_{\mathrm{lb}}$ & $\begin{array}{c}3.18 \\
{[4.17]}\end{array}$ & $\begin{array}{c}1.59 \\
{[2.29]}\end{array}$ & -0.5 & -0.92 & 2.56 & 1.79 & 1.33 & 1.18 \\
\hline $\mathrm{C}$ & $2.45(5.04)$ & $2.45(5.04)$ & N/A & 7.96 & 6.31 & 5.82 & 8.12 & 5.68 \\
\hline $\begin{array}{l}F_{\text {tot }} \\
{\left[F_{\text {tot }}\right]}\end{array}$ & $\begin{array}{c}5.63(8.22) \\
{[6.57(9.12)]}\end{array}$ & $\begin{array}{c}4.04(6.63) \\
{[4.69(7.24)]}\end{array}$ & N/A & 7.04 & 8.87 & 7.60 & 9.45 & 6.86 \\
\hline
\end{tabular}

${ }^{a}$ Values are given as annual average fluxes $\left(\mathrm{W} \mathrm{m}^{-2}\right)$. They were computed from the monthly mean components, with SHEBA values for the month of October interpolated from the September and November values. The third column is identical to the second, except that the $Q_{\text {so }}$ for July was determined assuming an albedo of 0.64 [Perovich et al., 2002]. $C$ and $F_{\text {tot }}$ in columns 2 and 3 use $k_{\mathrm{s}}=0.14 \mathrm{~W} \mathrm{~m}^{-1} \mathrm{~K}^{-1}\left(0.3 \mathrm{~W} \mathrm{~m} \mathrm{~K}^{-1}\right)$. The square brackets show annually averaged hourly atmospheric flux and $F_{\text {tot }}$ values (requiring all components to be measured that hour), rather than the summation of monthly mean budget components. Two ice categories from M82 are shown. $C$ and $F_{\text {tot }}$ are not available for B66.

$5 \mathrm{~ms}^{-1}$. The M82 3-m ice category probably represents conditions most similar to the ASFG site, though their $0.8-$ $\infty \mathrm{m}$ category is also compared (see Table 6). The 1-D model of EC93 was forced by radiative fluxes and cloudiness computed from the model of Curry and Ebert [1992], climatologies of atmospheric temperature, humidity, winds and precipitation [Vowinckel and Orvig, 1970; Oort, 1983], and oceanic heat flux estimates [McPhee and Untersteiner, 1982]. The forcing parameters were representative of approximately $80^{\circ} \mathrm{N}$. The EC93 model included the effects of melt ponds and leads as well as sophisticated parameterizations of some parameters such as albedo. The SHEBA ASFG site was on a 1.9-m-thick multiyear floe and leads were generally not directly sampled by the observations. Hence, we expect that the surface energy budget at the ASFG site is more similar to the conditions in the studies of MU71, L98, and the 3-m ice category of M82 than to EC93 and those in the other categories of M82. However, some effects from the nearby melt pond at the ASFG site make comparisons to the latter two useful as well.

[75] Comparisons of net radiation throughout the annual cycle (Figure 22a) show that the SHEBA Q* was generally comparable to the climatological (M82) and parameterized (B66, L98) fluxes, though there are differences of up to 29 $\mathrm{W} \mathrm{m}{ }^{-2}$ for some individual months (e.g., July compared to B66 and August compared to M82). However, despite the agreement in $\mathrm{Q}^{*}$, some notable differences exist in individual radiative components. Despite the SHEBA July Q* being very similar to M82, the albedo for July at the SHEBA ASFG site is lower by 0.08 . This is reconciled by the observation that the July SHEBA $\mathrm{Q}_{\mathrm{si}}$ is $10-26 \mathrm{~W}$ $\mathrm{m}^{-2}$ lower than the other studies (Figure $22 \mathrm{~b}$ ). Recall that the July ASFG albedo of 0.56 includes the effect of a melt pond during July. However, the July albedo of just the pure white ice along the IPG albedo line is 0.64 [Perovich et al., 2002], in excellent agreement with $M 82$ and L98. With a $Q_{\text {si }}$ of about $205 \mathrm{~W} \mathrm{~m}^{-2}$ at SHEBA, Q* over white ice for July would have been about $16 \mathrm{~W} \mathrm{~m}^{-2}$ lower than that at the ASFG site, $5-15 \mathrm{~W} \mathrm{~m}^{-2}$ less than M82 and L98, and $13 \mathrm{~W}$ $\mathrm{m}^{-2}$ greater than $\mathrm{B} 66$, but still well within the \pm 1 standard deviation given by L98. However, note that the $\mathrm{Q}_{\mathrm{si}}$ at SHEBA are close to being significantly lower (by 2 stand- ard deviations) than those given by L98 for June, July, and August. Note also that the large standard deviation given by L98 for the July albedo suggests that some of the stations used in that study may have been at least partially viewing meltponds similar to the ASFG site.

[76] During September, October, November, March and April, the $\mathrm{Q}_{\mathrm{li}}$ at SHEBA was $20-45 \mathrm{~W} \mathrm{~m}^{-2}$ greater than most of the other studies (Figure 22c), which is clearly significant based on the standard deviations provided by L98. This difference possibly indicates the occurrence of more fall and springtime clouds at SHEBA and/or warmer air at radiatively important altitudes. Whether the SHEBA floe's spring location in the Chukchi Sea just north of the Bering Strait favored clouds or warmer air compared to other regions in the Arctic Basin is unknown at this time but could be assessed with other data collected at SHEBA. Interestingly, the incoming shortwave radiation at SHEBA isn't lower during September, March, and April (Figure $22 \mathrm{~b}$ ), and the difference in the net radiation is much smaller than that for $\mathrm{Q}_{\mathrm{li}}$ though still significant for March (Figure 22a). As seen in Figure 9a, the surface temperature was abnormally high at SHEBA during these five months, so the $\mathrm{Q}_{\text {lo }}$ was unusually large, resulting in a $\mathrm{Q}_{1}$ comparable to the other studies.

[77] The observed SHEBA turbulent heat fluxes have an annual cycle similar to the previous studies (Figures 22d and 22e). However, the magnitudes of $H_{\mathrm{s}}$ are much smaller than for M82 for the entire year and smaller than for B66 during the summer. The May-September $\mathrm{H}_{1}$ are 4-10 W $\mathrm{m}^{-2}$ lower than M82 and L98. There is slightly better agreement with L98 than with M82, especially for $H_{\mathrm{s}}$ and since L98 shows a tendency for $H_{\mathrm{s}}$ to warm the surface in July. Note that the smaller summer SHEBA values imply that the atmosphere doesn't cool the surface as much, permitting more surface heating and melting. Our crude estimates of the SHEBA winter conductive flux using $k_{\mathrm{S}}=$ $0.3 \mathrm{~W} \mathrm{~m}^{-1} \mathrm{~K}^{-1}$ are similar to the M82 estimates for $3 \mathrm{~m}$ ice except in May and September; our estimates using $k_{\mathrm{s}}=0.14$ $\mathrm{W} \mathrm{m} \mathrm{m}^{-1} \mathrm{~K}^{-1}$ are $5-10 \mathrm{~W} \mathrm{~m}^{-2}$ less (Figure 22f). The negative $C$ in May for M82 implies that heat flows from the surface into the ice, a phenomenon not indicated by the SHEBA data. The L98 values represent conduction at the 

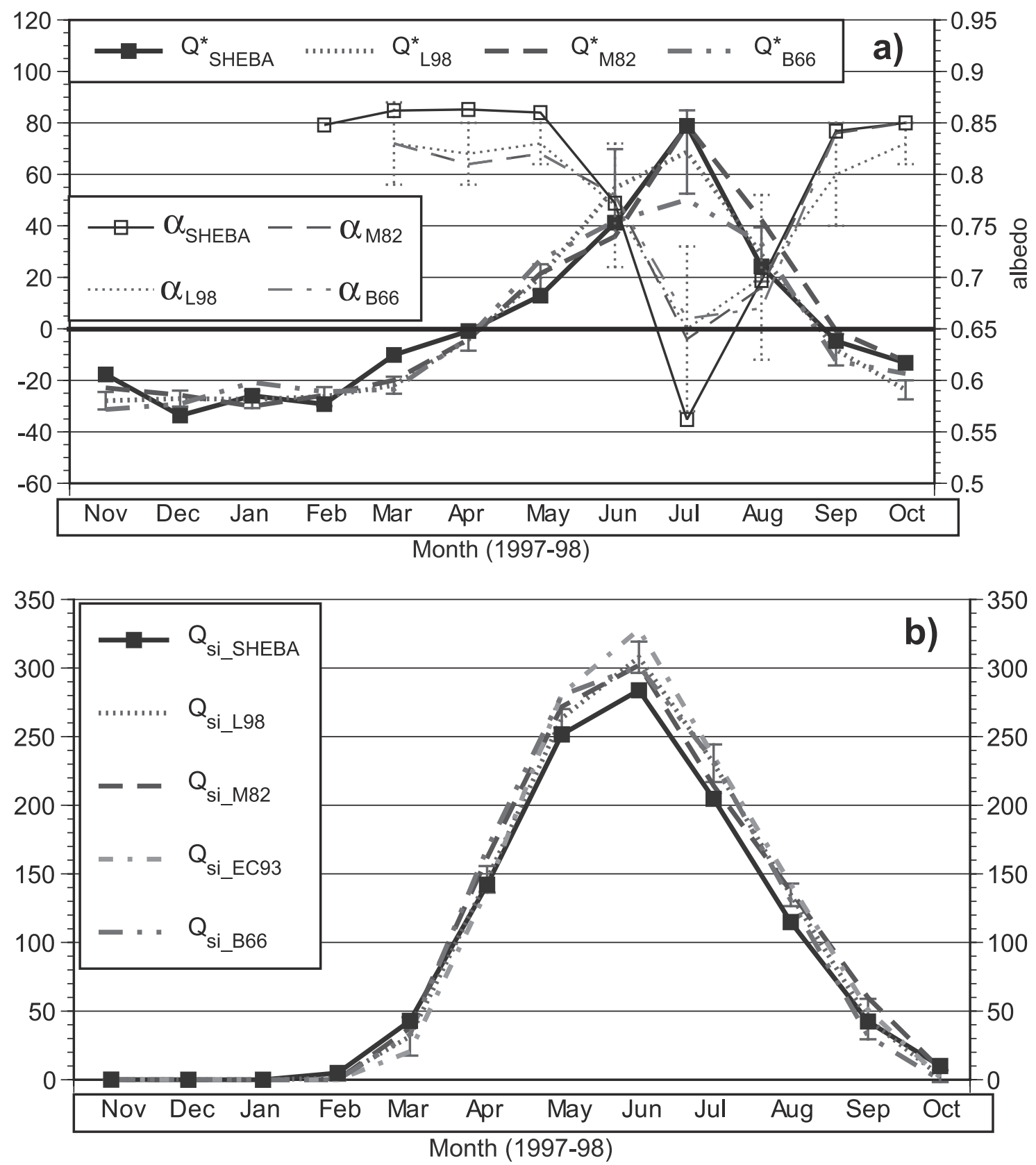

Figure 22. Comparisons of selected SHEBA monthly mean surface energy budget components with previous studies. Shown are (a) net radiation $\left(\mathrm{Q}^{*}\right.$; heavy lines) and albedo (thin lines), (b) incoming shortwave radiation $\left(\mathrm{Q}_{\mathrm{si}}\right)$, (c) incoming longwave radiation $\left(\mathrm{Q}_{\mathrm{li}}\right)$, (d) sensible heat flux $\left(H_{\mathrm{s}}\right)$, (e) latent heat flux $\left(\mathrm{H}_{\mathrm{lb}}\right)$, (f) conductive flux $(C)$, and $(\mathrm{g})$ the residual or net surface flux $\left(F_{\text {tot }}\right)$. The previous studies used in the comparisons are Badgley [1966] (B66), Maykut [1982] (M82) and Lindsay [1998] (L98). In (f) and (g), SHEBA curves are shown using $C$ determined from $k_{\mathrm{s}}=0.14 \mathrm{~W} \mathrm{~m}^{-1} \mathrm{~K}^{-1}$ (squares) and $k_{\mathrm{s}}=$ $0.3 \mathrm{~W} \mathrm{~m}^{-1} \mathrm{~K}^{-1}$ (dots). The error bars show \pm one standard deviation of the monthly means from L98. The 3-m ice category from M82 is used in (a), (d), (e), (f), and (g).

bottom of the ice, so direct comparisons to the SHEBA values aren't useful.

[78] For the total annual budget, the SHEBA-ASFG data show $5-10 \%$ less incoming solar radiation than the other studies (Table 6). However, because of the lower albedo, the net solar radiation is similar to B66, MU71, M82 and L98 but still lower than EC93. If the July white ice albedo of 0.64 is used, the annual average ASFG $Q_{s i}$ is lower by $1.6 \mathrm{~W} \mathrm{~m}^{-2}$ or $7-11 \%$ lower than B66, MU71, M82, and L98. The ASFG data show $10-19 \mathrm{~W} \mathrm{~m}^{-2}$ more incoming longwave radiation and a longwave radiative loss that is similar to M82, 1.4-3.1 $\mathrm{W} \mathrm{m}^{-2}$ less than B66, MU71 and L98, and 7.1 $\mathrm{W} \mathrm{m}{ }^{-2}$ less than EC93 which includes effects of leads and meltponds. The observed sensible heat flux is similar to estimates by EC93 and L98, but the observed latent heat flux is substantially less than all but B66 and EC93. When 

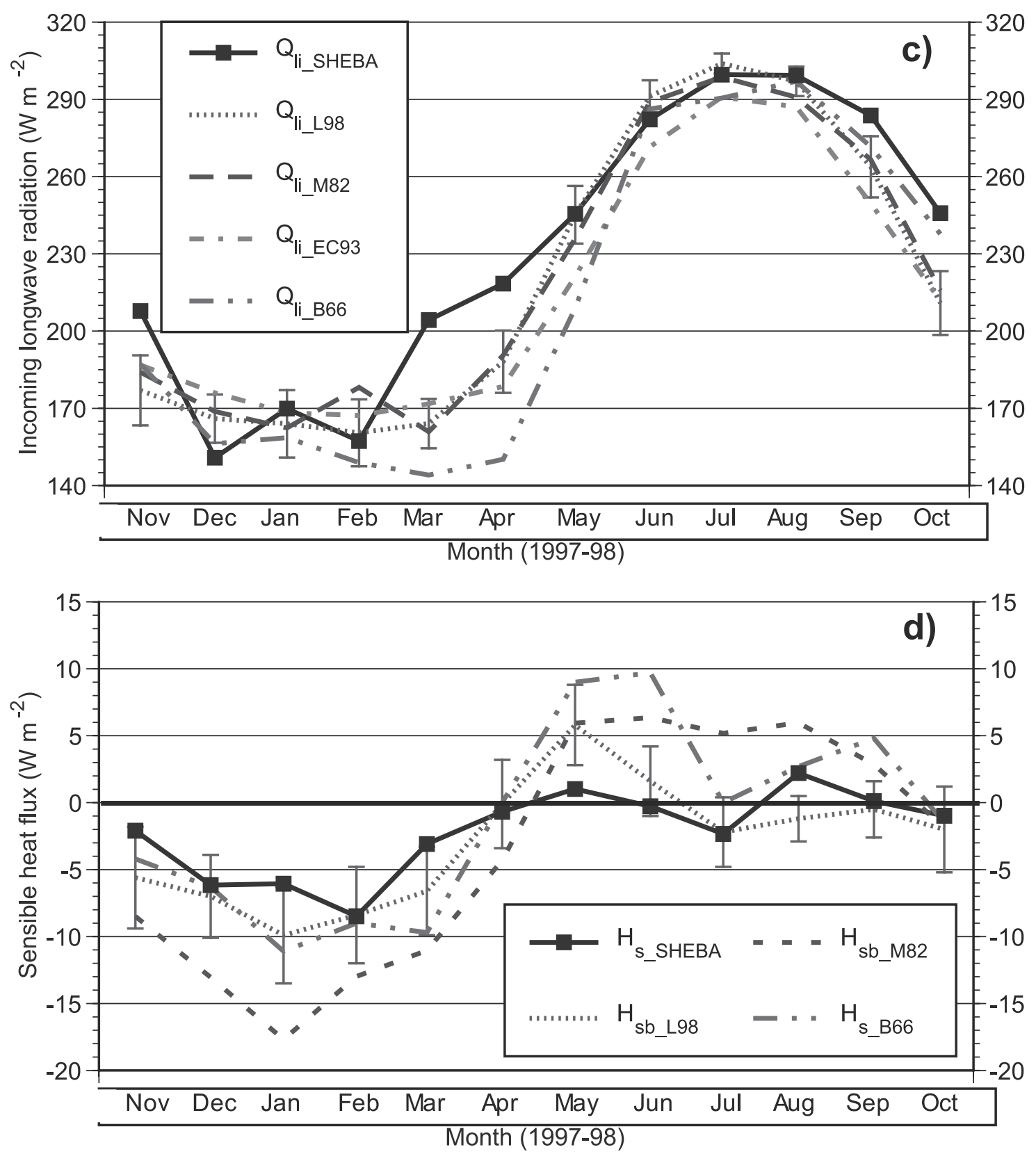

Figure 22. (continued)

comparing the sums of the atmospheric surface fluxes $\left(\mathrm{Q}_{\mathrm{s}}+\right.$ $\left.\mathrm{Q}_{1}-H_{\mathrm{s}}-\mathrm{H}_{\mathrm{lb}}\right)$, the ASFG data produce a larger excess than that seen in the other studies (B66 and MU71 have small deficits). However, if the July albedo of white ice is used, the ASFG atmospheric flux excess is very similar to the other studies. The estimates by Untersteiner [1961] indicate an annual average deficit in the atmospheric surface flux of about $6 \mathrm{~W} \mathrm{~m}^{-2}$, implying that the Arctic atmosphere is a heat sink. Except for B66 and MU71, the other studies, including the SHEBA data, imply that it is a heat source.

[79] Note that when the ASFG atmospheric flux is calculated from only those hours for which data from all terms are available (given in brackets in Table 1) rather than summing the mean components, the annual atmospheric flux excess for the ASFG data is larger by $0.7-1.0 \mathrm{~W} \mathrm{~m}^{-2}$. Hence, the presence of data gaps makes a nontrivial differ- ence in these calculations. This difference represents an estimate of the accuracy of the SHEBA mean annual fluxes. Because a change in one SEB term generally implies a compensating response in another term [e.g., Persson et al., 1999b], the bracketed values may be the better estimates. For the ASFG data, the annual average conductive flux is significantly smaller for $k_{\mathrm{s}}=0.14 \mathrm{~W} \mathrm{~m}^{-1} \mathrm{~K}^{-1}$ and only slightly so for $k_{\mathrm{s}}=0.30 \mathrm{~W} \mathrm{~m}^{-1} \mathrm{~K}^{-1}$ compared to the other studies. With the uncertainties due to the value of $k_{\mathrm{s}}$ and the data gaps, along with the possible unrepresentativeness of the ASFG July albedo, the observed annual excess net flux ranges from 4.0 to $9.1 \mathrm{~W} \mathrm{~m}^{-2}$. Probably the best ASFG estimate to use in comparisons to the other studies is $7.2 \mathrm{~W}$ $\mathrm{m}^{-2}$, which represents the data using a July white ice albedo, a $k_{\mathrm{s}}=0.30 \mathrm{~W} \mathrm{~m}^{-1} \mathrm{~K}^{-1}$, and the times with only the concurrent surface energy budget terms. 

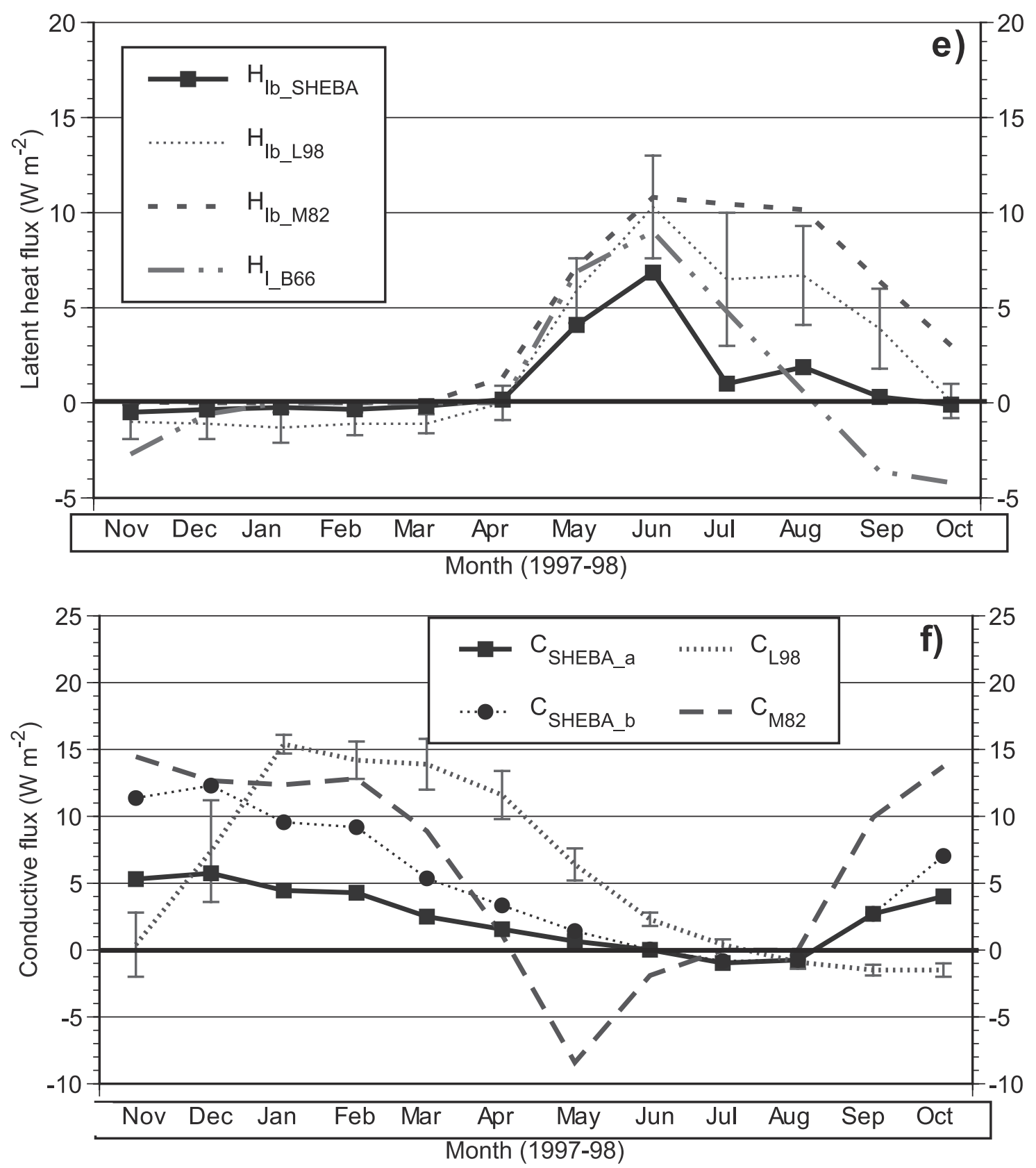

Figure 22. (continued)

[80] Other biases in the ASFG data set may also have an impact on these estimates. The possible "cold" bias of the Eppley pyranometers (see section 2.2.2) may add as much as $2-4 \mathrm{~W} \mathrm{~m}^{-2}$ to $\mathrm{Q}_{\mathrm{si}}$ and $1-3 \mathrm{~W} \mathrm{~m}^{-2}$ to $\mathrm{Q}_{\mathrm{s}}$ for the annual average, though quantifying the effects of the cold bias is difficult because of the unknown nature of this error [Dutton et al., 2001]. The overestimation in $\mathrm{Q}_{\mathrm{s}}$ due to solar transmission through the ice could reduce $\mathrm{Q}_{\mathrm{s}}$ by about $1 \mathrm{~W} \mathrm{~m}^{-2}$ for the annual average. The bulk latent heat flux may be underestimated during April and May because of the underestimation of the surface temperature, so the annual average $\mathrm{H}_{\mathrm{lb}}$ may increase by up to $1 \mathrm{~W} \mathrm{~m}^{-2}$. The range of the conductive flux shown in Table $1\left(2-5 \mathrm{~W} \mathrm{~m}^{-2}\right)$ is estimated to be representative, providing an uncertainty of up to $3 \mathrm{~W}$ $\mathrm{m}^{-2}$. Therefore, with the possible net bias of $0-2 \mathrm{~W} \mathrm{~m}^{-2}$, an adjusted $F_{\text {tot }}$ would be in the $4-11 \mathrm{~W} \mathrm{~m}^{-2}$ range and our best estimate is $8.2 \mathrm{~W} \mathrm{~m}^{-2}$. The best estimate is obtained by assuming a $2 \mathrm{~W} \mathrm{~m}^{-2}$ cold bias, a $0.5 \mathrm{~W} \mathrm{~m}^{-2}$ bias due to summertime transmission through the ice, and a $0.5 \mathrm{~W} \mathrm{~m}^{-2}$ bias in $\mathrm{H}_{\mathrm{lb}}$, producing a net bias of $+1 \mathrm{~W} \mathrm{~m}^{-2}$ added to our best estimate of $7.2 \mathrm{~W} \mathrm{~m}^{-2}$ from Table 6. This range encompasses the mean excess fluxes from all of the other studies, and our best estimate is greater than MU71, L98 and between the two values from M82 (Table 6). The observed ice/snowmelt of $0.88 \mathrm{~m}$ ice equivalent at SHEBA implies an annual average surface energy flux excess of $8.4 \mathrm{~W} \mathrm{~m}^{-2}$. This value falls within the range from the observations presented here and is surprisingly close to our best estimate.

[81] An estimate of the annual average surface flux excess for multiyear ice in equilibrium could be obtained by assuming that the SHEBA floe would have been in equilibrium if the surface melt had equaled the observed bottom 


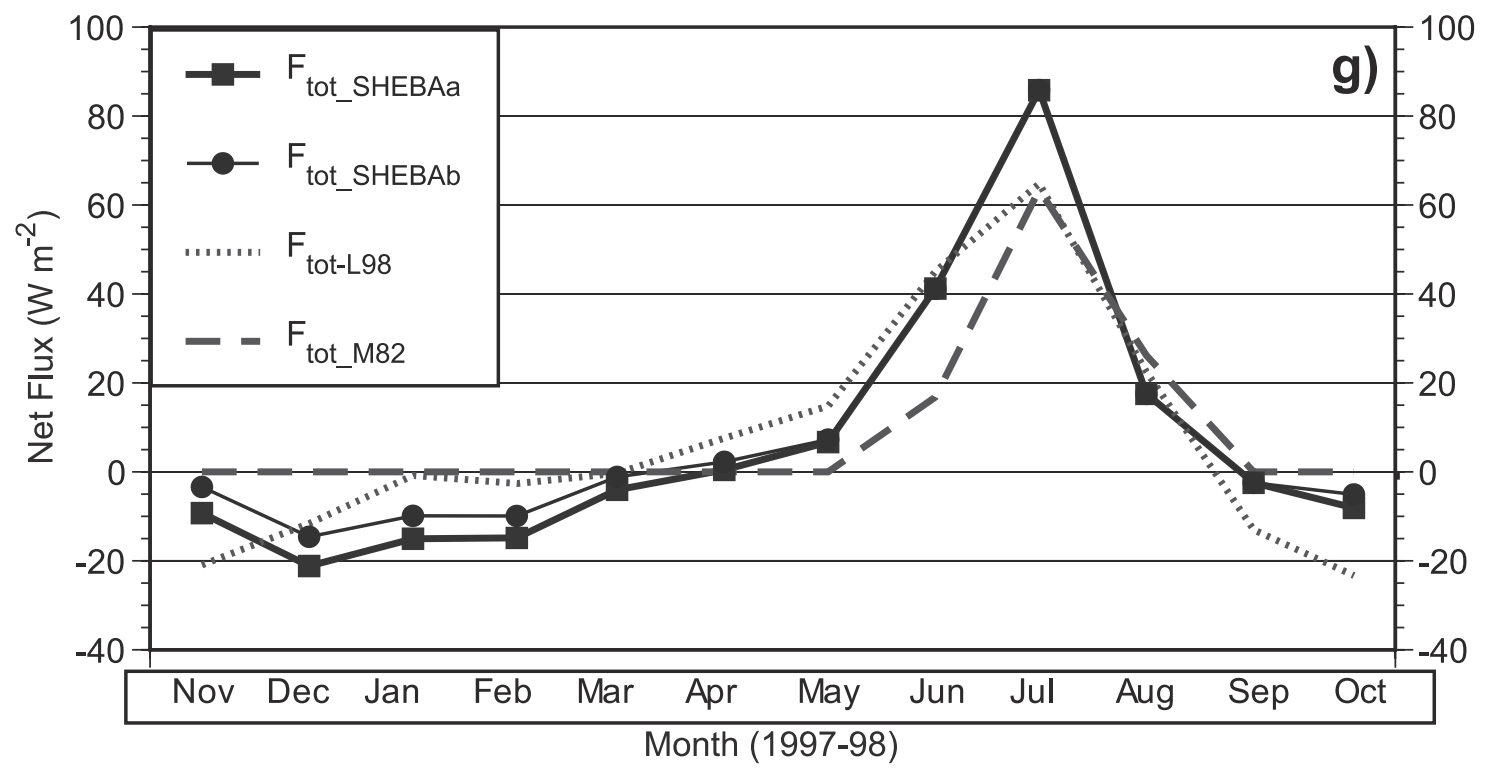

Figure 22. (continued)

accretion of $0.53 \mathrm{~m}$ of ice. This balance would imply a surface mean annual flux excess of $+5.1 \mathrm{~W} \mathrm{~m}^{-2}$. Alternatively, the annual average $F_{\text {tot }}$ values of $6.86-7.04 \mathrm{~W} \mathrm{~m}^{-2}$ from MU71 and L98 may be representative of equilibrium conditions, since the model in MU71 was run until equilibrium conditions were established and L98 used observations from 1957 to 1990 . For either equilibrium estimate, the larger annual average energy flux excess of $8.4 \mathrm{~W} \mathrm{~m}^{-2}$ estimated from the observed melt agrees qualitatively with the net loss of $0.35 \mathrm{~m}$ of ice (surface ablation minus bottom accretion) observed at SHEBA [Perovich et al., 1999]. Since the $4-11 \mathrm{~W} \mathrm{~m}^{-2}$ range of the observed SHEBA annual surface energy flux excess encompasses the equilibrium estimates and the value from the observed nonequilibrium conditions, differentiating between equilibrium conditions and ice-loss conditions such as observed at SHEBA will require an even better data set than was collected at SHEBA. This data set will need to have fewer data gaps, less uncertainty in the radiative fluxes, and a significant reduction in the uncertainty of the conductive flux estimates.

[82] If the effective $k_{\mathrm{s}}$ truly is $0.3 \mathrm{~W} \mathrm{~m}^{-1} \mathrm{~K}^{-1}$, as the results of Sturm et al. [2002] suggest is possible, and our estimates of the biases are accurate, our best estimate of the observed annual average flux excess of $8.2 \mathrm{~W} \mathrm{~m}^{-2}$ would be in remarkable agreement with the flux excess of $8.4 \mathrm{~W}$ $\mathrm{m}^{-2}$ expected from the observed surface melt. We could then conclude that the SHEBA year produced a net melt because of the unusually large surface melt due to 1 ) greater incoming longwave radiation during the fall and spring and 2) weaker cooling by the latent heat flux. Weaker warming by the sensible heat and conductive fluxes was inadequate to completely compensate. These conclusions are dependent on the above caveats and hence tentative.

\section{Summary, Implications, and Future Work}

[83] Eleven months of data describing the near-surface atmospheric conditions and the surface energy budget were collected at the ASFG tower site during the 1997-1998
SHEBA field deployment. The ASFG site, data calibration, and data processing methods have been described, with estimates of the uncertainties given for the various parameters. The availability of similar or complementary data from other SHEBA sites greatly increases the value of this data set for understanding physical processes relevant to climate and climate change over the Arctic pack ice.

[84] Daily mean near-surface temperatures during SHEBA were as low as $-40^{\circ} \mathrm{C}$ in winter and near $0^{\circ} \mathrm{C}$ during the entire summer melt season. During the nonmelting season, the temperature had large day-to-day variability. The humidity showed conditions close to saturation throughout the year, with slight supersaturation during the winter and subsaturation during the summer. Conditions during the SHEBA year have been compared to climatological estimates and observations from other studies. March and April were warmer than indicated by either climatology or the other field programs. The unusually early onset of the melt season and the subsequent unusually long melt season are of particular significance. Monthly mean temperature profiles show a fairly smooth annual cycle from stable conditions during the winter to near-neutral conditions during the summer. Closer examination shows the occurrence of both well-mixed and strong inversion conditions during the winter and the frequent existence of weakly stable conditions also during the summer, especially July. The vertical divergence of turbulent sensible heat flux in the $2-10 \mathrm{~m}$ layer produces atmospheric cooling during the winter and warming during the summer. Substantial diurnal variability of the near-surface temperature and heat flux occurs during April and May because of interactions between the diurnal amplitude of the solar flux, the near-surface stability, and the ability of the surface temperature to vary. Similar diurnal variations do not occur in the fall.

[85] The ASFG tower site provided direct measurements of all but one surface energy budget terms over the Arctic pack ice through nearly an entire annual cycle. The measurements show large day-to-day variations in the surface energy budget, not only in individual components but also 
in the net surface flux, indicating the importance of the high data recovery for producing an accurate estimate of the surface energy budget. In the mean, July had twice as much net surface flux as the next highest month (June) because of a low surface albedo (hence a large shortwave radiative contribution), a smaller negative contribution from the longwave radiative flux than in other months, and a warming effect from the turbulent heat fluxes. Compared to other surface energy budget studies, the contributions of the net radiative fluxes are similar, but a relatively larger contribution (less negative) comes from the net longwave radiation than the shortwave radiation in the SHEBA observations, despite the lower July albedos. Excess incoming longwave radiation occurred during the fall months and during March and April, while a deficit in incoming solar radiation occurred in May to August. The observed SHEBA turbulent latent heat fluxes are smaller in the summer, and hence produce a greater warming effect. The smaller magnitudes of the sensible heat flux throughout the year produce compensating winter and summer effects on the annual energy budget. The conductive fluxes are also significantly smaller and, hence, produce less warming, especially if we use the lower snow conductivity. Error estimates indicate that the true relative importance of the various terms is not likely to differ substantially from that given here.

[86] When summing all components of the surface energy budget for the entire year, the best estimate of the observed annual mean net surface flux excess, $8.2 \mathrm{~W} \mathrm{~m}^{-2}$, is very close to the net flux excess of $8.4 \mathrm{~W} \mathrm{~m}^{-2}$ implied by the observed annual net loss of surface ice and snow at SHEBA. This agreement instills confidence in the observed fluxes, and is an attestation to the quality of the SHEBA ASFG data set. The multiyear pack ice at SHEBA was clearly not in equilibrium conditions, as a net loss of several decimeters of ice (bottom accretion minus surface ablation) was observed. Hence, it is again encouraging that the best estimate of the observed annual mean surface flux excess is slightly larger than that estimated for multiyear pack ice equilibrium conditions $\left(7.04 \mathrm{~W} \mathrm{~m}^{-2}\right.$ by MU71 and $6.86 \mathrm{~W} \mathrm{~m}^{-2}$ by L98), for which a net loss of surface ice is balanced by a net growth of bottom ice. To the extent that these studies represent equilibrium conditions, this result might suggest that the nonequilibrium conditions at SHEBA are due to increased surface melt. However, the uncertainties in the measured radiative, turbulent, and conductive fluxes are large enough and the differences in the mean surface flux excesses between equilibrium and the observed nonequilibrium conditions are small enough that the range of the possible observed mean surface flux excess $\left(4-11 \mathrm{~W} \mathrm{~m}^{-2}\right)$ also encompasses the flux excess for the equilibrium conditions. Hence, the accuracy provided by the SHEBA data set is inadequate to differentiate between equilibrium and nonequilibrium conditions.

[87] The agreement between the best estimate of the observed annual mean net surface flux obtained from the surface energy budget measurements and that estimated from the observed surface melt is remarkable, albeit perhaps fortuitous considering the estimated range of that from the energy flux measurements. If this best estimate is correct, it suggests that the components leading to the larger surface energy flux excess in this budget compared to the equilibrium studies were at least a partial cause of the net loss of ice during SHEBA. These components were greater incoming longwave radiation, a smaller net longwave radiative loss, and a smaller turbulent latent heat flux. This is of particular interest because of the observed thinning of the Arctic pack ice over the last few decades [Rothrock et al., 1999]. If our best estimate is incorrect and the net surface flux calculations are instead closer to the net surface fluxes from the studies representing equilibrium conditions, then either the budgets and processes in these studies (as well as the observed SHEBA fluxes) are in error or the energy budget of the bottom of the ice at SHEBA is significantly different than in the equilibrium studies.

[88] The atmospheric and surface measurements at the SHEBA ASFG site are a part of a larger data set collected at SHEBA. This data set is to be used for process studies, and as such includes measurements of more parameters and fluxes than has been done at one site on the Arctic pack ice before. This present study summarizes the data collection, data processing and data accuracy, presents analyses that utilize some of the unique aspects of this data set, and provides comparisons that illustrate some of the notable near-surface characteristics of this one year compared to studies better representing the Arctic climate. Future studies will examine the significant Arctic processes revealed by this data set in more detail.

[89] Acknowledgments. The authors thank all of those involved in the huge effort of obtaining a yearlong data set in the Arctic, especially Scott Abbott, Roy Belyea, Bill Bosworth, Kerry Claffey, Dave Costa, Bruce Elder, Dan Gottas, John Govoni, Tom Grenfell, Janet Intrieri, Ann Keane, Bonnie Light, Marty Mulhern, Jeff Otten, M. J. Post, Jacqueline RichterMenge, Dominique Ruffieux, Cat Russell, Scott Sandberg, Brian Templeman, Terry Tucker, and Dan Wolfe. We also appreciate the efforts of the Des Groseilliers crew and the SHEBA Project Office and staff for their support and for providing the SPO data. Ellsworth Dutton's thoughtful suggestions for processing of the radiometer data were especially helpful. Comments by Ron Lindsay and Richard Moritz led to an improved manuscript. The National Science Foundation supported this work with awards to NOAA's Environmental Technology Laboratory (OPP-9701766), the Cooperative Institute for Research in Environmental Sciences (OPP-00-84323), the Army's Cold Regions Research and Engineering Laboratory (OPP-97-02025, OPP-00-84190), and the Naval Postgraduate School (OPP-97-01390 and OPP-00-84279). The NASA FIRE program and the NOAA Office of Global Programs also supported this work at ETL.

\section{References}

Andreas, E. L., A new method of measuring the snow-surface temperature, Cold Reg. Sci. Technol., 12, 139-156, 1986.

Andreas, E. L., A theory for the scalar roughness and the scalar transfer coefficients over snow and sea ice, Boundary Layer Meteorol., 38, 159184, 1987.

Andreas, E. L., and B. Murphy, Bulk transfer coefficients for heat and momentum over leads and polynyas, J. Phys. Oceanogr., 16, 1875$1883,1986$.

Andreas, E. L., C. W. Fairall, P. S. Guest, and P. O. G. Persson, An overview of the SHEBA atmospheric surface flux program, in Preprints, Fifth Conference On Polar Meteorology and Oceanography, 10-15 January 1999, Dallas, Tex., pp. 411-416, American Meteorological Society, Boston, 1999 .

Andreas, E. L., P. S. Guest, P. O. G. Persson, C. W. Fairall, T. W. Horst, R. E. Moritz, and S. R. Semmer, Near-surface water vapor over polar sea ice is always near ice-saturation, J. Geophys. Res., 107, 10.1029/ 2000JC000411, 2002.

Badgley, F. I., Heat budget at the surface of the arctic ocean, in Proceedings of the Symposium on the Arctic Heat Budget and Atmospheric Circulation, edited by J. O. Fletcher, pp. 267-277, Memo. RM-5233-NSF, The RAND Corporation, 1966.

Banke, E. G., S. D. Smith, and R. J. Anderson, Drag coefficients at AIDJEX from sonic anemometer measurements, in Sea Ice Processes and Models, edited by R. S. Pritchard, pp. 430-442, Univ. of Washington Press, 1980. 
Bush, B. C., F. P. J. Valero, and A. S. Simpson, Characterization of thermal effects in pyranometers: A data correction algorithm for improved measurement of surface insolation, J. Atmos. Oceanic Technol., 17, 165-175, 2000

Claffey, K. J., E. L. Andreas, A. P. Makshtas, and B. V. Ivanov, In situ measurements of the surface temperature in the western Weddell Sea, in Preprints, Fifth Conference on Polar Meteorology and Oceanography, 10-15 January 1999, Dallas, Tex., pp. 327-332, American Meteorological Society, Boston, 1995.

Claffey, K. A., E. L. Andreas, D. K. Perovich, C. W. Fairall, P. S. Guest, and P. O. G. Persson, Surface temperature measurements at SHEBA, in Preprints, Fifth Conference on Polar Meteorology and Oceanography, 10-15 January 1999, Dallas, Tex., pp. 86-90, American Meteorological Society, Boston, 1999.

Colony, R., I. Appel, and I. Rigor, Surface air temperature observations in the Arctic Basin, Tech. Memo. TM 1-92, 120 pp., Applied Physics Laboratory, University of Washington, Seattle, Wash., 1992.

Curry, J. A., and E. E. Ebert, Annual cycle of radiation fluxes over the Arctic Ocean: Sensitivity to cloud optical properties, J. Clim., 5, $1267-$ 1280, 1992

Curry, J. A., D. Randall, W. B. Rossow, and J. L. Schramm, Overview of Arctic cloud and radiation characteristics, J. Clim., 9, 1731-1764, 1996.

Curry, J. A., et al., FIRE Arctic Clouds Experiment, Bull. Am. Meteorol. Soc., 81, 5-29, 2000

Doronin, Yu. P., On the heat balance of the Central Arctic (in Russian), Proc. Arctic Antarctic Res. Inst., 253, 178-184, 1963.

Dutton, E. G., J. J. Michalsky, T. Stoffel, B. W. Forgan, J. Hickey, D. W. Nelson, T. L. Alberta, and I. Reda, Measurement of broadband diffuse solar irradiance using current commercial instrumentation with a correction for thermal offset errors, J. Atmos. Oceanic Technol., 18, 297-314, 2001.

Ebert, E. E., and J. A. Curry, An intermediate one-dimensional thermodynamic sea-ice model for investigating ice-atmosphere interactions, J. Geophys. Res., 98, 10,085-10,109, 1993.

Fairall, C. W., E. F. Bradley, D. P. Rogers, J. B. Edson, and G. S. Young, Bulk parameterization of air-sea fluxes for Tropical Ocean-Global Atmosphere Coupled-Ocean Atmosphere Response Experiment, J. Geophys. Res., 101, 3747-3764, 1996.

Fairall, C. W., P. O. G. Persson, E. F. Bradley, R. E. Payne, and S. P. Anderson, A new look at calibration and use of Eppley precision infrared radiometers, 1, Theory and application, J. Atmos. Oceanic Technol., 15, $1229-1242,1998$

Grachev, A. A., C. W. Fairall, P. O. G. Persson, E. L. Andreas, and P. S. Guest, Stable boundary-layer regimes observed during SHEBA experiment, paper presented at 15th Symposium on Boundary Layers and Turbulence, Am. Meteorol. Soc., Wageningen, Netherlands, 15-19 July, 2002.

Grenfell, T. C., and D. K. Perovich, Spectral albedos of sea ice and incident solar irradiance in the southern Beaufort Sea, J. Geophys. Res., 89, 3573-3580, 1984.

Grenfell, T. C., et al., Evolution of electromagnetic signatures of sea ice from initial formation to the establishment of thick first-year ice, IEEE Trans. Geosci. Remote Sens., 36, 1642-1654, 1998.

Guest, P. S., E. L. Andreas, C. W. Fairall, and P. O. G. Persson, Problems with surface layer similarity theory in the Arctic, in Preprints, Fifth Conference on Polar Meteorology and Oceanography, 10-15 January 1999, Dallas, Tex., pp. 132 - 135, American Meteorological Society, Boston, 1999.

Holtslag, A. A. M., and H. A. R. DeBruin, Applied modeling of the nighttime surface energy balance over land, J. Appl. Meteorol., 27, 689-704, 1988.

Houghton, J. T., G. J. Jenkins, and J. J. Ephraums, (Eds.), Climate Change. The IPCC Scientific Assessment, 364 pp., Cambridge Univ. Press, New York, 1990 .

Jordan, R. E., E. L. Andreas, and A. P. Makshtas, The heat budget of snowcovered sea ice at North Pole 4, J. Geophys. Res., 104, 7785-7806, 1999.

Kristensen, L., J. Mann, S. P. Oncley, and J. C. Wyngaard, How close is close enough when measuring scalar fluxes with displaced sensors?, J. Atmos. Oceanic Technol., 14, 814-821, 1997.

Leavitt, E., Surface-based air stress measurements made during AIDJEX, Chapter in Sea Ice Processes and Models, edited by R. S. Pritchard, pp. 419-429, Univ. of Washington Press, 1980.

Lindsay, R. W., Temporal variability of the energy balance of thick Arctic pack ice, J. Clim., 11, 313-333, 1998.

Malmgren, F., Studies of humidity and hoar-frost over the Arctic Ocean, Geof. Publ.4(No. 6), Oslo, pp. 1-20, 1927.

Manabe, S., and R. J. Stouffer, Sensitivity of a global climate model to an increase of $\mathrm{CO}_{2}$ concentration in the atmosphere, J. Geophys. Res., 85, 5529-5554, 1980 .
Marshunova, M. S., Principal characteristics of the radiation balance of the underlying surface and of the atmosphere in the Arctic, Proc. Arctic Antarctic Res. Inst., 229, 5-53, (Translated by The Rand Corporation, RM-5003-PR, 1966), 1961.

Marshunova, M. S., and A. A. Mishin, Handbook of the Radiation Regime of the Arctic Basin (Results From the Drifting Stations), 69 pp., Applied Physics Laboratory, University of Washington, Seattle, Wash., 1994.

Martin, S., and E. A. Munoz, Properties of the Arctic 2-m air temperature for 1979 -present derived from a new gridded data set, J. Clim., 10, 1428-1440, 1997.

Maykut, G. A., Large-scale heat exchange and ice production in the Central Arctic, J. Geophys. Res., 87, 7971-7984, 1982.

Maykut, G. A., and N. Untersteiner, Some results from a time-dependent thermodynamic model of sea ice, J. Geophys. Res., 76, 1550-1575, 1971.

McPhee, M., and N. Untersteiner, Using sea ice to measure vertical flux in the ocean, J. Geophys. Res., 87, 2071-2074, 1982.

Michalsky, J., E. Duttton, M. Rubes, D. Nelson, T. Stoffel, M. Wesley, M. Splitt, and J. DeLuisi, Optimal measurement of surface shortwave irradiance using current instrumentation, J. Atmos. Oceanic Technol., 16, 55-69, 1999 .

Mohn, H., The Norwegian North Polar Expedition 1893-1896, Scientific Results, vol. VI, Meteorology, edited by F. Nansen, F. Nansen Fund for Advancement of Science, Christiania, Oslo, 1905.

Moritz, R. E., J. A. Curry, A. S. Thorndike, and N. Untersteiner, SHEBA, a Research Program on the Surface Heat Budget of the Arctic Ocean, Arctic System Science Center: Ocean-Atmosphere Interactions, Rep. No. 3, 34 pp., University of Washington, Seattle, Wash., 1993.

National Snow and Ice Data Center (NSIDC), Arctic Ocean Snow and Meteorological Observations from Russian Drifting Stations, NSIDC, University of Colorado, Boulder, Colo., 1996, CD-ROM.

Oort, A. H., Global circulation statistics, 1958-1973, NOAA Prof. Pap. 14, National Oceanic and Atmospheric Administration, Washington, D. C., 1983.

Overland, J. E., Atmospheric boundary layer structure and drag coefficients over sea ice, J. Geophys. Res., 90, 9029-9049, 1985.

Perovich, D. K., et al., Year on ice gives climate insights, Eos Trans. $A G U$, 80(41), 481-486, 1999.

Perovich, D. K., T. C. Grenfell, B. Light, and P. V. Hobbs, Seasonal evolution of the albedo of multiyear Arctic sea ice, J. Geophys. Res., 107, 10.1029/2000JC000438, in press, 2002.

Persson, P. O. G., E. L. Andreas, C. W. Fairall, P. S. Guest, and D. R. Ruffieux, The surface energy budget during the onset of the melt season on the Arctic icepack during SHEBA, in Preprints, Fifth Conference on Polar Meteorology and Oceanography, 10-15 January 1999, Dallas, Tex., pp. 321-326, American Meteorological Society, Boston, 1999a.

Persson, P. O. G., T. Uttal, J. Intrieri, C. W. Fairall, E. L. Andreas, and P. S. Guest, Observations of large thermal transitions during the Arctic night from a suite of sensors at SHEBA, in Preprints, Fifth Conference on Polar Meteorology and Oceanography, 10-15 January 1999, Dallas, Tex., pp. 306-309, American Meteorological Society, Boston, $1999 \mathrm{~b}$.

Persson, P. Ola G., C. W. Fairall, E. Andreas, P. Guest, and D. Perovich, Measurements near the Atmospheric Surface Flux Group tower at SHEBA: Site description, data processing, and accuracy estimates, NOAA Tech. Memo. OAR ETL, 2002.

Philipona, R., C. Frohlich, and C. Betz, Characterization of pyrgeometers and the accuracy of atmospheric long-wave radiation measurements, Appl. Opt., 34, 1598-1605, 1995.

Philipona, R., et al., The Baseline Surface Radiation Network pyrgeometer round-robin calibration experiment, J. Atmos. Oceanic Technol., 15, 687-696, 1998

Pritchard, R. S., (Ed.), Sea Ice Processes and Models, Univ. of Washington Press, 474 pp., 1980.

Rigor, I. G., R. L. Colony, and S. Martin, Variations in surface air temperature observations in the Arctic, 1979-97, J. Clim., 13, 896-914, 2000.

Rothrock, D. A., Y. Yu, and G. A. Maykut, Thinning of the Arctic sea-ice cover, Geophys. Res. Lett., 26, 3469-3472, 1999.

Ruffieux, D., P. O. G. Persson, C. W. Fairall, and D. E. Wolfe, Ice pack and lead surface energy budgets during LEADEX 1992, J. Geophys. Res., 100, 4593-4612, 1995.

Russell, C. A., C. W. Fairall, P. O. G. Persson, E. L. Andreas, P. S. Guest, R. Lindsay, H. A. Eide, and T. Horst, Intercomparison of downward longwave flux measurements during the first two months of SHEBA, in Preprints, Fifth Conference on Polar Meteorology and Oceanography, 10-15 January 1999, Dallas, Tex., pp. 314-318, American Meteorological Society, Boston, 1999.

Sturm, M., J. Holmgren, M. König, and K. Morris, The thermal conductivity of seasonal snow, J. Glaciol., 43(143), 26-42, 1997. 
Sturm, M., D. K. Perovich, and J. Holmgren, Thermal conductivity and heat transfer through the snow on the ice of the Beaufont Sea, J. Geophys. Res., 107, 10.1029/2000JC000409, in press, 2002

Sverdrup, H. U., The Norwegian North Polar Expedition with the "Maud" 1918-1925, Scientific Results, vol. II, Meteorology, 1: Discussion, Geofysisk Institutt, Bergen, 1933.

Untersteiner, N., On the mass and heat budget of Arctic sea ice, Arch. Meteorol. Geophys. Bioklimatol, Ser. A, 12, 11-182, 1961.

Uttal, T., et al., The surface heat budget of the Arctic, Bull. Am. Meteorol. Soc., 83, 255-275, 2002

Vowinckel, E., and S. Orvig, The climate of the North Polar Basin, in Climates of the Polar Regions, World Survey of Climatology, vol. 14, edited by S. Orvig, Elsevier Sci., New York, 1970.

Webb, E. K., G. I. Pearman, and R. Leuning, Correction of flux measurements for density effects due to heat and water vapor transport, J. $Q$. R. Meteorol. Soc., 106, 85-100, 1980.
Yakovlev, G. N., The Thermal Regime of the Ice Cover in Observational Data of the Scientific Drifting Research Station of 1950-51, vol. II, Sec. 7, Art. 4, edited by M. M. Somov, 1954 (ASTIA No. AD 117138)

E. L. Andreas and D. K. Perovich, Army Cold Regions Research and Engineering Laboratory (CRREL), Hanover, NH, USA.

C. W. Fairall, NOAA/Environmental Technology Laboratory (ETL), Boulder, CO, USA

P. S. Guest, Naval Postgraduate School (NPS), Monterey, CA, USA.

P. O. G. Persson, Cooperative Institute for Research in Environmental Sciences/NOAA/ETL, 325 Broadway, Boulder, CO, 80303, USA. (ola.persson@noaa.gov) 